\title{
WestVirginiaUniversity
}

THE RESEARCH REPOSITORY @ WVU

Graduate Theses, Dissertations, and Problem Reports

2001

\section{Kinematic synthesis of a well service machine}

\author{
Prashanth Kaparthi \\ West Virginia University
}

Follow this and additional works at: https://researchrepository.wvu.edu/etd

\section{Recommended Citation}

Kaparthi, Prashanth, "Kinematic synthesis of a well service machine" (2001). Graduate Theses, Dissertations, and Problem Reports. 1197.

https://researchrepository.wvu.edu/etd/1197

This Thesis is protected by copyright and/or related rights. It has been brought to you by the The Research Repository @ WVU with permission from the rights-holder(s). You are free to use this Thesis in any way that is permitted by the copyright and related rights legislation that applies to your use. For other uses you must obtain permission from the rights-holder(s) directly, unless additional rights are indicated by a Creative Commons license in the record and/ or on the work itself. This Thesis has been accepted for inclusion in WVU Graduate Theses, Dissertations, and Problem Reports collection by an authorized administrator of The Research Repository @ WVU. For more information, please contact researchrepository@mail.wvu.edu. 


\title{
Kinematic Synthesis of a Well Service Machine \\ Prashanth Kaparthi
}

\author{
Thesis submitted to the \\ College of Engineering and Mineral Resources \\ at West Virginia University \\ in partial fulfillment of the requirements for the degree of
}

\author{
Master of Science \\ in \\ Mechanical Engineering
}

Kenneth H. Means, Ph.D., Chair

Gary J. Morris, Ph.D.

Scott Wayne, Ph.D.

Department of Mechanical and Aerospace Engineering

Morgantown, West Virginia

2001

Keywords: Kinematic Synthesis, Four-position, Burmester, Four-bar, ADAMS 


\section{ABSTRACT \\ Kinematic Synthesis of a Well Service Machine \\ Prashanth Kaparthi}

Blowout preventers are used in the oil well industry to prevent accidental oil fires and flare ups. These preventers are on site and guide valves need to be assembled atop the preventers. The current solution is to use cranes for this purpose. As this is time-consuming and relatively expensive, a solution using an appropriate mechanism for this purpose was contemplated. In this research project, a four-bar mechanism was designed using Burmester theory and the fourposition synthesis method.

The angles and distance of the four positions were calculated and the data obtained was specified as input for the synthesis of the four-bar mechanism using four-position synthesis programmed in MATLAB ${ }^{\mathrm{TM}}$. The moving pivots $(k)$ and the ground pivots $(m)$ were obtained from the MATLAB program. These values were then used in calculating the link lengths $\mathbf{W}$ and $\mathbf{Z}$. These link lengths were input to ADAMS ${ }^{\mathrm{TM}}$ software to simulate the behavior of the mechanism. Two mechanism configurations were evaluated and the mechanical advantage was calculated to select the better design.

Results suggest that the method of four-position synthesis can used to design an appropriate mechanism to place the guide valve on the blowout preventer. The mechanical advantage of the mechanisms obtained was in the range of 1-7. Different parameters of interest like the output force and coupler curves were also obtained for both mechanisms. 
To Family, God, and Friends 


\section{ACKNOWLEDGEMENTS}

First and foremost, I would like to thank my parents Mr. K.N.S.Gupta, Mrs. K.Nirmala Gupta, and my Sisters and also my Supervisor Mr. Larry Leahy at Ford Motor Company for supporting and encouraging me all along.

I would like to express my heartfelt gratitude to my research advisor, Dr. Kenneth H. Means, without whose support and patient guidance, this thesis would never have been completed. I would like to thank my committee members, Dr. Gary J. Morris and Dr. Scott Wayne for being very supportive and helpful.

I would like to thank my friends Mr. Govinda Raju Mandapati, Mr. Ron Johnson and Mr. Ganesh Thyagarajan for their help and suggestions.

Last but obviously not the least, I would like to thank God for providing me with the necessary persistence and patience to see it through. 


\section{Table of contents}

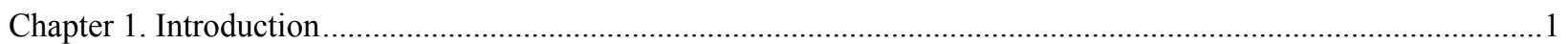

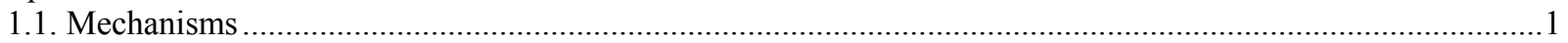

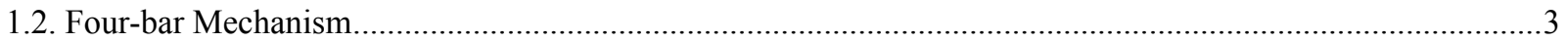

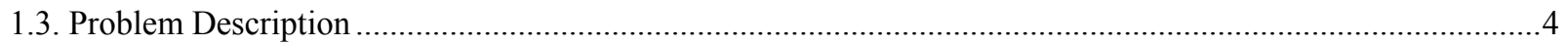

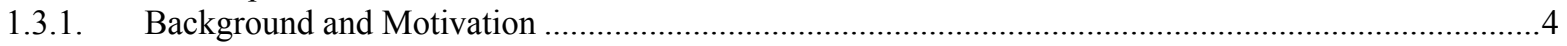

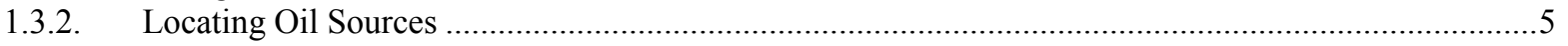

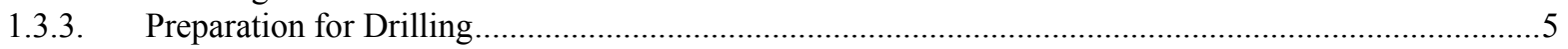

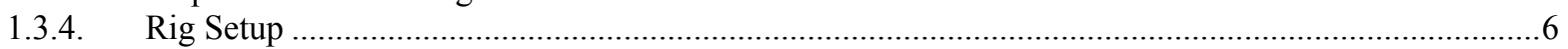

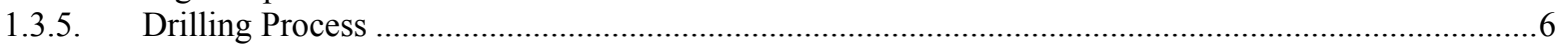

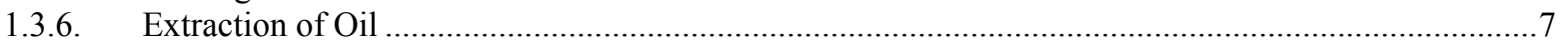

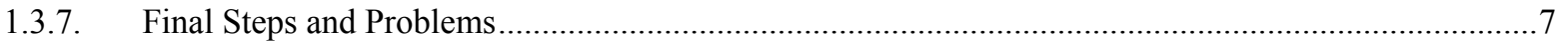

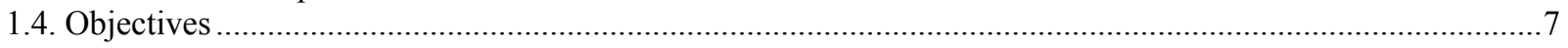

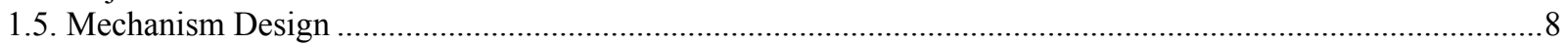

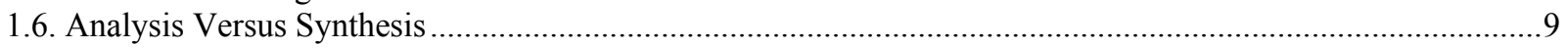

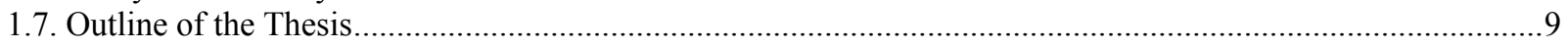

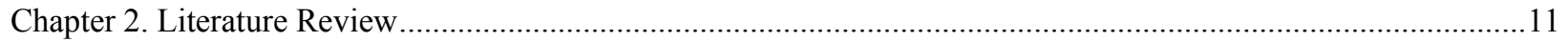

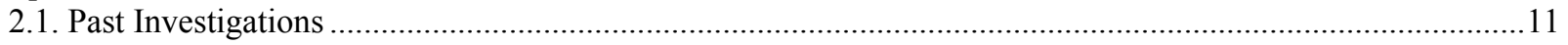

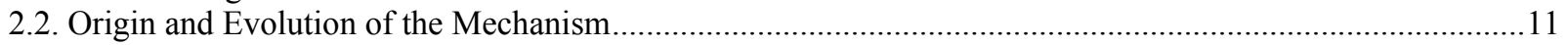

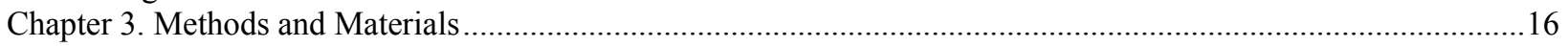

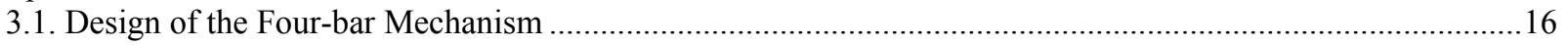

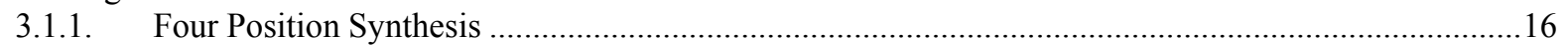

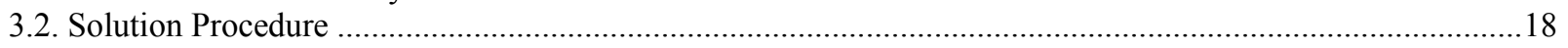

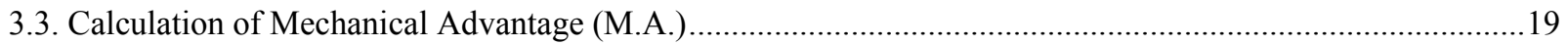

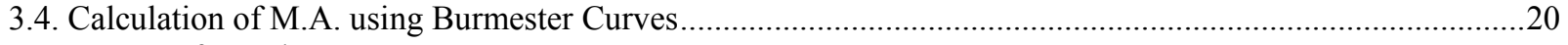

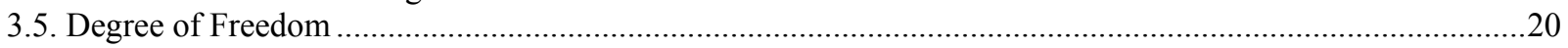

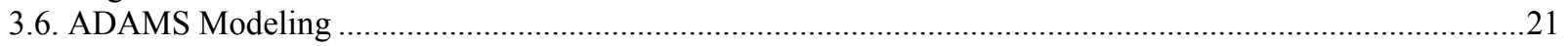

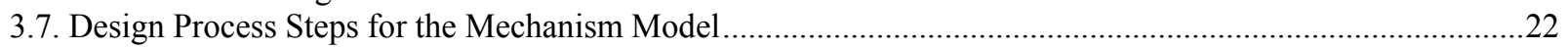

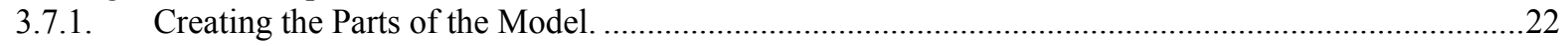

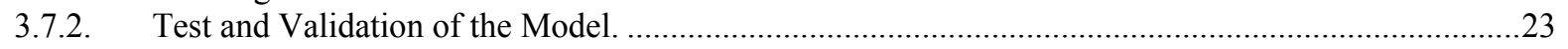

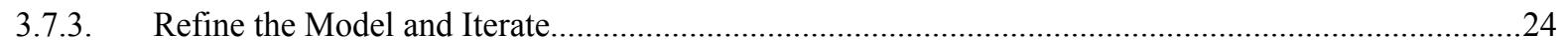

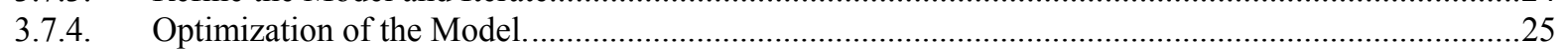

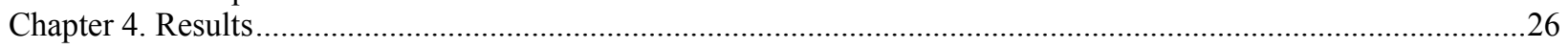

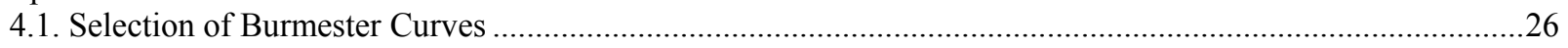

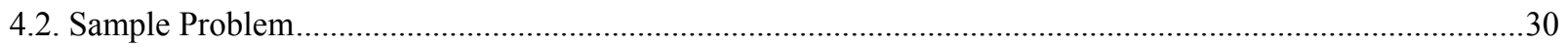

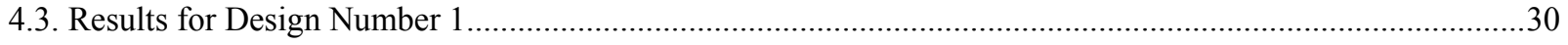

4.3.1. Movement of Mechanism Through Four Accuracy Points ..............................................................30

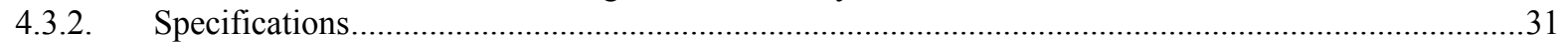

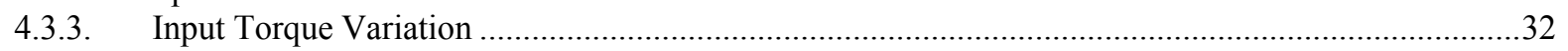

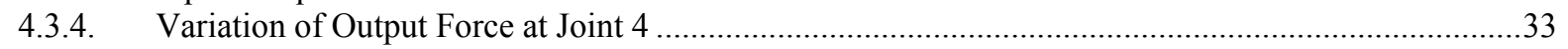

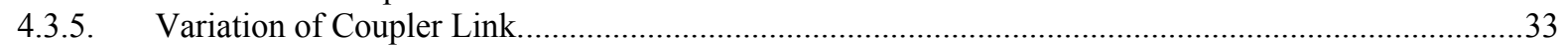

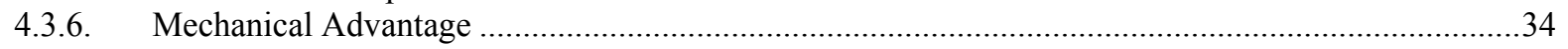

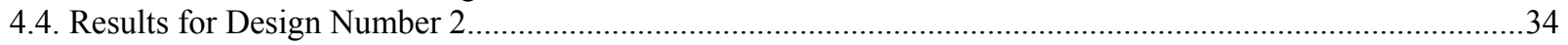

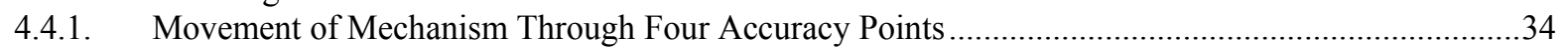

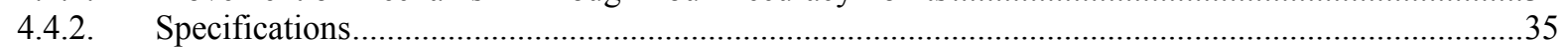

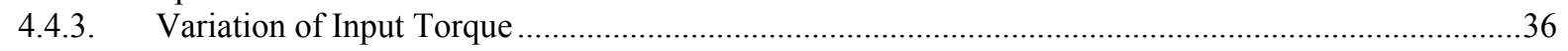

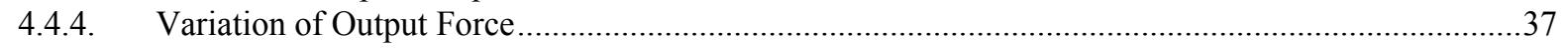

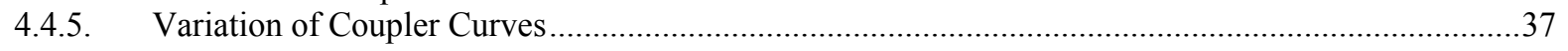

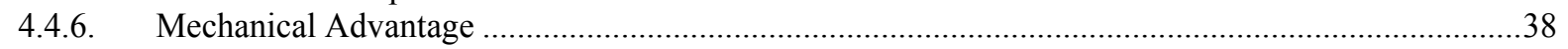

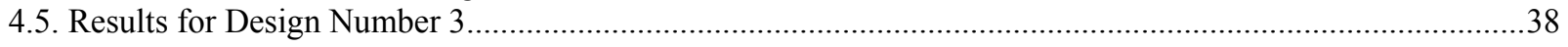

4.5.1. Movement of Mechanism Through Four Accuracy Points .................................................................38

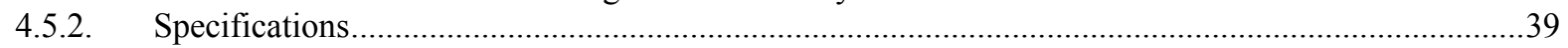

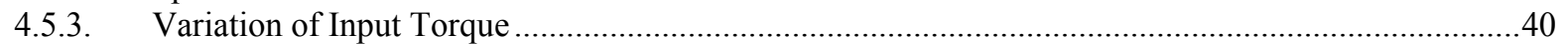

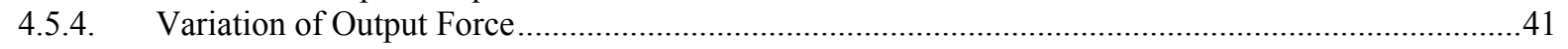




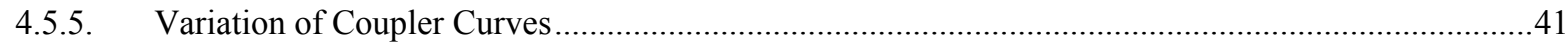

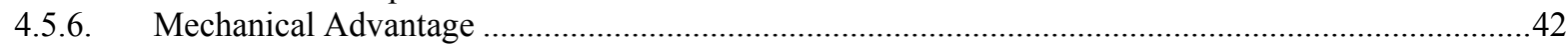

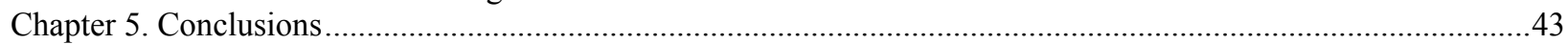

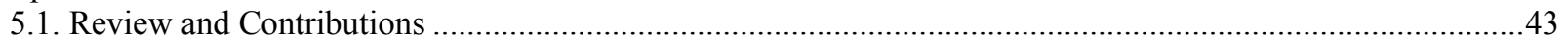

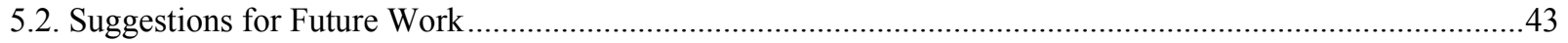

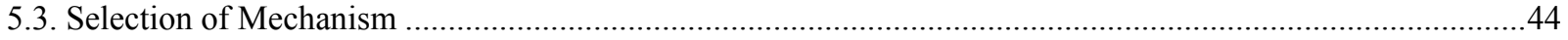

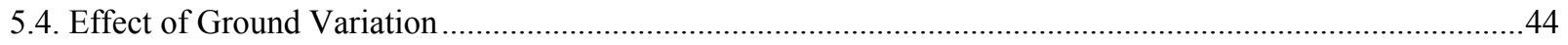

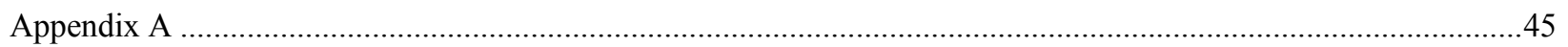

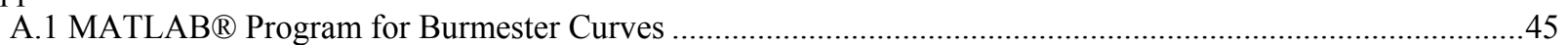

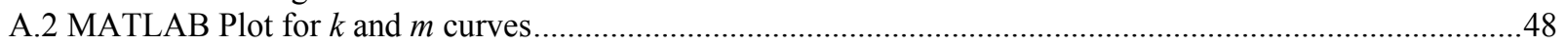

A.3. Numerical values of $k$ and $m$ obtained using the MATLAB program …............................................50

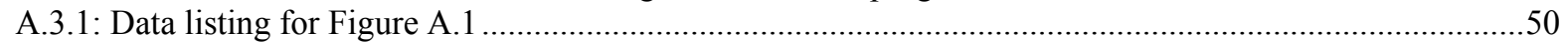

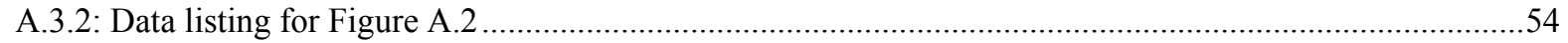

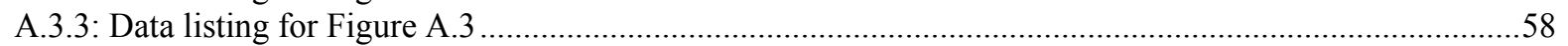

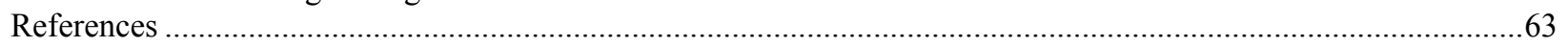




\section{List of figures}

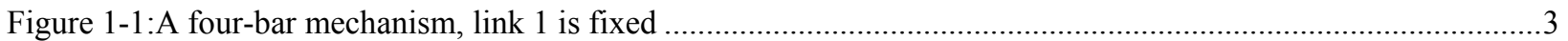

Figure 1-2:Different uses of four-bar mechanisms (Sandor, 1991) ..................................................................

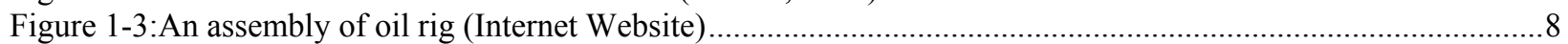

Figure 2-1:Trip hammer in a smithy, an example of the extension of the water wheel's utility by the conversion of

continuous rotation into periodic "up-and-down" motion. (From Spechtshart's "Flores musicae").................12

Figure 2-2:Water wheel and grain about 1160. Mechanically, this geared type is about the same as that described by

Vitruvius some 1,200 years earlier; the hopper agitator (a) is an added refinement. (Herrad, 1175) ................13

Figure 3-1: Figure showing four position synthesis

Figure 3-2: (a) two coplanar prescribed positions of moving plane p; (b) three prescribed positions; (c) four

prescribed positions: perpendicular bisectors $\left(k_{24}^{1}\right.$ and $\left.k_{24}^{2}\right)$ constructed for the second and four positions do

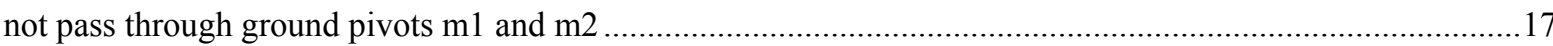

Figure 3-3:The unknown dyad W,Z, which can guide the moving plane $\mathrm{p}$ from the first to the jth position. Points $\mathrm{m}$

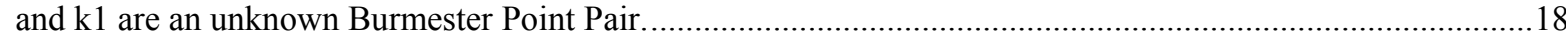

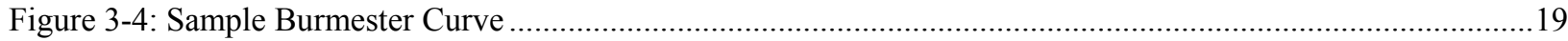

Figure 3-5: Flow chart showing the process involved in building a mechanism using ADAMS ..........................22

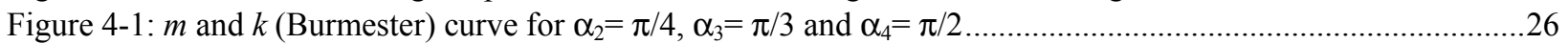

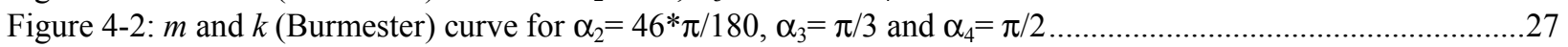

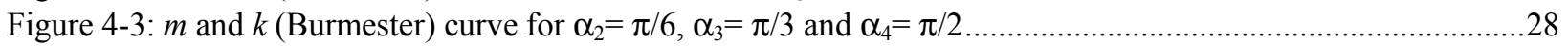

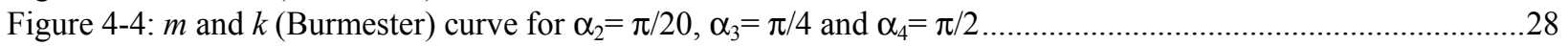

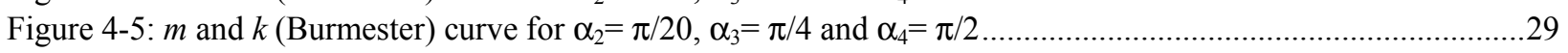

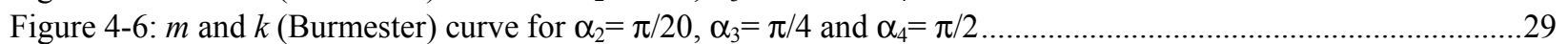

Figure 4-7: Movement of Mechanism with Guide Valve through four Accuracy Points for Design Number 1 .........31

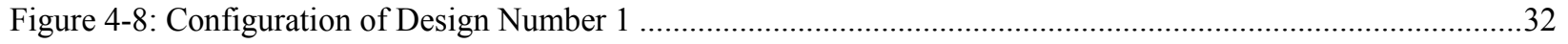

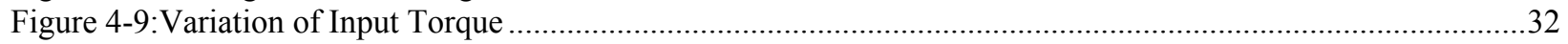

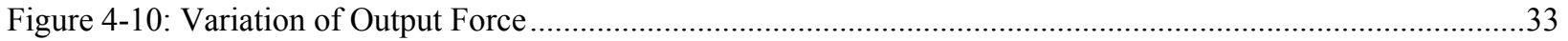

Figure 4-11: Distance moved by the Coupler Link when the Mechanism moves. ................................................33

Figure 4-12: Movement of Mechanism through Four Accuracy Points for Design Number 2 ..............................35

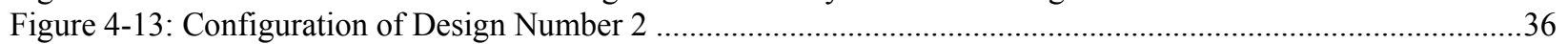

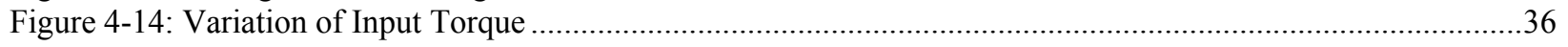

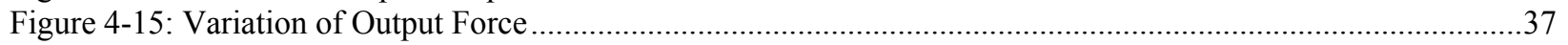

Figure 4-16: Distance moved by the coupler Link when the Mechanism moves..............................................37

Figure 4-17: Movement of Mechanism Through Four Accuracy Points for Design Number 3 .............................39

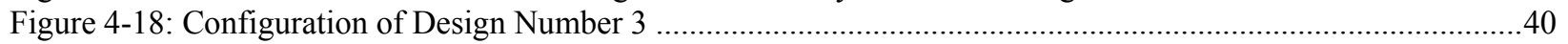

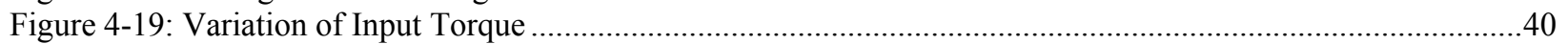

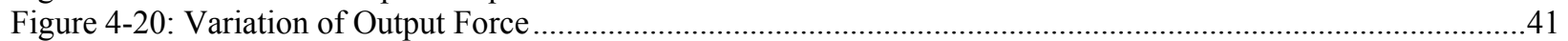

Figure4-21: Distance moved by the Coupler Link when the Mechanism moves. ................................................41 


\section{List of Tables}

Table 1: Table showing different types of links ..................................................................................................

Table 2: Table showing different types of joints (Erdman, 1984) ..........................................................................2

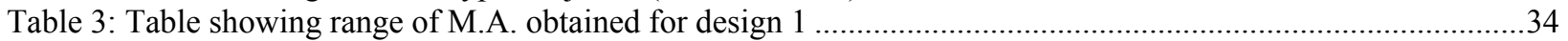

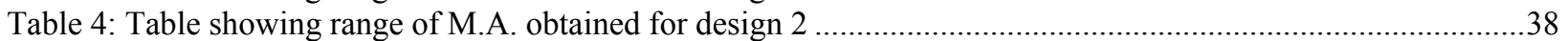

Table 5: Table showing range of M.A. obtained for design 3 ...........................................................................42 


\section{Chapter 1. Introduction}

The theory of machines and mechanisms is an applied science, which is used to understand the relationships between the geometry and motion of the parts of a machine or mechanisms and the forces, which produce these motions.

Reuleaux defines a machine as a combination of resistant bodies so arranged that by their means the mechanical forces of nature can be compelled to do work accompanied by certain determinate motions. He also defines a mechanism as an "assemblage" of resistant bodies, connected by movable joints, to form a closed kinematic chain with one link fixed and having the purpose of transferring motion (Reuleaux, 1963).

\subsection{Mechanisms}

Mechanisms are assemblages of solid members connected together by joints. Mechanisms transfer motion and mechanical work from one or more actuators to one or more output members. For the purpose of kinematic design, we idealize a mechanism to a kinematic linkage in which all the members are assumed to be perfectly rigid and are connected by kinematic joints. A kinematic joint is formed by direct contact between the surfaces of two members. Joints are further divided into pairs called "lower pairs" and "higher pairs" as explained by Reuleaux. A lower pair occurs at every point of one or more surface segments. A higher pair is one which contact occurs only at isolated points or along line segments. (Shigley 1995) (See Table 1 for links and Table 2 for joints).

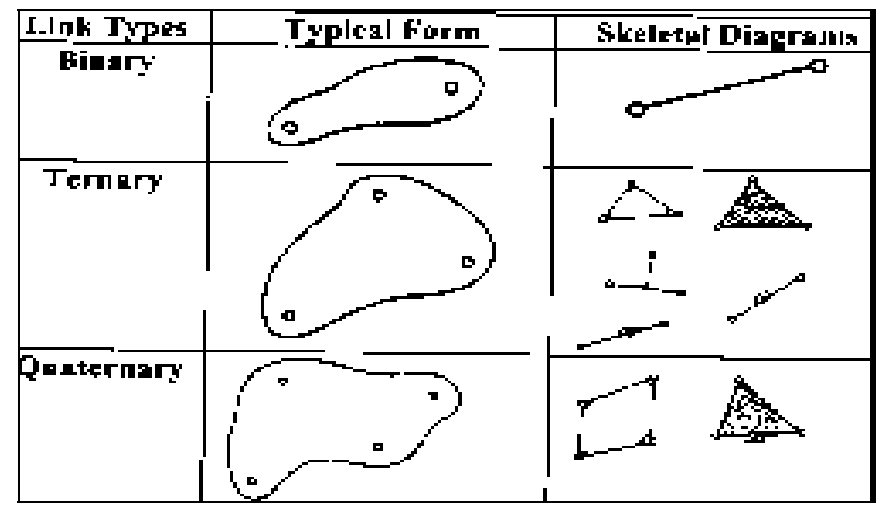

Table 1: Table showing different types of links 


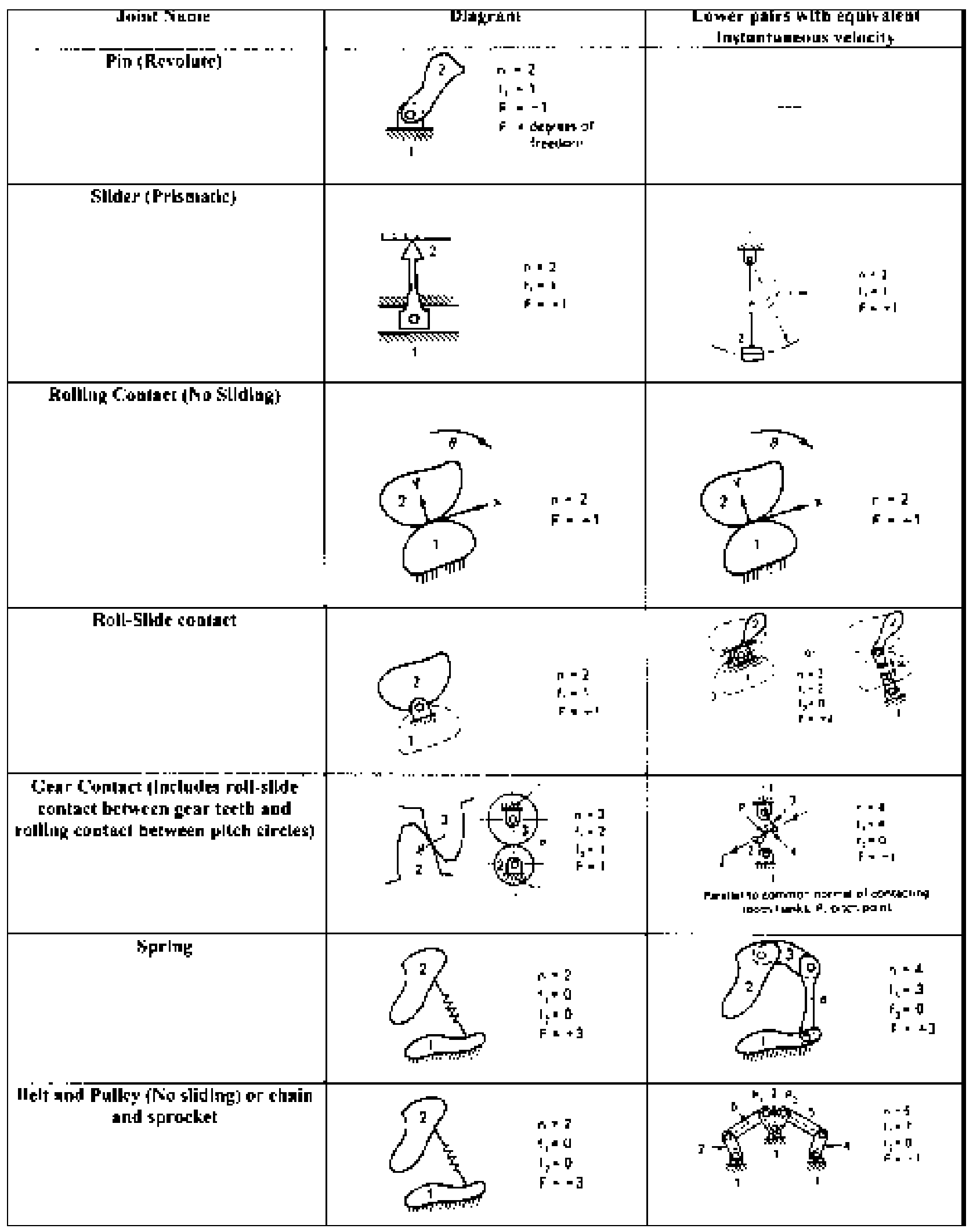

Table 2: Table showing different types of joints (Erdman, 1984) 


\subsection{Four-bar Mechanism}

The four bar linkage is the simplest possible closed-loop mechanism and has numerous uses in industry and for simple devices found in automobiles, toys etc. The device gets its name from the four distant links (or bars) as shown in Figure 1-1. Link 1 is the ground link (sometimes called the frame or fixed link), and is assumed to be motionless. Links 2 and 4 each rotate relative to the ground link about fixed pivots $\left(\mathrm{A}_{0}\right.$ and $\left.\mathrm{B}_{0}\right)$. Link 3 is called the coupler link, and is only link that can trace paths of arbitrary shape (because it is not rotating about a fixed pivot). Usually one of the "grounded links"(link 2 or link 4) serves as the input link, link 2 in this case, which may either be turned by hand or perhaps driven by an electric motor or a hydraulic or pneumatic cylinder. If link 2 is the input link, then link 4 is called the follower link, because its rotation merely follows the motion as determined by the input and coupler link motion. If link 2 is the input link and its possible range of motion is unlimited, it is called a crank, and the linkage is called a crank-rocker. Crank-rockers are very useful because the input link can be rotated continuously while a point on its coupler traces a closed complex curve.

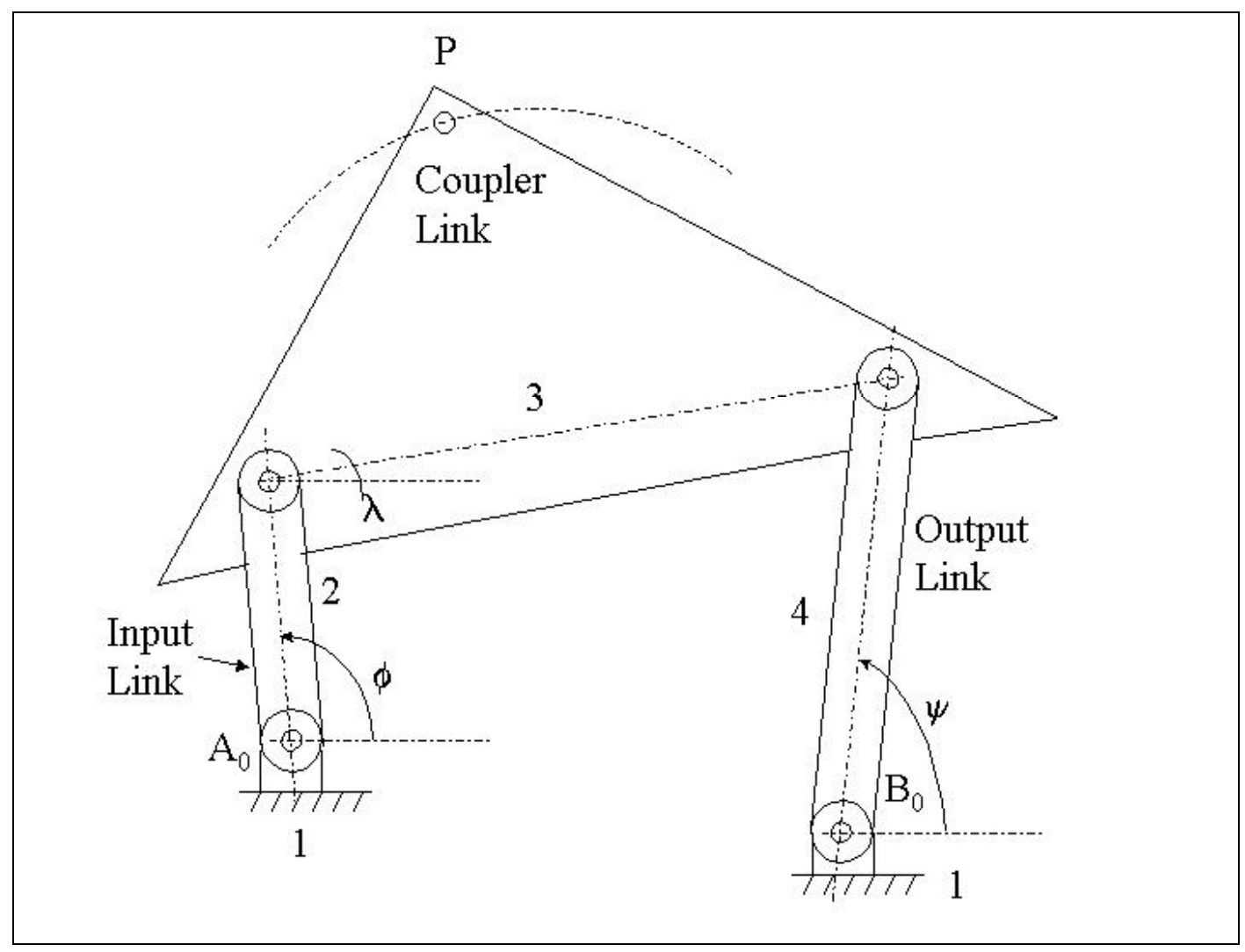

Figure 1-1:A four-bar mechanism, link 1 is fixed 
Although a simple mechanism, the four-bar is very versatile and is used in thousands of applications. The figures shown (Figure 1-2) below illustrate the wide variety of uses of the mechanism, Even though these applications are quite different, the linkages can be classified into three categories depending on the task that the linkage performs: function generation, path generation and motion generation. A function generator is a linkage in which the relative motion (or forces) between links connected to ground is of interest. In function generation, the task does not require a path tracer point on the coupler link. In path generation, we are concerned only with the path of a tracer point and not with the rotation of the coupler link. In motion generation, the entire motion of the coupler link is of concern (Sandor, 1991).

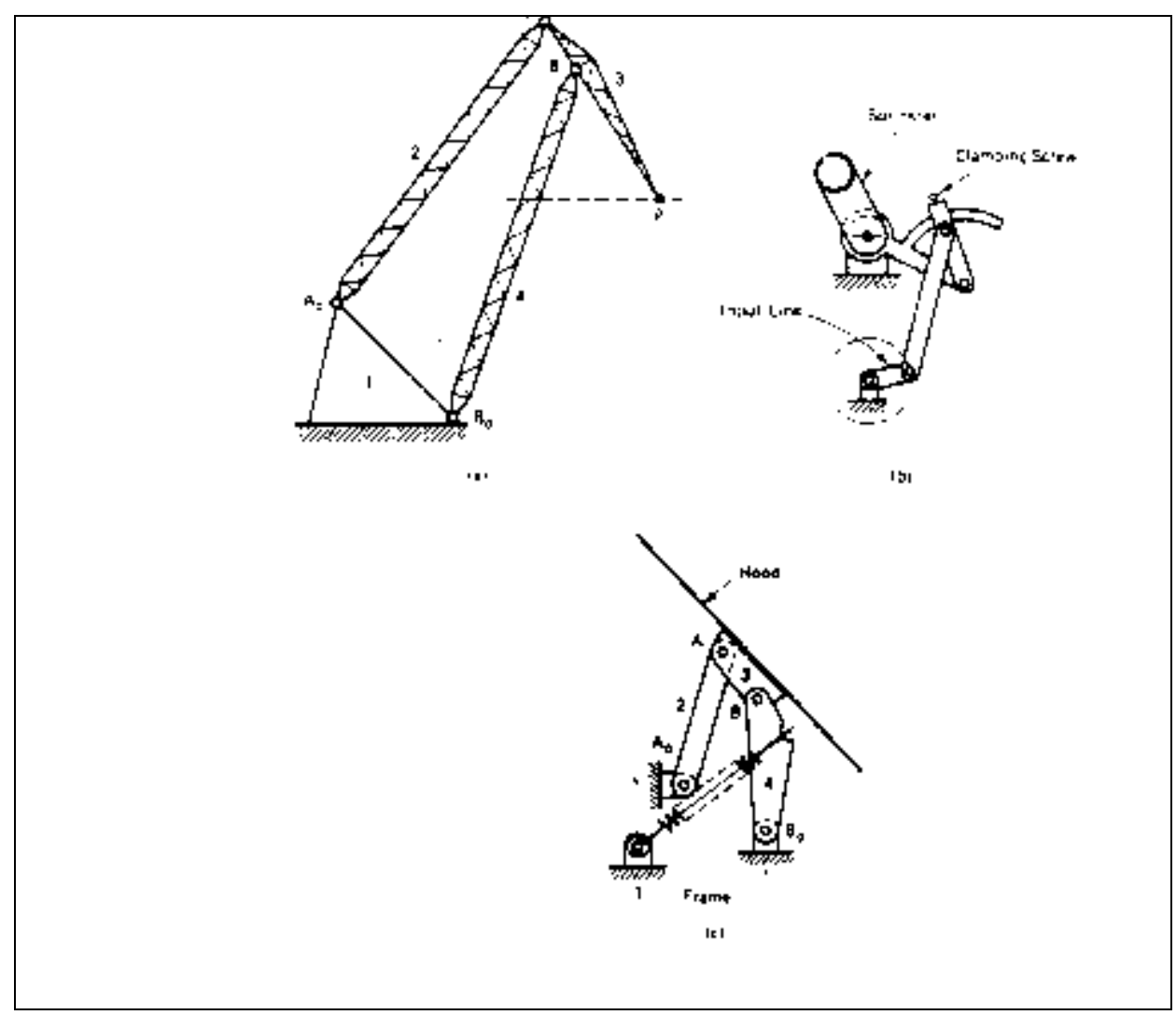

Figure 1-2:Different uses of four-bar mechanisms (Sandor, 1991)

\subsection{Problem Description}

\subsubsection{Background and Motivation}

The oil industry in the United States alone produced an estimated 181 million barrels of crude oil and imported 273 million barrels from other countries, in January 2001. Crude oil is 
refined into gasoline, kerosene, heating oil and other products. New sources of petroleum are constantly needed as demand continues to increase. The subsequent sections outline the process of oil exploration and drilling. This information is useful in understanding the motivation of this research.

\subsubsection{Locating Oil Sources}

Geologists determine the location of oil sources. Primarily they look at surface features, surface rock, and soil types and if possible, some samples obtained by shallow drilling. Satellite images are also sometimes used in locating oil. Oil can be located by using any of the following methods.

1. By detecting changes in the earth's gravitational field. This can be accomplished using instruments called gravity meters.

2. By detecting changes in the earth's magnetic field. The instruments used for this purpose are called magnetometers.

3. By detecting hydrocarbons through the use of electronic "sniffers" (sensors).

4. Through the use of seismology (most common method). Oil is located in this case by creating shock waves that pass through the rock layers and studying the reflected waves.

\subsubsection{Preparation for Drilling}

Once the location has determined, the site is prepared for drilling. The requirements for this part of the process are:

1. Clearing and leveling the land. Access roads are built if necessary.

2. Locating a water source or drilling water well. The oil drilling process requires water.

3. Digging a reserve pit to dispose of rock cuttings and drilling mud and lining it with plastic. Suitable ecological considerations must be kept in mind.

After the land has been prepared, several holes are dug around the main drilling hole location. Among these is the cellar, which is a rectangular pit to provide a workspace for the workers. Additional holes are dug around the drilling hole to store equipment. A larger and shallower hole is drilled first at the main drilling site and lined with a large-diameter conductor pipe. 


\subsubsection{Rig Setup}

The equipment is transported to the site by truck, helicopter or barge. Some rigs are also built on ships or barges for work on inland water when there is no foundation to support a rig. Once the equipment is at the site, it is set up. The rig consists of a power system (diesel or electrical generators), a mechanical system (hoists, winches, turntables etc.), rotating equipment (swivel, kelly, turntable, drill string, drill bits etc.), casing and a circulating system (pump, pipes and hoses, shale shaker etc.).

\subsubsection{Drilling Process}

The actual drilling process consists of several steps. From the starter hole, a surface hole is dug down to a pre-set depth, which is approximately near the oil trap location. Then a sequence of steps as outlined below is followed.

1. The drill bit, collar and drill pipe are placed in the hole.

2. The kelly and turntable are attached and drilling is begun.

3. As drilling progresses, mud is circulated through the pipe and out of the bit to float the rock cuttings out of the hole.

4. New sections (joints) of drill pipes are added as the hole gets deeper.

5. The drill pipe, collar and bit are removed when the pre-set depth is reached.

The casing is then cemented to prevent the hole from collapsing on itself. Casing pipe is put in the hole and cement is pumped down the casing pipe using a bottom plug, cement slurry, a top plug and drill mud. The pressure causes the cement slurry to move through the casing and fill the space between the outside of the casing and the hole. When the cement hardens, it forms a seal between the casing and the hole. The sequence of steps given above is repeated (drilling followed by cementing).

When the rock cuttings from the mud reveal the oil sand from the reservoir rock, the drilling apparatus is removed from the hole. The finding is confirmed using well logging (using electrical and gas sensors to measure rock formations), Drill-stem testing (measurement of pressures which will reveal whether reservoir rock has been reached) and Core samples testing (samples of rock to look for characteristics of reservoir rock). 


\subsubsection{Extraction of Oil}

Once the final depth has been reached, the well is completed to allow oil to flow through the casing. Explosive charges are lowered into the well through the use of a perforating gun. The explosion of these charges creates small holes in the casing through which oil can flow. A smalldiameter pipe is then run into the hole to act as a conduit. A "packer" device is used to seal the outside of the tubing. A multi-valve structure is then connected to the top of the tubing and cemented to the top of the casing. This structure (called a Christmas tree) allows the crew to control the oil flow.

Once the well is completed, the flow of oil into the well is accomplished by pumping acid (for limestone reservoir rock) or special fluid proppants (sand, walnut shells, aluminum pellets) for sandstone reservoir rock. The pressure from this fluid causes the oil to flow into the well. Once the oil starts flowing, the rig is removed.

\subsubsection{Final Steps and Problems}

A pump is placed on the well head and driven by an electric motor to draw the oil up the well. In some cases, steam is used to thin heavy oil, which may not flow (enhanced oil recovery). In other cases, oil gushes out when the final depth is reached, even without the use of acids or proppants. This situation (called blowout) is remedied by assembling blowout preventers. A schematic of an oil well is given in Figure 1-3. Guide valves are assembled on top of these blowout preventers. While the blowout preventers remain permanently on-site as long as oil is available, the guide valves are assembled only when drilling for oil takes place. These guide valves are brought to the site on trucks and need to be transferred to their place on the blowout preventers. Doing this requires the use of cranes. However, cranes are expensive and timeconsuming. The use of a mechanism to accomplish the goal of transferring the guide valve to the blowout preventer is therefore attractive.

\subsection{Objectives}

The purpose of this research is to design a four bar mechanism, which is used to lift the guide valve from the floor bed of the truck and place it to the top of the blow out preventers. This problem is supported by Halliburton Energy Services of Texas, USA. The company is currently using cranes to lift the guide valve, which is time-consuming and labor intensive process. The specific objectives of this study were: 


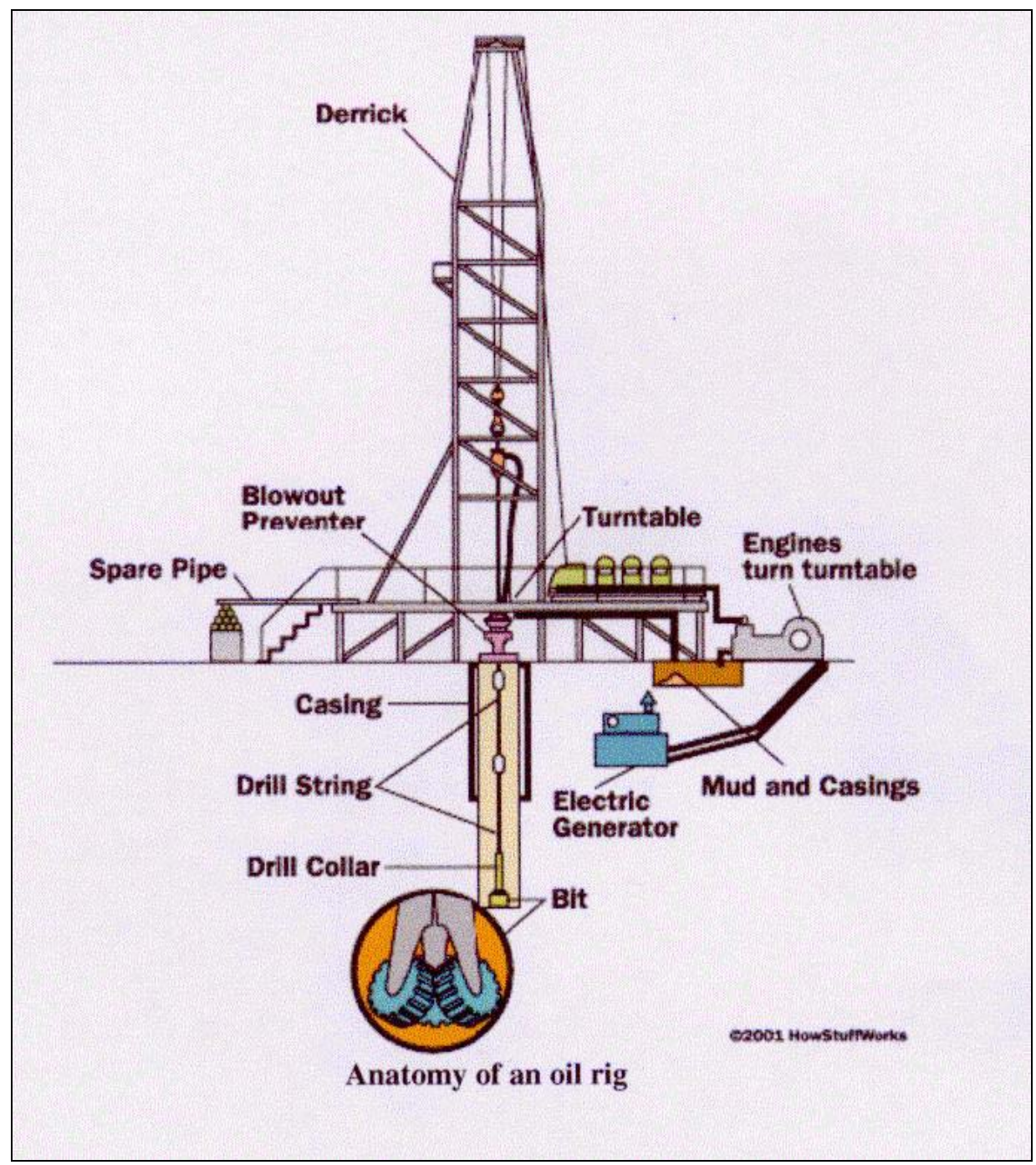

Figure 1-3:An assembly of oil rig (Internet Website)

a) Devise four-bar mechanisms to lift the guide valve from the truck bed, using fourposition synthesis.

b) Obtain the right design by calculating the Mechanical Advantage of the mechanisms obtained in (a) above.

\subsection{Mechanism Design}

The design of the of mechanism, begins with an analysis of the motion and path it has to follow, In other words we can say that the motion is given and the mechanism is to be found. This is what is called the essence of kinematics synthesis. Thus kinematics synthesis deals with the systematic design of mechanisms for a given performance. 
1) Type synthesis: Given the required performance, what type of mechanism will be suitable (Gear trains, Linkages, Cam mechanisms). Also, how many links should the mechanism have, how many degrees of freedom are required, what configuration is suitable?

2) Dimensional synthesis: The second major category of kinematics synthesis is best defined by way of its objective. Dimensional synthesis seeks to determine the significant dimensions and the starting position of a mechanism of preconceived type for a specified task and prescribed performance.

In designing a mechanism, the engineer must find answers to many questions. For example: what is the relation between the motion of the driving link and the follower link? What is the force to be given to the link? What is the required output torque? What should be done to change the output torque? What are the limitations of mechanisms? Which positional synthesis is suitable for the mechanisms? All these questions apply to the current study. But mechanisms must also be synthesized. That is to say, the geometries must be determined so that they will fit into the required spaces and deliver the motion characteristics, which are desired (Shigley, 1976).

\subsection{Analysis Versus Synthesis}

The process of drawing kinematic diagrams and determining degrees of freedom of more complex mechanisms are the first steps in both the kinematics analysis and the synthesis process. In kinematics analysis, a particular given mechanism is investigated based on the mechanism geometry plus possibly other known characteristics (such as the input velocity and force). Kinematics synthesis, on the other hand, is the process of designing a mechanism to accomplish a desired task. Here, both the type synthesis as well as dimensional synthesis of the new mechanism can be a part of kinematics synthesis (Erdman, 1984).

\subsection{Outline of the Thesis}

This thesis presents versatile and efficient solution methods to study the synthesis of four-bar mechanisms using four-position synthesis (i.e., by Burmester curves). It is expected that this kind of study is useful to design engineers who deal with the synthesis of mechanisms. This thesis consists of five chapters, the first (Chapter 1) being Introduction. Chapter 2 describes the developments in the field of mechanisms. 
Chapter 3 describes the synthesis, kinematics analysis of four-bar mechanism using four positions synthesis of Burmester curves. The analysis is carried out using ADAMS.

(Mechanical Dynamics Inc., Ann Arbor, MI, USA)

Chapter 4 describes the results of the analytical study done and comparisons of various solutions obtained.

Chapter 5 describes the conclusions and future study, which explains what can be done to improve the efficiency and how well can a mechanism be designed. 


\section{Chapter 2. Literature Review}

A mechanism is a set of machine elements arranged so as to produce a specific motion. The four bar mechanism as previously shown in Figure 1-1 is most common and widely used, which has three moving links and four pin joints. The link that is connected to the power source or prime mover is called the input link. The output link connects the moving pivot to the ground pivot. The coupler or floating link connects the two moving pivots, A and B, thereby coupling the input to the output link. The origin, history and operation of these mechanisms are of some interest in establishing the background for this investigation.

\subsection{Past Investigations}

In recent years, the design on the link mechanism of a working device in a load is gradually being perfected, but the design on the link mechanism seems to be still at the trial and error level. In order to further improve the design method of four-bar mechanisms, in this project using a concept of "deficiency" or "advantage" and a method combining the theoretical analysis with the computer computation, we make an attempt at analyzing and discussing this problem and finally we obtain some conclusions for increasing the design quality of four-bar mechanisms (Waldron, 1999).

\subsection{Origin and Evolution of the Mechanism}

The history of kinematics, the story of development of the geometry of motion, is composed of evolvements in machines, mechanisms, and mathematics.

Machine and Mechanism are words giving two different images. The term machine is associated with the use and transformation of force, and although motion in varying degrees is encountered in a machine, the idea of force dominates. Mechanisms on the other hand, definitely conjures up the idea of motion, and while forces do exist, they are relatively small and unimportant compared with the exploitation of motion. However, machine and mechanism inhabit the same body (Hartenburg, 1964). 
The design of mechanisms is a technical area that is unique to mechanical engineering. Its history stretches back to prehistoric times. Artisans such as blacksmith and carpenters also functioned as the designers of mechanisms.

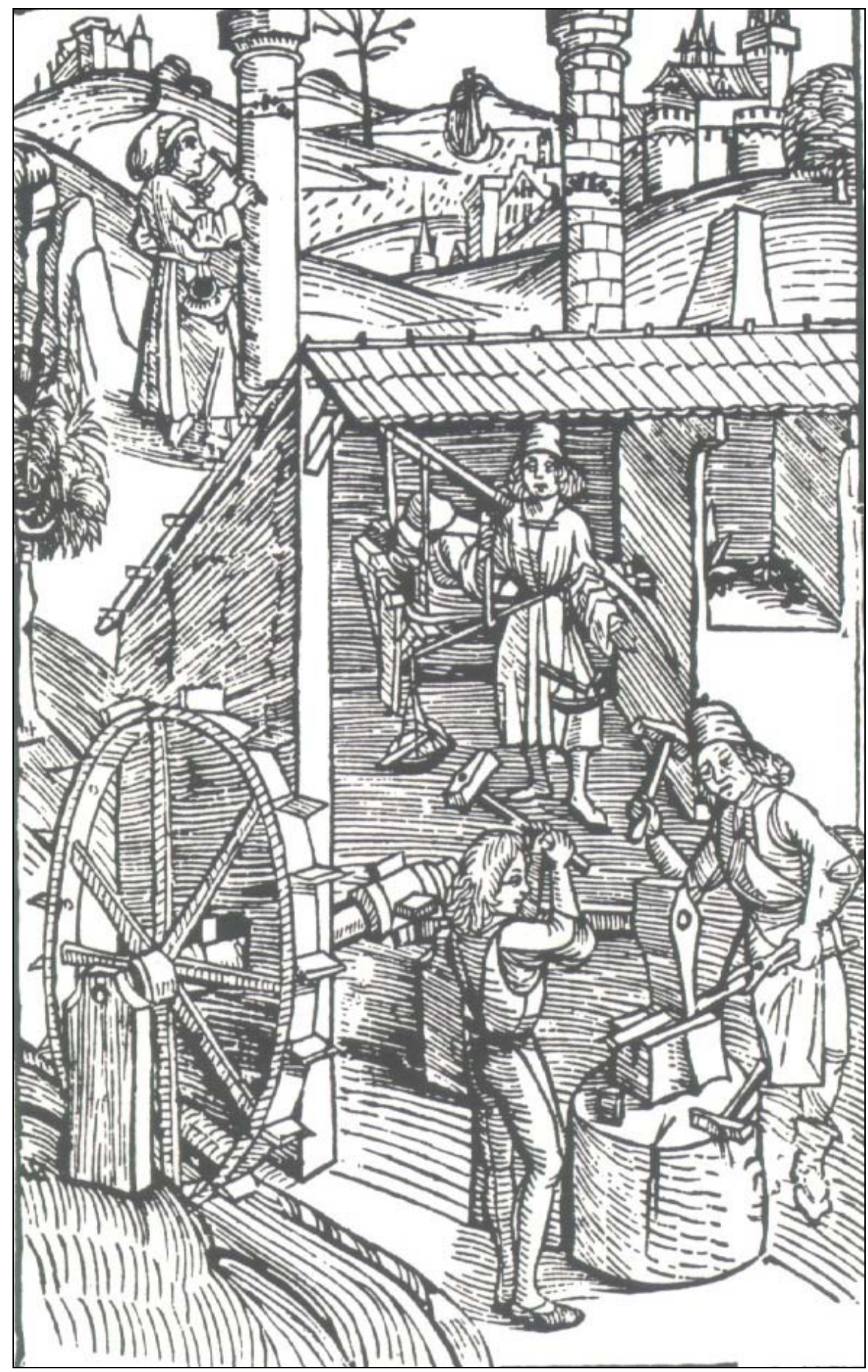

Figure 2-1:Trip hammer in a smithy, an example of the extension of the water wheel's utility by the conversion of continuous rotation into periodic "up-and-down" motion. (From Spechtshart's "Flores musicae"). 
One of the original functions of engineers was the design of mechanisms both for warfare and for peaceful uses. In renaissance times, we find Leonardo Da Vinci depicting a sophisticated variety of mechanisms, mostly for military purposes. Sometimes thereafter the distinction between civil engineering and military engineering appeared. The modern era in mechanism design, along with history of mechanical engineering as a distinct discipline, can be viewed as starting with James Watt. That is not to say that the subject has remained static. In fact, there have been dramatic changes in the practice of mechanism design in recent years. Traditionally, machines have been designed to be powered by a single "prime mover," with all functions mechanically coordinated. That tradition certainly predated Watt. Recent developments in computer technology, coupled with improvements in electric motors and other actuators, have made it possible to use a different approach. This is an approach in which machines are powered by multiple actuators coordinated electronically. The resulting machines are simpler, less expensive, more easily maintained, and more reliable. Another major change is in the techniques used in mechanism design. The use of interactive computer graphics has had a dramatic impact on design practice (Denavit, 1964).

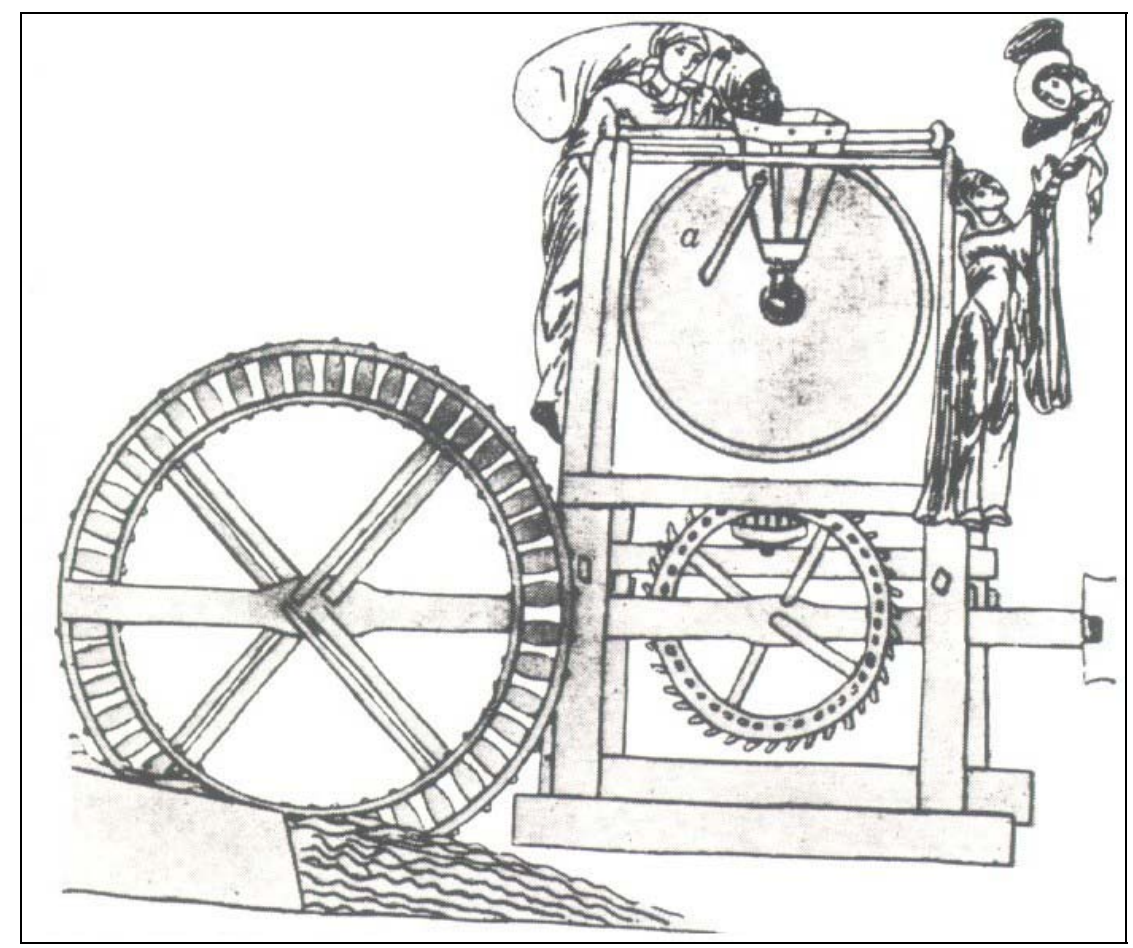

Figure 2-2:Water wheel and grain about 1160. Mechanically, this geared type is about the same as that described by Vitruvius some 1,200 years earlier; the hopper agitator (a) is an added refinement. (Herrad, 1175) 
Some of the machines and mechanisms, which were used in earlier years, are shown in Figure 2-1 and Figure 2-2.

When conducting research, it is useful to follow and to set objectives. A method for systematic mechanism design has been proposed by D.G. Olson et al. and is shown in Table. The procedure consists of three steps: problem definition, type synthesis and dimensional synthesis.

The specific objectives of this research are:

To enumerate all mechanisms that fit the topological and functional requirements for a controllable four bar mechanism. The enumerate is to use the Chebyshev-Gruebler equation with loop closures to find all groups of kinematic chains. A method developed by Freudenstein (Freudenstein, 1954) is used to find the basic kinematics chains. The mechanisms are then to be found by kinematic inversion. The input links, output links and the joints are then to be assigned according to the search specifications and the remaining mechanisms are then to be listed.

I Problem Definition

Topological Requirements

Nature of Motion (planar or Spatial)

Degree of Freedom (number of Inputs)

Functional Requirements

Number of Distinct outputs

Task to be accomplished by each output

Complexity of Each task.

Constraints

Dimensional Constraints

Inertial Constraints

II Type Synthesis

Topological Synthesis

Enumerate basic kinematic chains satisfying topological requirements Enumerate basic mechanisms derivable from each BKC by assigning ground link. Topological Analysis

Determine type of freedom and distinct ways of applying inputs. 
Identify possible output(s) to satisfy functional requirements.

Assign Joint types based on specified Input and Functional requirements.

Evaluate each mechanism based on functional requirements.

\section{Dimensional Synthesis}

Kinematic Synthesis-For a given type of mechanism, determine dimensions based on functional requirements.

Kinematic Analysis - Evaluate mechanism based on dimensional constraints and kinematic criteria.

Dynamic analysis - Evaluate mechanism based on inertial constraints.

To develop a method of dimensional synthesis to apply to said mechanisms. This was to be done by writing the equality and inequality constraint equations, assigning the known, unknown and design variables, and giving these variables values, initial guesses and ranges respectively. The next step was to then use an exploratory method to search the design space and to use the Newton-Raphson method to attempt loop-closures at that point. If a solution was not found that satisfied the constraints, then no solution for that mechanism existed in the design space and the mechanism was not further analyzed.

To select the mechanism with the best dimensional, inertial, and forces characteristics. Using McArthur's Monte Carlo method to search the design space did this and to find the global minimum value of the corporate utility function that is calculates at each design point. The utility values were calculated using information derived from a dimensional synthesis, acceleration synthesis, dynamic analysis, and kinetostatic analysis performed at that point and then combined by a multifactor optimization method to calculate the corporate utility. When the process is finished, the result should be a point, which has the global minimum corporate utility value and is therefore an optimal mechanism. (D.G. Olson, 1985) To do a simulation and analysis of the mechanism. This was done using software package, Automated Dynamic Analysis of Mechanical Systems (ADAMS), from which the dimensional constraints, dynamics, and the force characteristics of the mechanism could be evaluated. 


\section{Chapter 3. Methods and Materials}

As mentioned in the Introduction chapter, the design of a four-bar mechanism using fourposition synthesis and the subsequent calculation of its efficiency were the goals of this thesis. The methods used for obtaining these results are given in this chapter.

\subsection{Design of the Four-bar Mechanism}

\subsubsection{Four Position Synthesis}

Figure 3-2 shows a moving plane $\pi$ in two and three positions. Ground pivots are designated by $m$, while moving pivots of ground-pivoted binary links are indicated by $k$. For any two prescribed positions, there are three infinities of $k$ and $m$ point pairs. This is because $k_{l}$ (The moving pivot in its first position) may be located anywhere in the first position of plane $\pi$, and $m$ anywhere along the perpendicular bisector of $k_{1}$ and $k_{2}$. Figure 3-3 shows the three previously positions, plus an additional position, $\pi_{4}$. Also shown are the two-ground pivots $m^{1}$ and $m^{2}$ corresponding to the moving pivots $k^{1}$ and $k^{2}$. However, $k^{1}$ and $k^{2}$ are not acceptable pivots since the perpendicular bisectors, $k_{24}^{1}$ and $k_{24}^{2}$ do not pass through $m^{1}$ and $m^{2}$. However, we know in general that there should be an infinite number of solutions. Therefore, the problem is one of finding the point's $k$ in a body $\pi$ whose corresponding positions lie on a circle of the fixed plane for the four arbitrarily prescribed positions of $\pi$. Burmester reported the fact that there are indeed such points. (Burmester, 1876). Referring to the Figure 3-2 and Figure 3-3, for four-position synthesis, we adopt the following procedure. We first find the path displacement vector $\delta_{\mathrm{j}}=\mathrm{R}_{\mathrm{j}}-\mathrm{R}_{1}$. The rotation of the plane from 1 to $j$ is equal to the rotation of the directed line segment $P a$, signified as $\alpha_{\mathrm{j}}$.

If point $k_{l}$ represents the unknown location of a possible circle point, and if point $m$ is the corresponding unknown center point, since both $k$ and $\mathrm{P}$ are embedded in the moving plane, an unknown vector $\mathrm{Z}$ embedded in plane $\pi_{1}$, may be drawn from $k_{1}$ to $\mathrm{P}_{1}$. Another circle point $k_{1}$ with respect to center point $m$, is located by another unknown vector W. As plane $\pi$ moves from $\pi_{1}$ to $\pi_{\mathrm{j}}$, vector $\mathrm{W}$ rotates by the unknown angle $\beta_{\mathrm{j}}$ about $m$, while $\mathrm{P}_{1} \mathrm{a}_{1}$ rotates to $\mathrm{P}_{\mathrm{j}} \mathrm{a}_{\mathrm{j}}$ by the angle $\alpha_{\mathrm{j}}$. 
Figure 3-1 shows the schematic of four-bar mechanism on the truck bed and movement of guide valve through the four accuracy points chosen.

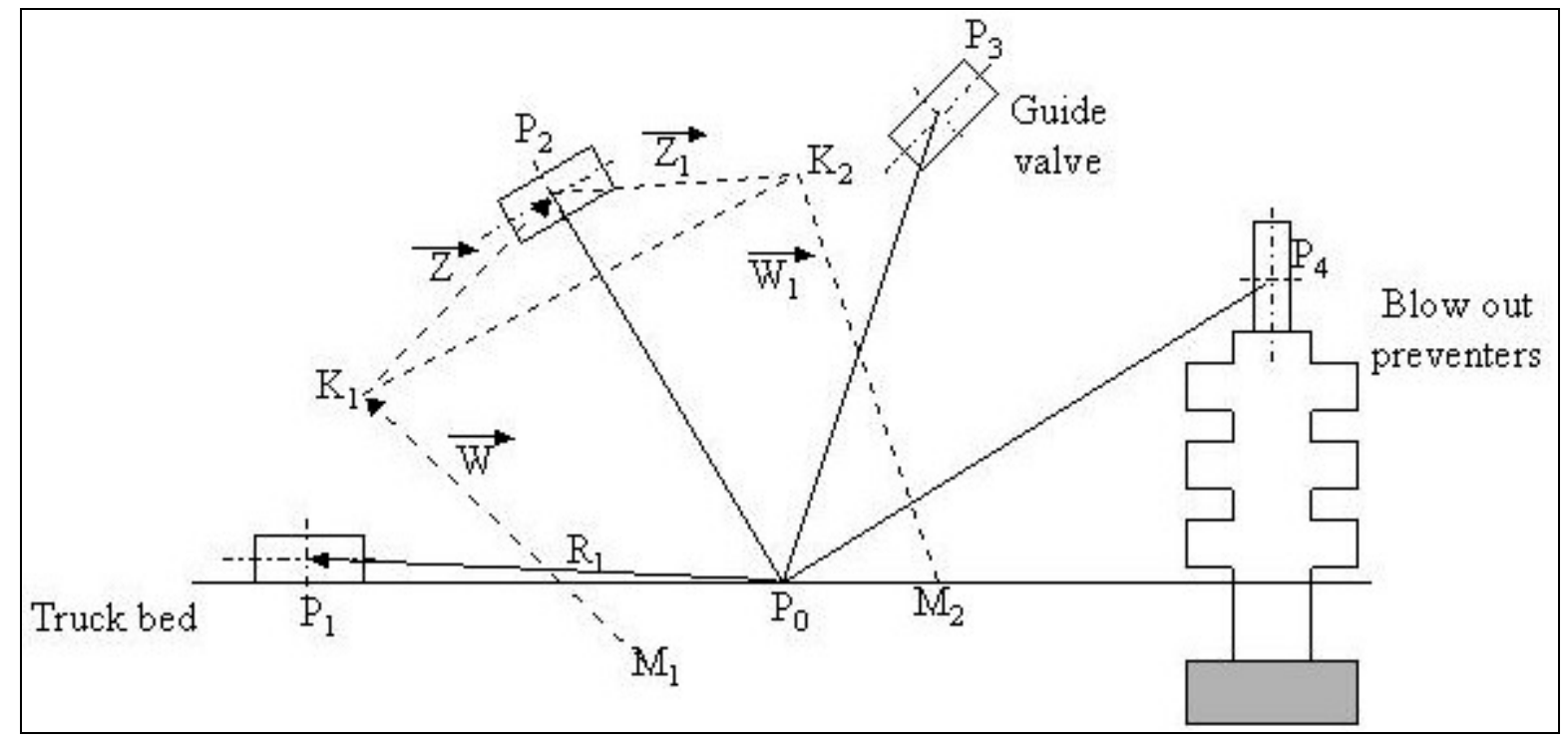

Figure 3-1: Figure showing four position synthesis

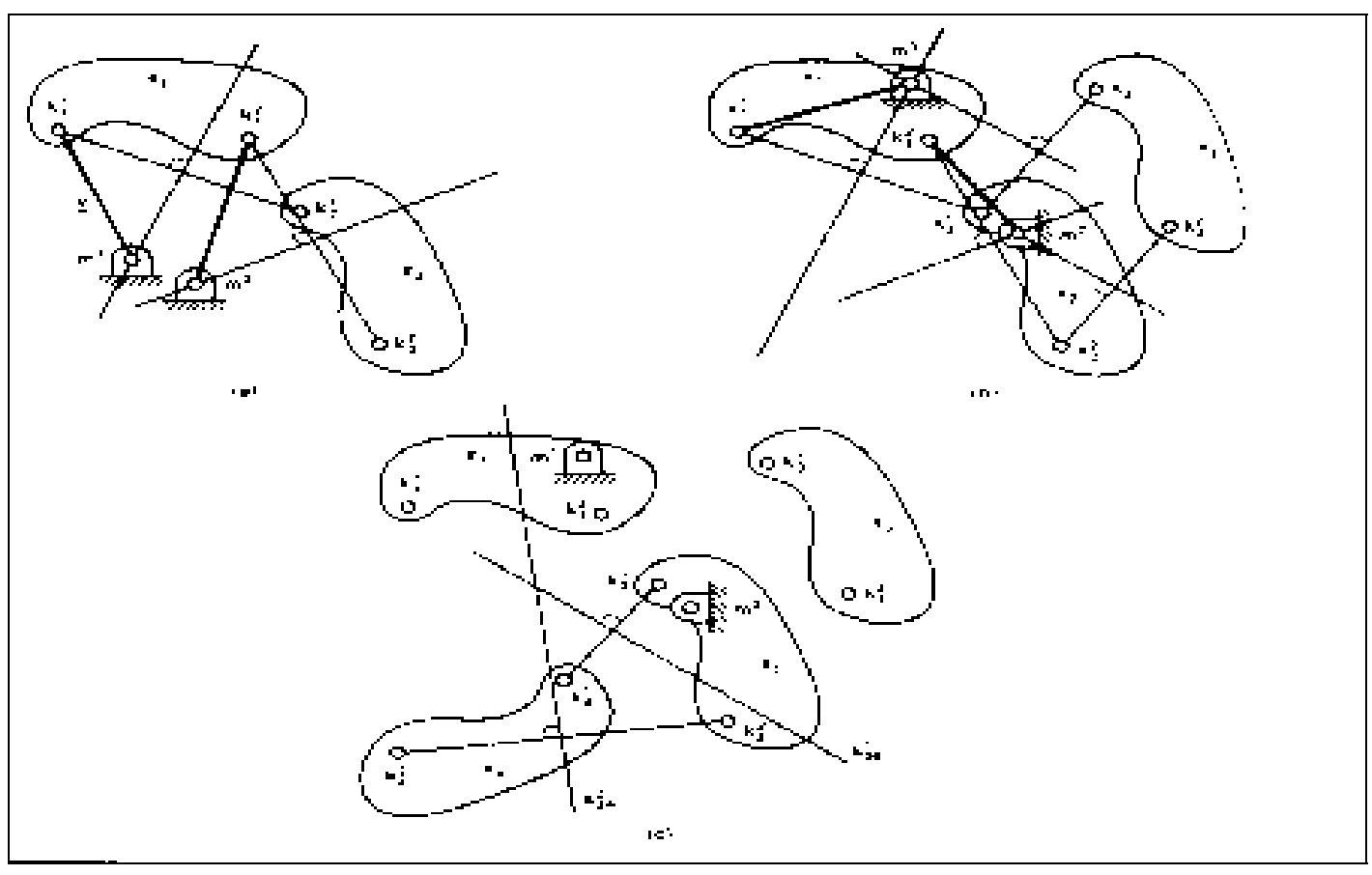

Figure 3-2: (a) two coplanar prescribed positions of moving plane p; (b) three prescribed positions; (c) four prescribed positions: perpendicular bisectors $\left(k_{24}^{1}\right.$ and $\left.k_{24}^{2}\right)$ constructed for the second and four positions do not pass through ground pivots $\mathrm{m} 1$ and $\mathrm{m} 2$ 


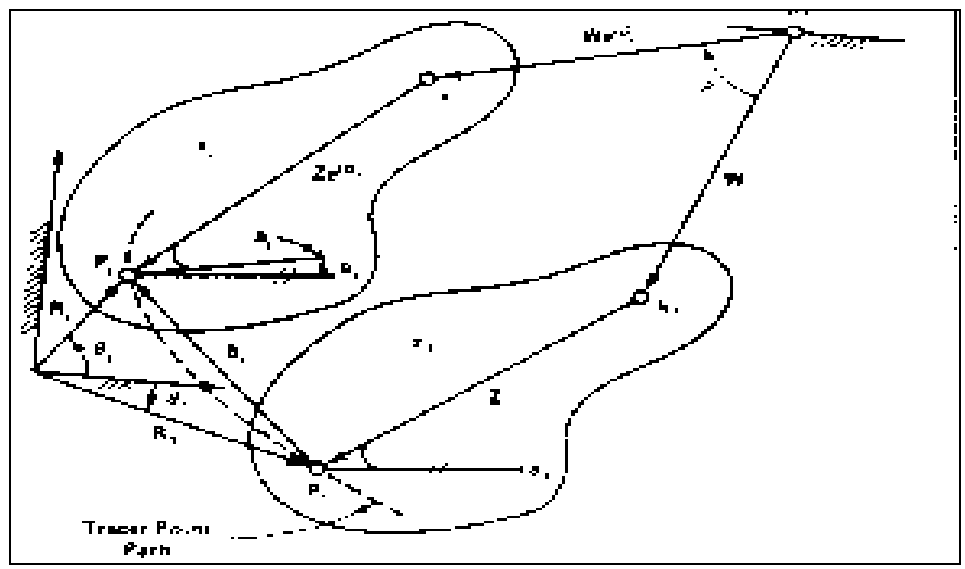

Figure 3-3:The unknown dyad $W, Z$, which can guide the moving plane $p$ from the first to the jth position. Points $m$ and $k 1$ are an unknown Burmester Point Pair.

Since the vectors defined, form a closed loop, including the first and $j^{\text {th }}$ positions:

$\mathbf{W} e^{i \beta_{j}}+\mathbf{Z} e^{i \alpha_{j}}-\delta_{j}-\mathbf{Z}-\mathbf{W}=0$

Combining terms, we obtain:

$$
\mathbf{W}\left(e^{i \beta_{j}}-1\right)+\mathbf{Z}\left(e^{i \alpha_{j}}-1\right)=\delta_{j}
$$

For four positions, there will be three equations like Equation (3.2). For $j=2,3$ and 4,

$$
\begin{aligned}
& \mathbf{W}\left(e^{i \beta_{2}}-1\right)+\mathbf{Z}\left(e^{i \alpha_{2}}-1\right)=\delta_{2} \\
& \mathbf{W}\left(e^{i \beta_{3}}-1\right)+\mathbf{Z}\left(e^{i \alpha_{3}}-1\right)=\delta_{3} \\
& \mathbf{W}\left(e^{i \beta_{4}}-1\right)+\mathbf{Z}\left(e^{i \alpha_{4}}-1\right)=\delta_{4}
\end{aligned}
$$

\subsection{Solution Procedure}

Consider the above three equations to be a set of complex equations, linear and non homogeneous in the two complex unknowns, $\mathrm{Z}$ and W. For this set of three equations to have a simultaneous solution, one of the complex equations must be linearly dependent on the other two. Thus, equation (3.3) may be expressed in matrix form as:

$$
\left[\begin{array}{cc}
e^{i \beta_{2}}-1 & e^{i \alpha_{2}}-1 \\
e^{i \beta_{3}}-1 & e^{i \alpha_{3}}-1 \\
e^{i \beta_{4}}-1 & e^{i \alpha_{4}}-1
\end{array}\right]\left[\begin{array}{l}
\mathbf{W} \\
\mathbf{Z}
\end{array}\right]=\left[\begin{array}{l}
\delta_{2} \\
\delta_{3} \\
\delta_{4}
\end{array}\right]
$$

The second column of the coefficient matrix on the left side of equation (3.4) as well as the right side of the equation contain prescribed input data, while the first column contains unknown rotations $\beta_{3}$ and $\beta_{4}$. 
For purposes of design of the four-bar mechanism by this method, $\beta_{2}$ were varied in steps and $\mathrm{W}$ and $\mathrm{Z}$ were calculated for each value of $\beta_{2}$. A MATLAB (The MathWorks Limited, Boston, MA, USA) program was written to calculate the values of W and Z, using Cramer's Rule, writing them to a text file. The listing of this program is given in Appendix A. Plots were also produced showing the variation in the values of $m$ and $k$, as $\beta_{2}$ was varied. These will be referred to as the Burmester curves. A sample plot showing such variation is given below.

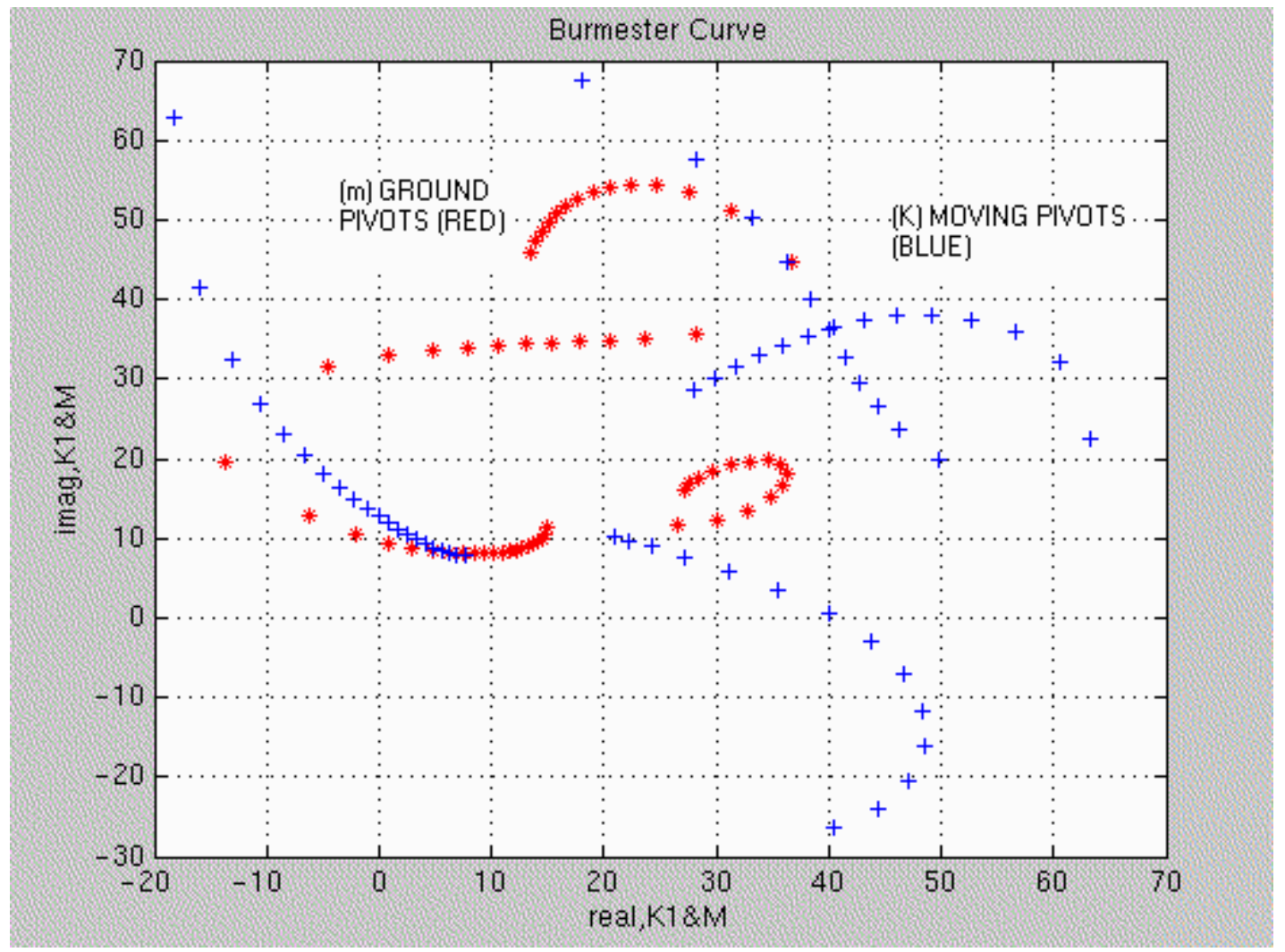

Figure 3-4: Sample Burmester Curve

\subsection{Calculation of Mechanical Advantage (M.A.)}

By definition, mechanical advantage (M.A.) is the ratio of the magnitudes of output force over input force.

M.A. $=F_{\text {out }} / \mathrm{F}_{\text {in }}$

For conservative systems (no loss of energy), M.A can be shown to be:

$$
\text { M.A. }=\left(\frac{r_{\text {out }}}{r_{\text {in }}}\right)\left(\frac{\omega_{\text {out }}}{\omega_{\text {in }}}\right)
$$


Therefore, the mechanical advantage is a product of two factors. (1) a ratio of distances that depend on the placement of the input and output forces and (2) an angular velocity ratio. The first factor may not change in value, as the mechanism moves, but the second one will change in most linkage mechanisms. Mechanisms with a higher value of M.A are better (Erdman, 1984).

\subsection{Calculation of M.A. using Burmester Curves}

For this thesis, the M.A. was calculated using ADAMS software (Mechanical Dynamics Inc., Ann Arbor, MI, USA). From the Burmester curves, the values of $\mathrm{k}_{1}$ and $\mathrm{m}$ were obtained. From these values, the values of the vectors $\mathrm{W}$ and $\mathrm{Z}$ were obtained from the following relations between these quantities:

$\mathbf{k}_{1}=\mathbf{R}_{1}-\mathbf{Z}$

$\mathbf{m}=\mathbf{k}_{1}-\mathbf{W}$

In this section, a sample problem is presented to illustrate the method of four-position synthesis. Referring to Figure 3-1, the following values are provided as input.

These values are then used to calculate the lengths of the links of the four-bar mechanisms. These lengths were then specified as input in ADAMS to obtain the configuration of the mechanism. The output force at joint 3 and the input force at joint 1 are then obtained as output from the software. The M.A can then be easily calculated using equation (3.5) above.

\subsection{Degree of Freedom}

The degree of freedom of the mechanical system is dependent on the number of independent inputs to the mechanical system. The input for this mechanical system is Torque, which is applied to the link 1 . The degree of freedom is calculated using Greubler's equation that is $F=3(n-1)-2 f_{1}$

Where $F$ is the degree of Freedom, $n$ is the number of links and $f_{l}$ is the number of lower pair joints. Most mechanism tasks require a single input to be transmitted to a single output.

Therefore, single-degree-of-freedom mechanisms, those that have constrained motion, are the types used most frequently 
ADAMS also uses Greubler's Equation to calculate the degree of freedom for the mechanism.

\subsection{ADAMS Modeling}

The $m$ and $k_{l}$ values obtained from Burmester curves are then solved for $\mathrm{W}$ and $\mathrm{Z}$ using the Equations 3.7 and 3.8. And this will be the length of links in the ADAMS model, which is

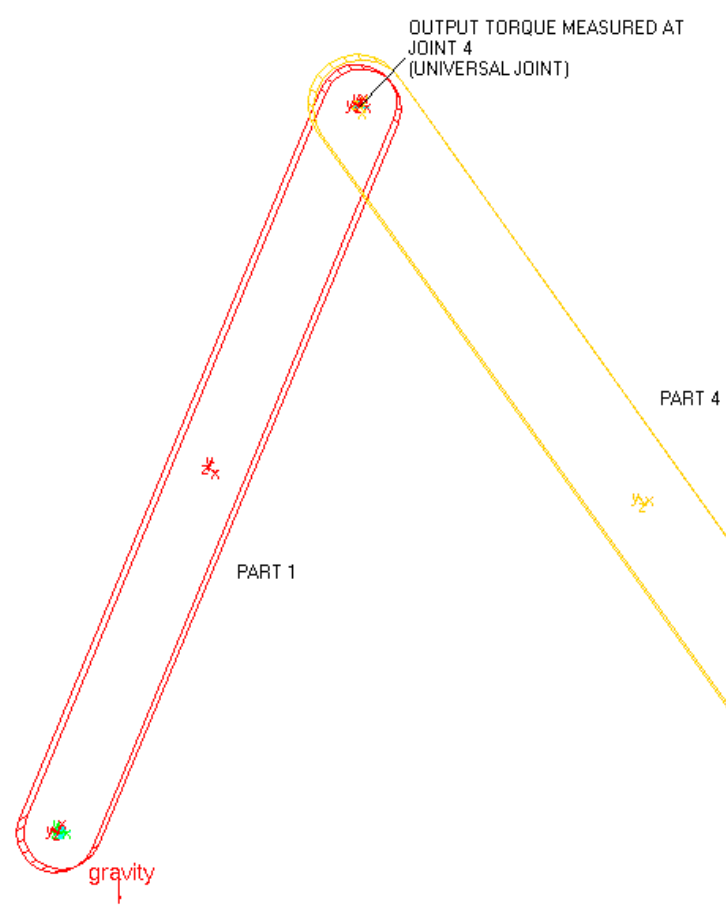

ALL DIMENSIONS ARE IN FOOT

PART 4

INPUT TORQUE APPLIED AT JOINT 3 [REVOLUTE JOINT] - PART 2
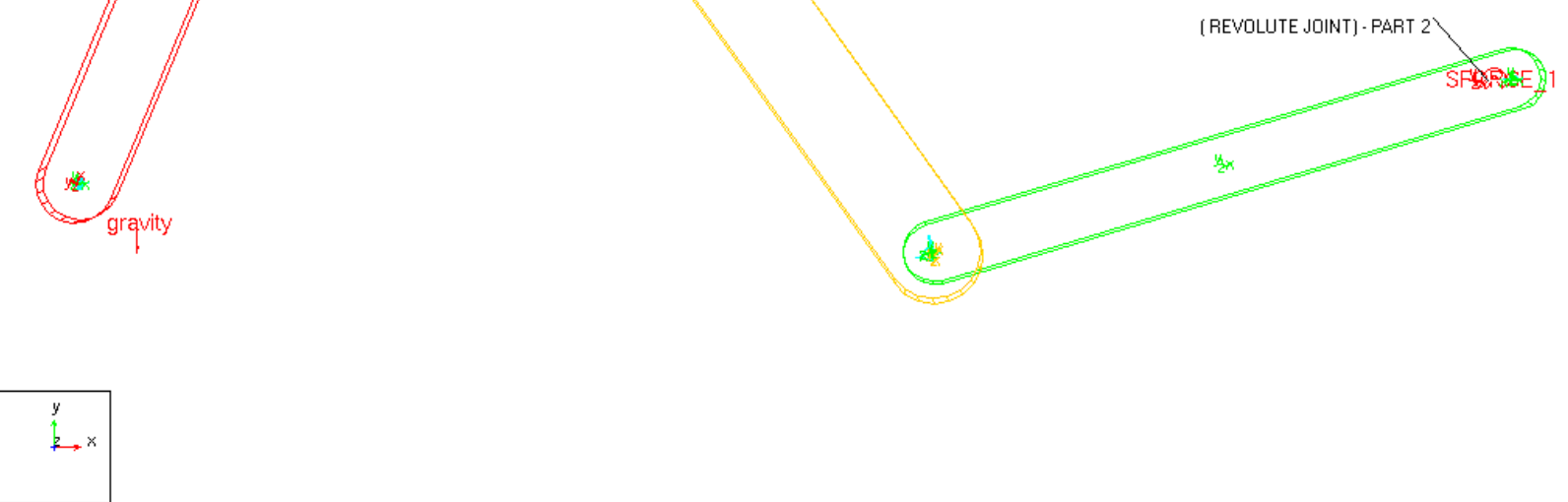

Figure 4-8. Referring to the figure the links are named as part 1, part 2 and part 4, part 1 and part 2 are connected to the ground by revolute joint and spherical joint which have one degree of freedom and that is the rotation of the link with respect to $\mathrm{z}$. The two parts are joined by part 4 also called as the coupler link and it is connected with revolute joint and with universal joint and the mechanism shown has one degree of freedoms. The degree of freedom is calculated using Gruebler's equation and the torque provided by the motor, which is connected at part 2, drives the mechanism. The motor provides a constant torque of 100 
kpound_force-foot and the output force is calculated at joint 4 . The mechanism is dynamically simulated.

\subsection{Design Process Steps for the Mechanism Model}

The various process involved in building the mechanism is shown in Figure 3-5 and explained in the subsequent sections.

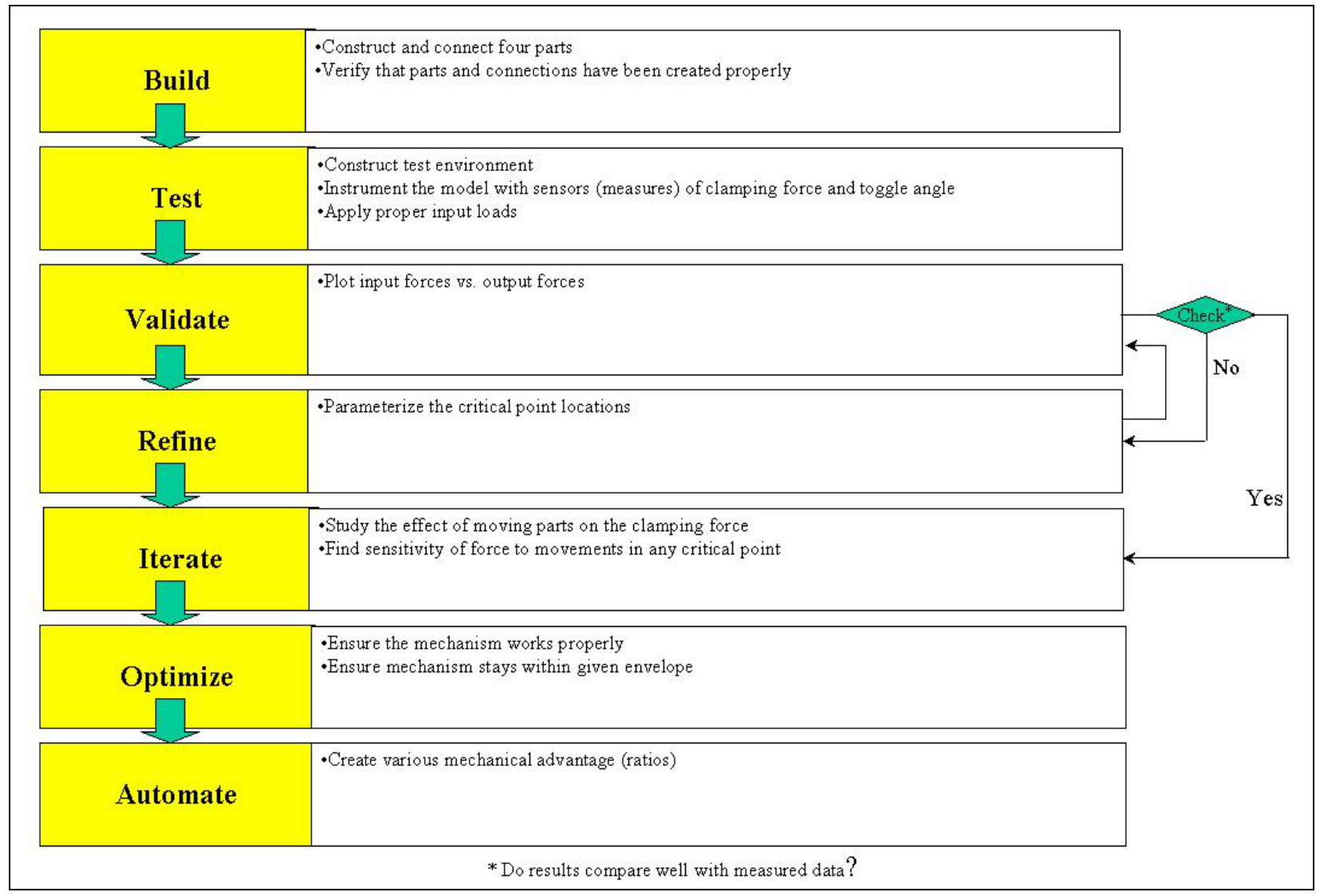

Figure 3-5: Flow chart showing the process involved in building a mechanism using ADAMS

\subsubsection{Creating the Parts of the Model.}

Start building the model by building the physical attributes of the movable elements (parts) in your mechanical system. Build the geometry using Rigid Bodies. Rigid Bodies are parts that have mass and inertia properties but cannot deform. ADAMS/View has the capability of modeling the movable parts as rigid bodies. We can change the material characteristics of the parts i.e; we can have our own values of mass and inertia properties and the material type like aluminum, cast iron, and steel etc. 
Adding Constraints and Motion to Mandate Part Movements.

Constraints define how parts are attached and how they are allowed to move relative to each other. ADAMS/View has various constraints including Idealized Joints: Idealized joints have a physical counterpart, such as revolute (hinge) or translational joint (sliding dovetail)

Joint Primitives: Joint Primitives place a restriction on relative motion, such as the restriction that one part always moves parallel to another part.

Motion Generators: Motion Generators drives the model.

Contacts: Contacts specify how bodies react when they come in contact with one another when the model is in motion.

The addition of idealized joints removes the degree of freedom from the mechanical system.

Revolute Joint - Allows the rotation of one part with respect to another part about a common axis. The orientation of the revolute joint defines the direction of the axis about which the joint's parts can rotate with respect to each other.

Spherical Joint - A spherical joint allows the rotation about a common point of one part with respect to another part. The location of the spherical joint determines the point about which the joint's parts can pivot freely with respect to each other.

Adding Forces that Induce or Resist Part Movements ADAMS/View provides a variety of forces that can apply to the mechanical systems. These forces will affect the reaction forces on constraints.

Flexible Connectors, such as springs-dampers and bushings, that provides pre-defined, compliant force relationships.

Special Forces, such as aerodynamic force, that provides pre-defined forces that are commonly encountered.

Applied Forces that allow you to write own equations to represent a wide variety of force relationship

\subsubsection{Test and Validation of the Model.}

After the model is created, to ensure it's been created correctly we can run tests to verify its system characteristics. The tests available to check the model are: 
Defining Results to be Output - when the simulation is run. ADAMS/View calculates all predefined information for the objects like velocities and displacements. We can define measures or request that ADAMS/View tracks during a simulation. We can measure almost any characteristics of the objects in the model, such as the force applied to a spring or the distance or angle between objects. We can view the results as the simulation is in progress. Performing a Simulation - To perform a simulation, ADAMS/View submits the model to MDI's analysis engine, ADAMS/Solver, which formulates and solves the equations of motion for the model. As ADAMS/Solver performs the analysis, ADAMS/View displays an animation of your model in motion. ADAMS/View provides many different categories of simulation, including dynamic simulation, which calculates the dynamic motion of your model, static equilibrium simulations and more.

Reviewing the Simulation Results - After simulation is complete, we can rerun the animation of the simulation and, pause it at any frame in the animation. We can also view the results of the simulation by plotting them in the ADAMS/View plotting window. The plotting window allows measurment of all the data specified by the users.

Validating Simulation Results - We can import the numeric results from physical tests of a mechanical system and compare them to the results of simulation in ADAMS/View to validate the accuracy of the model.

\subsubsection{Refine the Model and Iterate}

After the initial simulation is being run, which determines the basic motion of the model, we can refine the model by adding friction to the components and adding more complexity to the model as defining control systems using linear or general state equations. The parameters, which can be changed to analyze the alternative designs, are:

Design Points - Design points allow you to build automatic parameterization between objects, as well as position and orientation of the objects.

Design Variables - Design variables allows varying any aspect of a modeling object. We can then run a design study that changes a single variable over a range of values to investigate the sensitivity of the design to change in this variable. 


\subsubsection{Optimization of the Model.}

ADAMS/View provides tools that help you find the optimal design for the mechanical system

Design of experiments - Helps us to understand which design variables have the greatest impact on a design objective.

Optimization - Helps us to find an optimal design. We can define the objective and specify the parameters of the model that can change. 


\section{Chapter 4. Results}

Initially, five designs were considered. However, in two of these, a very high output force prevented the mechanism from being properly simulated in ADAMS. Finally, three designs were obtained. The results for these are presented in the subsequent sections

\subsection{Selection of Burmester Curves}

The moving pivots $(k)$ and ground pivots $(m)$ are the Burmester point pairs, which are obtained from the MATLAB ${ }^{\mathrm{TM}}$ program shown in Appendix A.1, the Burmester point pair values are written to the output file and these values are used in calculating the link lengths $\mathrm{W}$ and $\mathrm{Z}$ of the mechanism. The $m$ and $\mathrm{k}$ points are not independent but they are conjugate pairs and a set of $m$ and $k$ values form half of a mechanism. The Burmester curves, which are also obtained as the output of the program, are used in selecting the ground pivots $(m)$ which are shown in red color in the figure(s) to obtain a suitable mechanism. As different values of $k$ and $m$ gives the different mechanism, so there should be a way of selecting this points. The ground pivots are selected in such a way that, most of the ground pivot points lie slightly on or near the truck bed. The Burmester curves can be varied with the slight variation of the angles Alpha's in the program.

The following figures show the Burmester curves for the various angles of Alpha and also explanation of the better Burmester curves.

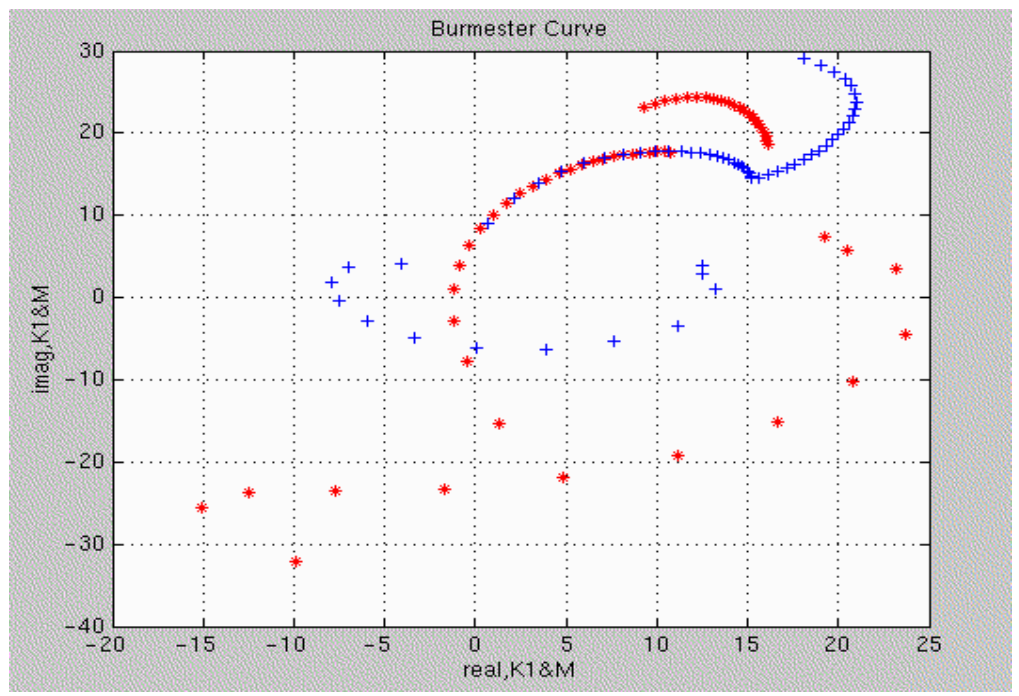

Figure 4-1: $m$ and $k$ (Burmester) curve for $\alpha_{2}=\pi / 4, \alpha_{3}=\pi / 3$ and $\alpha_{4}=\pi / 2$ 
For this particular problem, it's shown from the equations of synthesis of mechanism and from the program that the truck bed lays horizontally at zero of the x-axis. So the ground pivots (' $m$ ' shown in red color) selected should lie slightly above or on the zero of the x-axis. The reason of selecting these points is it can be easily transported in truck without building large pivots attaching the base of the truck bed or to the ground.

In the program the $\beta_{2}$, which is the only variable, is varied from $0^{\circ}$ to $360^{\circ}$ in sixty steps. And the angle $\alpha$ 's are varied, and output of the program is Burmester curves as shown in Figure 4-1 as you can see from the figure the maximum number of ground pivot points meet the required need. The values are good enough for building a mechanism, the various other angles considered are shown below and the values are shown in Appendix A-3

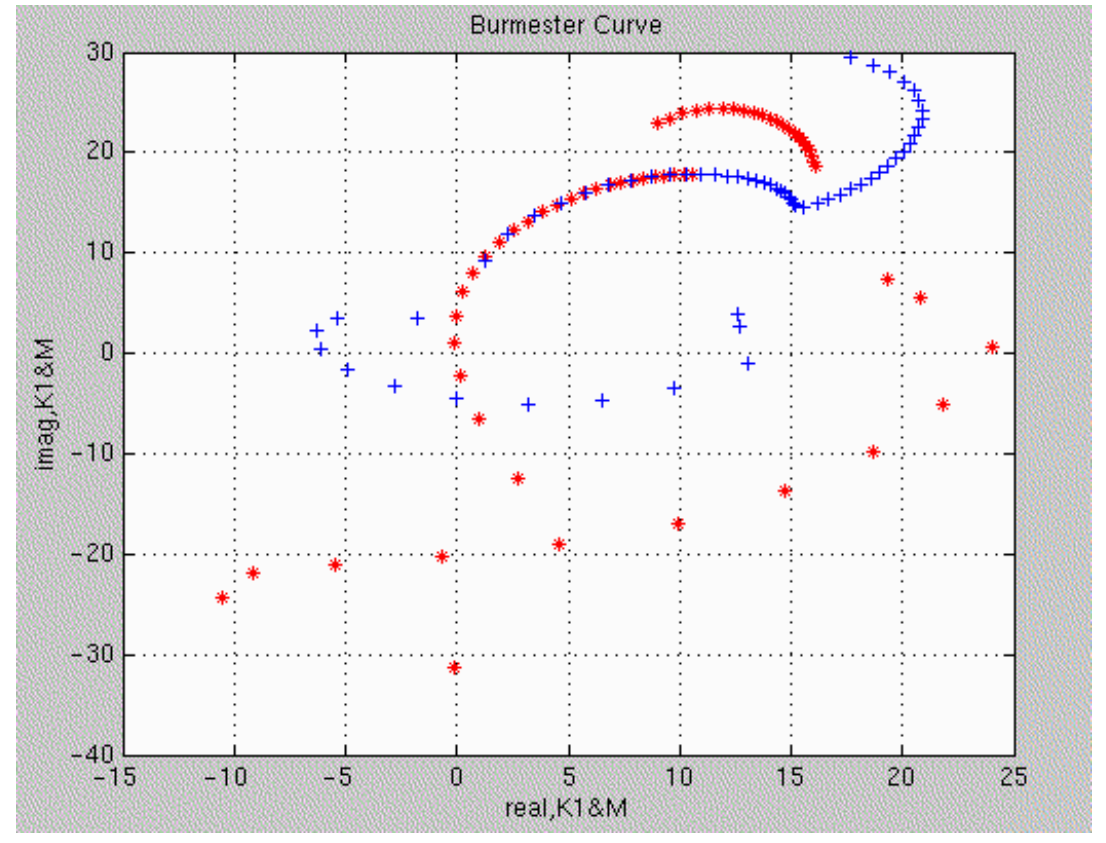

Figure 4-2: $m$ and $k$ (Burmester) curve for $\alpha_{2}=46 * \pi / 180, \alpha_{3}=\pi / 3$ and $\alpha_{4}=\pi / 2$

As seen from the figures that the ground pivots are above the truck bed, which gives us a good choice of selecting the values. One of the requirements of the mechanism is to pass thru the four accuracy points chosen. And gives a good mechanical advantage A sample problem is presented in next section, showing the calculation of the dyads of the mechanism. 


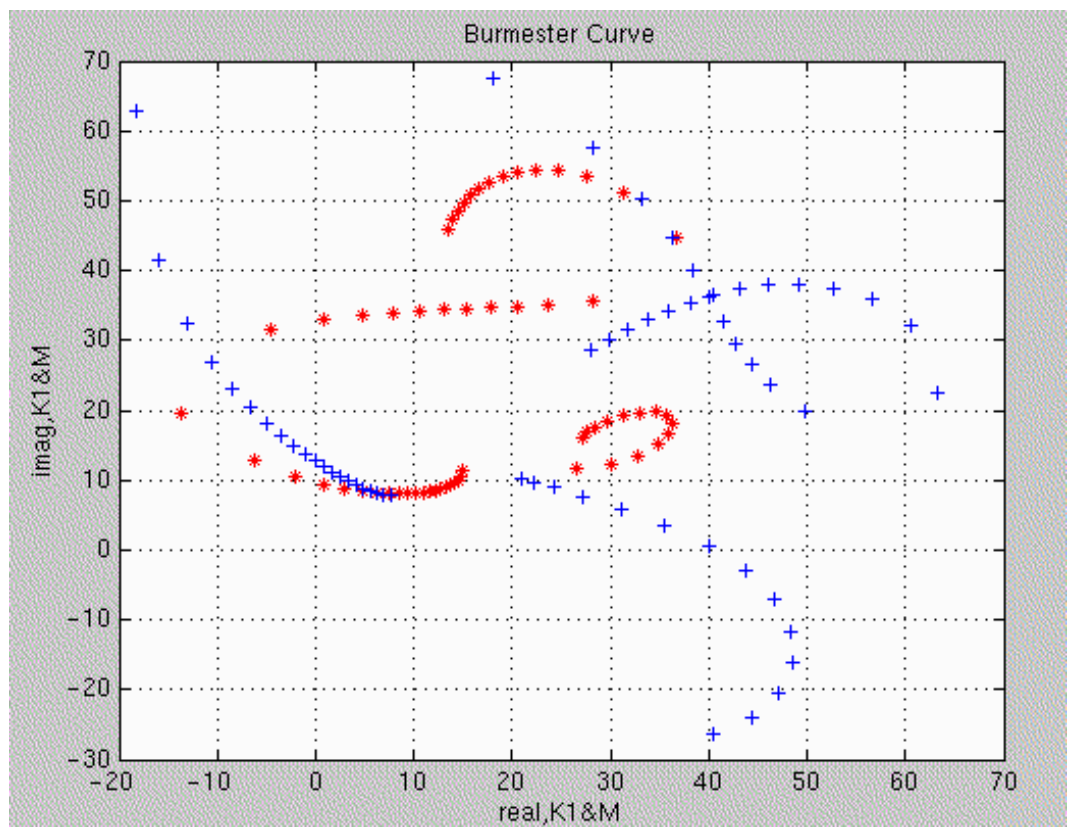

Figure 4-3: $m$ and $k$ (Burmester) curve for $\alpha_{2}=\pi / 6, \alpha_{3}=\pi / 3$ and $\alpha_{4}=\pi / 2$

The above figures show the ground pivots above or on the truck bed, it's known that the Burmester curves varies with the slight variation of the angles Alpha's $(\alpha)$ so there are some angles for which the ground pivots lie all over the plane and not valid for consideration.

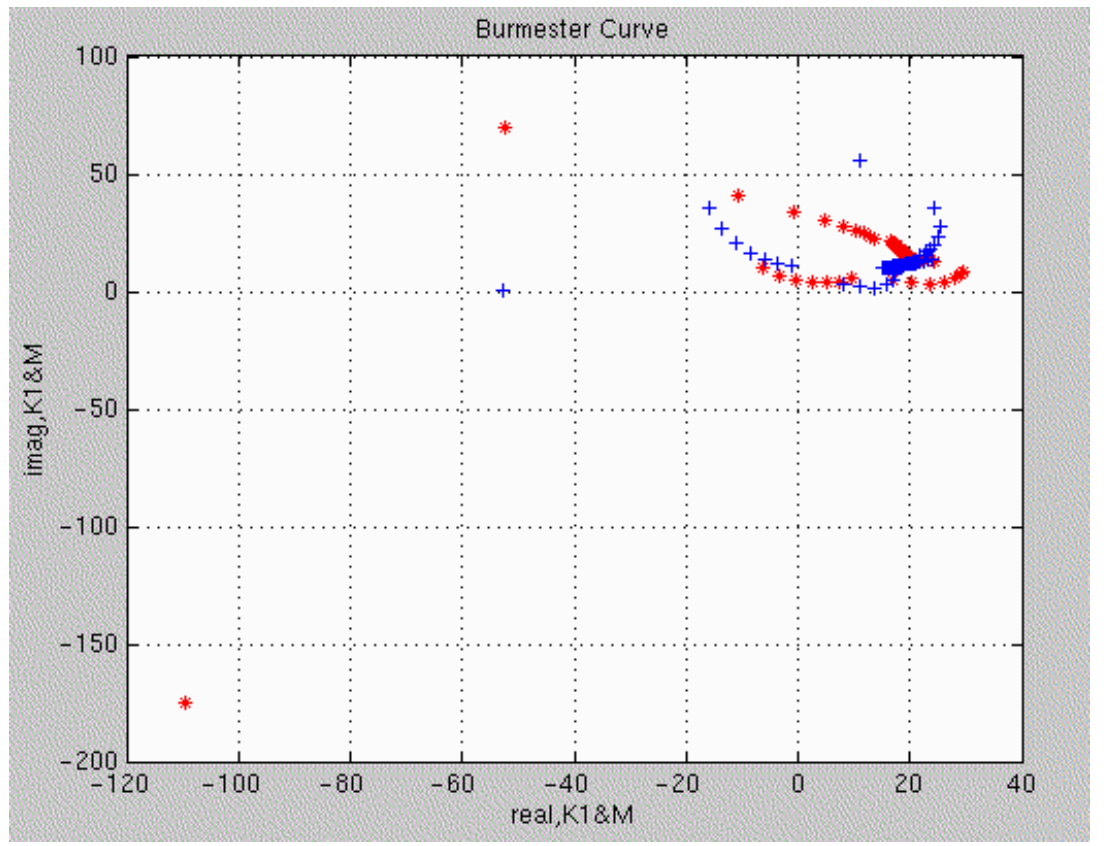

Figure 4-4: $m$ and $k$ (Burmester) curve for $\alpha_{2}=\pi / 20, \alpha_{3}=\pi / 4$ and $\alpha_{4}=\pi / 2$ 
For these particular angles you can see from the Figure 4-4 that the ground pivot points and moving pivot points are very close together, this one will still give a good mechanism but the link lengths will be small which gives a poor mechanical advantage.

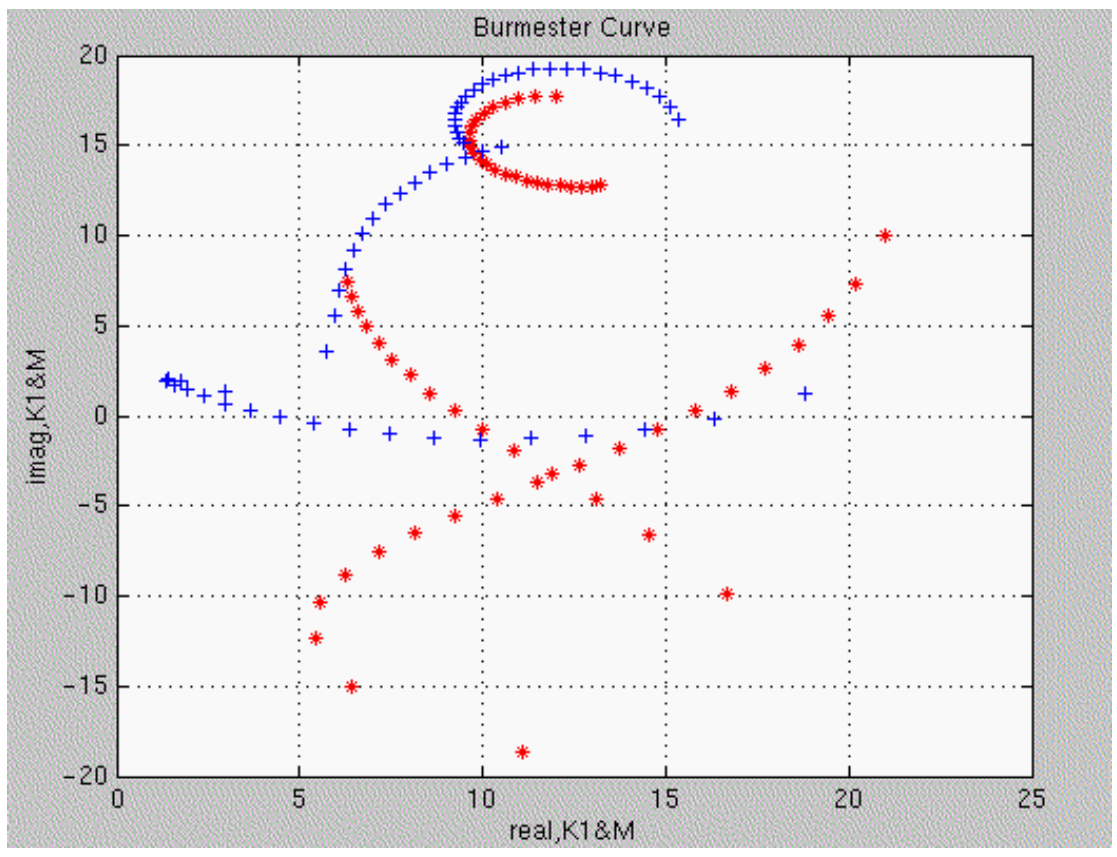

Figure 4-5: $m$ and $k$ (Burmester) curve for $\alpha_{2}=\pi / 20, \alpha_{3}=\pi / 4$ and $\alpha_{4}=\pi / 2$

Figure 4-5 and Figure 4-6 show the ground pivot points, distributed over the truck bed.

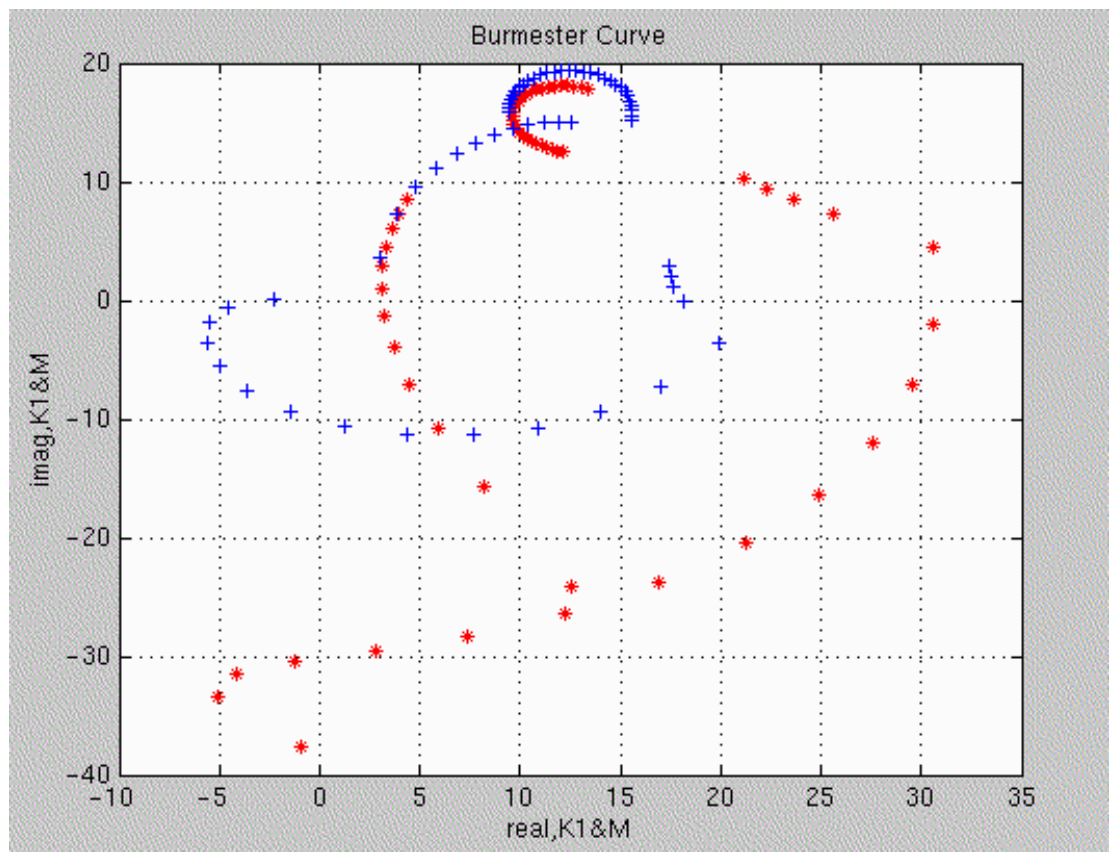

Figure 4-6: $m$ and $k$ (Burmester) curve for $\alpha_{2}=\pi / 20, \alpha_{3}=\pi / 4$ and $\alpha_{4}=\pi / 2$ 


\subsection{Sample Problem}

$R_{1}=-8+i$

A pair of $k_{l}$ and $m$ values gives the one-half of the mechanism; $\mathrm{W}$ and $\mathrm{Z}$ are calculated as follows for the first half. Referring to Figure 3-4 and Appendix A, the values of $k_{l}$ and $m$ (values are underlined in appendix) are obtained.

$$
\begin{aligned}
& m=-1.1975+0.9594 i \\
& k_{1}=4.7745+15.3620 i \\
& Z=R_{1}-k_{1} \\
& Z=-8+i-4.7745-15.3620 i=-12.7745-14.3620 i \\
& W=k_{1}-m \\
& W=4.7745+15.3620 i+1.1975-0.9594 i=5.972+14.4026 i
\end{aligned}
$$

Similarly for the second half of the mechanism, $\mathrm{W}_{1}$ and $\mathrm{Z}_{1}$ are calculated as:

$$
\begin{aligned}
& m=27.7554+3.0574 i \\
& k_{1}=16.0641-0.4461 i \\
& Z=R_{1}-k_{1} \\
& Z=-8+i-16.0641+0.4461 i=-24.0641+1.4461 i \\
& W=k_{1}-m \\
& W=16.0641-0.4461 i-27.7554-3.0574 i=-11.6913-3.5035 i
\end{aligned}
$$

With these four values, $\mathrm{W}, \mathrm{Z}, \mathrm{W}_{1}$, and $\mathrm{Z}_{1}$, we draw a four bar mechanism as shown in Figure $3-1$.

\subsection{Results for Design Number 1}

\subsubsection{Movement of Mechanism Through Four Accuracy Points}

The Figure 4-7 shows the movement of mechanism through four accuracy points designated by $\mathrm{P} 1, \mathrm{P} 2, \mathrm{P} 3$ and $\mathrm{P} 4$. The Guide valve is placed eight feet horizontally and one feet below the reference point as shown, the distances P2 - P1, P3 - P1 and P4 - P1 are indicated as delta2, delat 3 and delat 4 in the MATLAB ${ }^{\mathrm{TM}}$ shown in Appendix. As explained earlier that a pair of $m$ (ground pivots) and $k$ (moving pivots) values form a half of mechanism or a dyad of mechanism. So we need to have two sets of values to form a mechanism. 


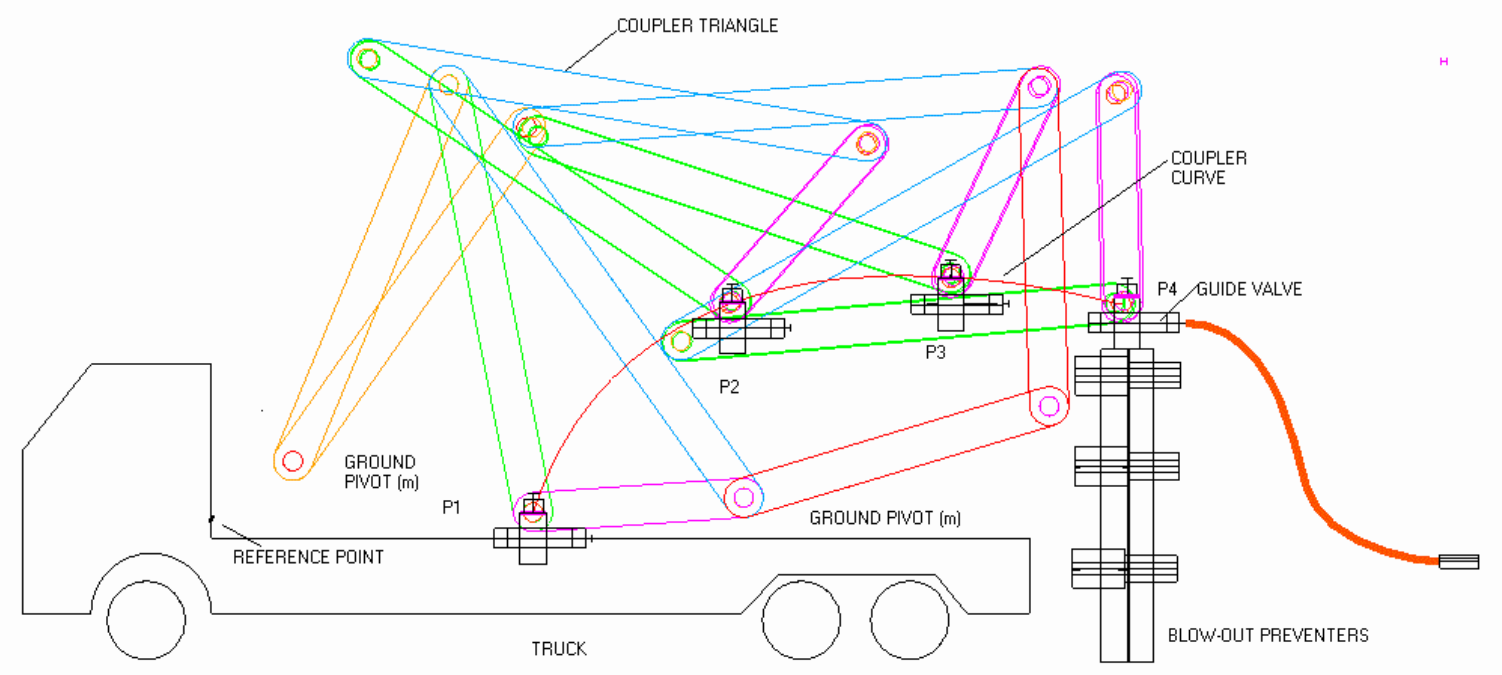

Figure 4-7: Movement of Mechanism with Guide Valve through four Accuracy Points for Design Number 1

\subsection{2. $\quad$ Specifications}

For the first design, the mechanism obtained had the following specifications:

$\mathrm{W}=12$ feet.

$\mathrm{W}_{1}=16$ feet.

Coupler length $=19$ feet.

Where $\mathrm{W}$ is the length of the input link, and $\mathrm{W}_{1}$ is the length of the output link. The configuration of this mechanism as obtained from ADAMS is given in Figure 4-8 


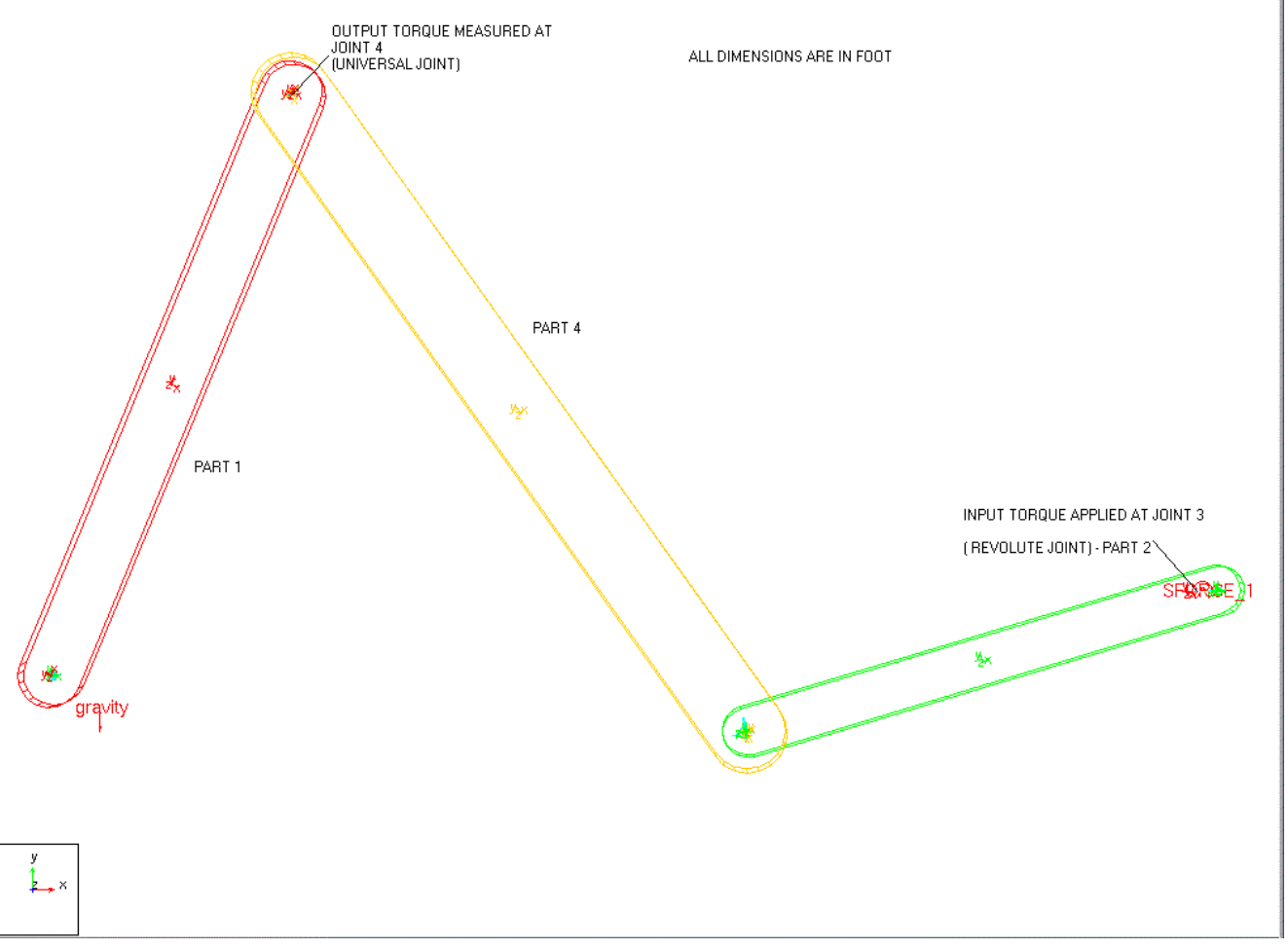

Figure 4-8: Configuration of Design Number 1

\subsubsection{Input Torque Variation}

Figure 4-9 shows the variation of the input torque with time for the first design, whose specifications are given in Section. 4.3.2. It is clear from the figure that the input torque is constant with time and has the value of 100.00 kpound_force-foot.

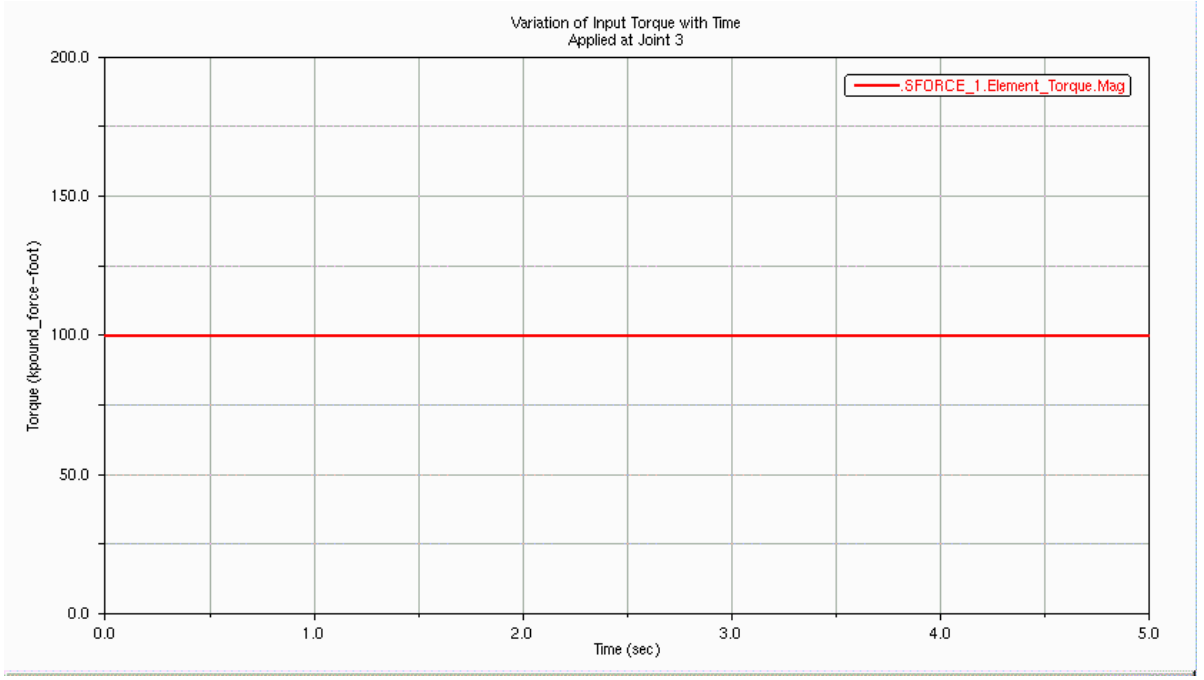

Figure 4-9: Variation of Input Torque 


\subsubsection{Variation of Output Force at Joint 4}

Figure 4-10 shows the output force at joint 4 . Unlike the input torque, the output torque varies non-linearly with time, with a maximum value of 53kpound_force and has the minimum value of $8 \mathrm{kpound} \_$force.

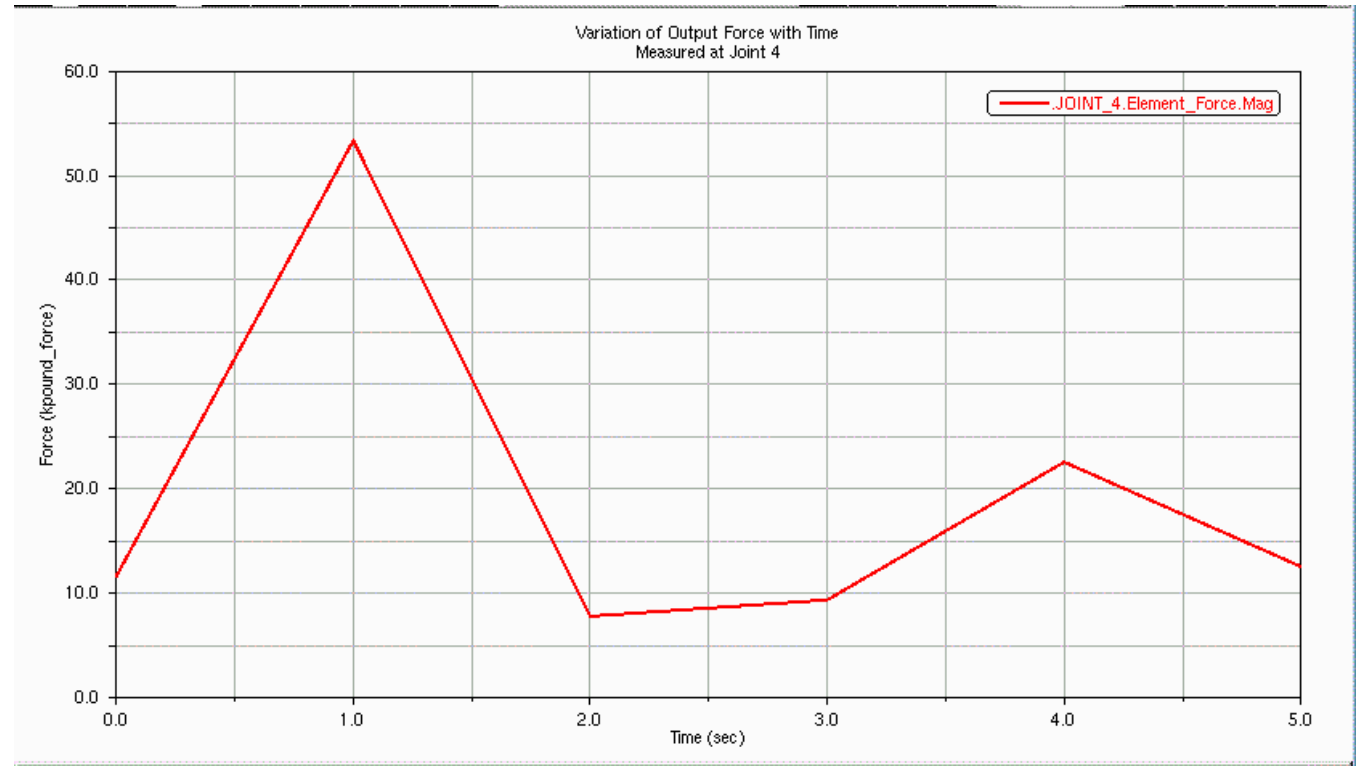

Figure 4-10: Variation of Output Force

\subsubsection{Variation of Coupler Link.}

The displacement of the coupler link, which shows the distance moved by the mechanism, is shown in Figure 4-11.

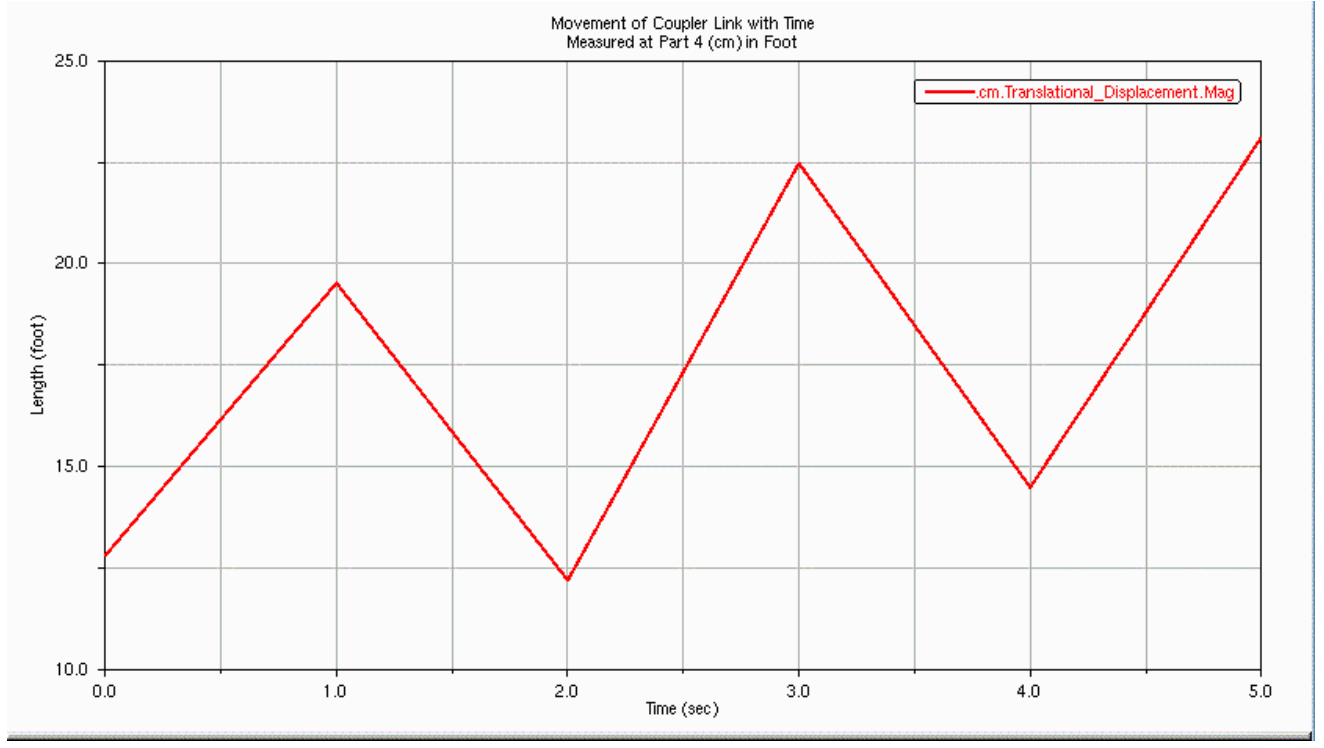

Figure 4-11: Distance moved by the Coupler Link when the Mechanism moves. 
From Figure 4-9 and Figure 4-10 the M.A. is calculated as follows:

Since the input torque is 100 kpound_force-foot and this torque is applied to link 2 which is 12.2 foot long so the force is calculated as $\mathrm{F}=\mathrm{T} / \mathrm{r}$, where $\mathrm{T}=100$ kpound_force-foot and $\mathrm{r}=12.2$ foot. And the output force is measured at joint 4 and has maximum of 53 kpound_force and minimum of 8 kpound_force.

\subsubsection{Mechanical Advantage}

The mechanical advantage is calculated as $F_{\text {out }} / F_{\text {in }}$ where the $F_{\text {out }}$ maximum is 53 kpound_force and the minimum is 8 kpound_force, $F_{\text {in }}$ is 8.2 kpound_force. Therefore the range of mechanical advantage obtained with this design is given in the table below:

Table 3: Table showing range of M.A. obtained for design 1

\begin{tabular}{|l|c|c|}
\hline $\begin{array}{c}\mathrm{F}_{\text {in }} \\
\text { (kpound_force) }\end{array}$ & $\begin{array}{c}\mathrm{F}_{\text {out }} \\
\text { (kpound_force) }\end{array}$ & Mech. Adv. (M.A) \\
\hline 8.2 & 53 (maximum) & 6.0 \\
\hline 8.2 & 8.0 (minimum) & 1.0 \\
\hline
\end{tabular}

\subsection{Results for Design Number 2}

\subsubsection{Movement of Mechanism Through Four Accuracy Points}

The Figure 4-12 shows the movement of mechanism through four accuracy points designated by P1, P2, P3 and P4. The Guide valve is placed eight feet horizontally and one feet below the reference point as shown, the distances P2 - P1, P3 - P1 and P4 - P1 are indicated as delta2, delat3 and delat4 in the MATLAB ${ }^{\mathrm{TM}}$ shown in Appendix. As explained earlier that a pair of $m$ (ground pivots) and $k$ (moving pivots) values form a half of mechanism or dyad of a mechanism. So we need to have two sets of values to form a mechanism. 


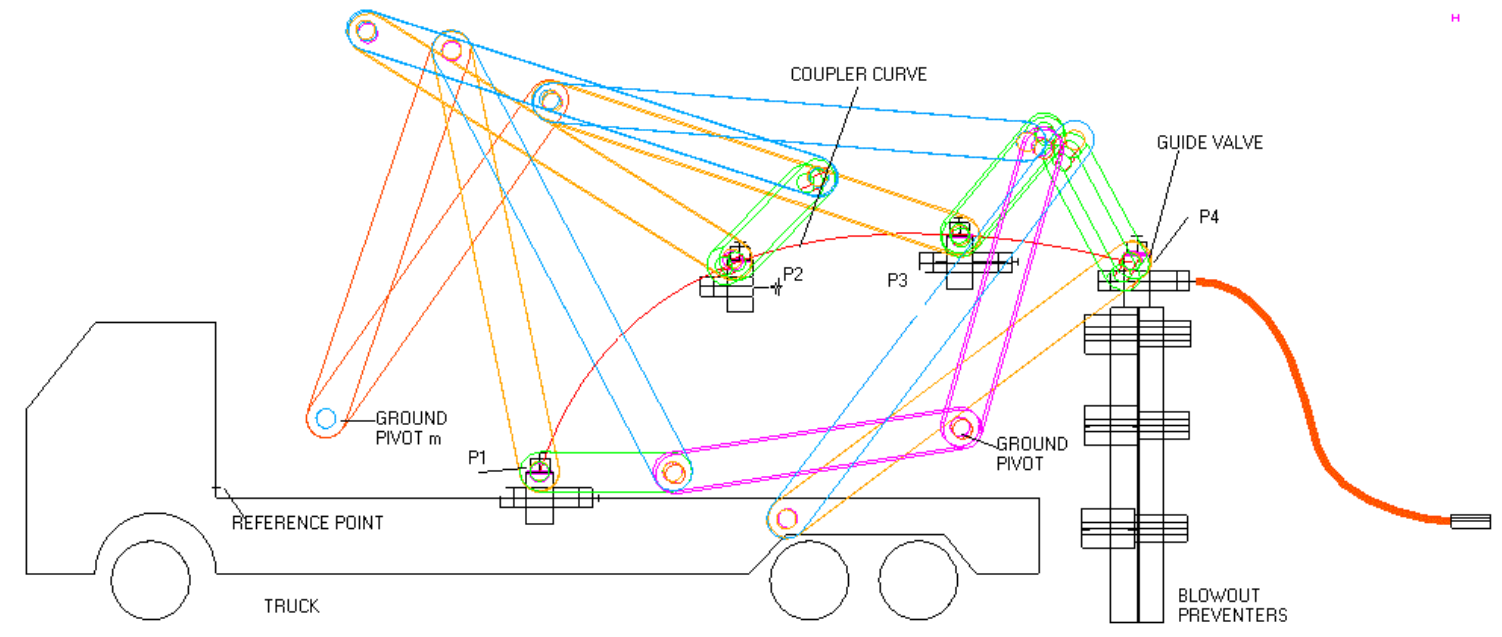

Figure 4-12: Movement of Mechanism through Four Accuracy Points for Design Number 2

\subsubsection{Specifications}

For the second design, the mechanism obtained had the following specifications

$\mathrm{W}=14.83$ foot

$\mathrm{W}_{1}=11.12$ foot

Coupler length $=16$ foot.

Where $\mathrm{W}$ is the length of the output link, and $\mathrm{W}_{1}$ is the length of the input link. The configuration of this mechanism as obtained from ADAMS is given in Figure 4-13 


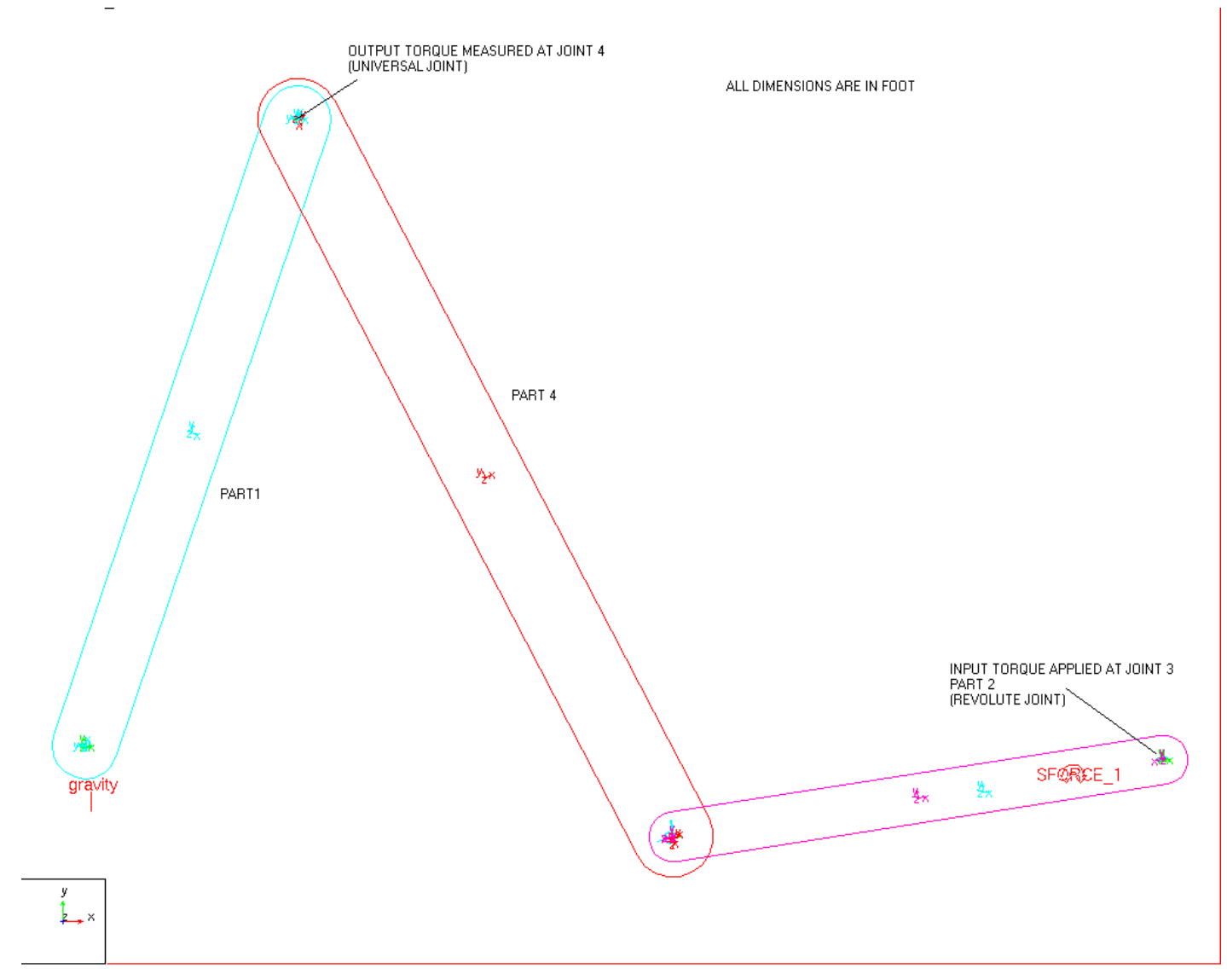

Figure 4-13: Configuration of Design Number 2

\subsubsection{Variation of Input Torque}

Figure 4-14 shows the variation of the input torque with time for the second design, whose specifications are given in Section. 4.4.2. It is clear from the figure that the input torque is constant over time and has the value of 100kpound_force-foot.

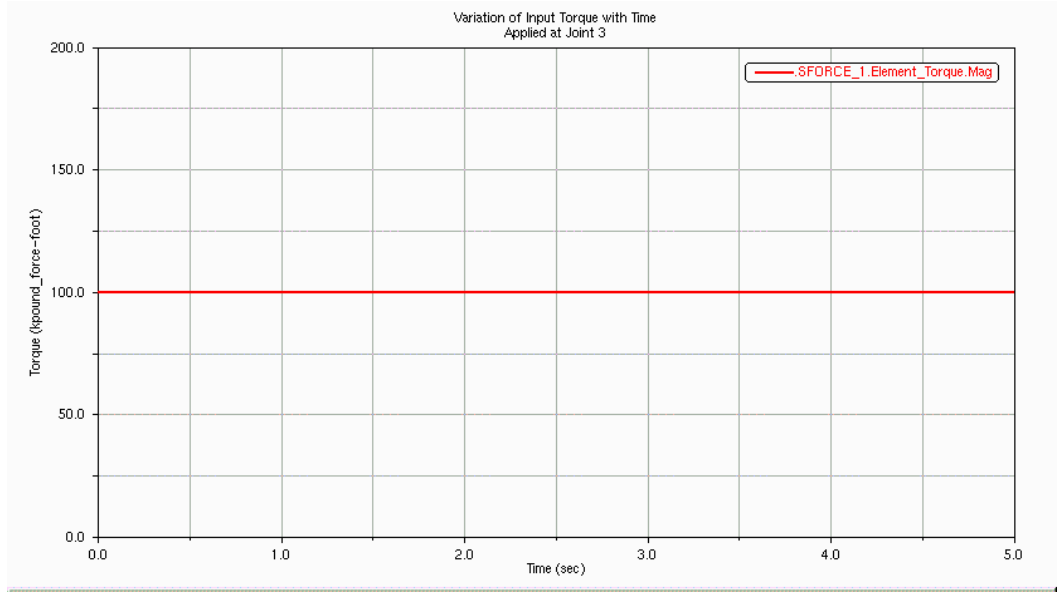

Figure 4-14: Variation of Input Torque 


\subsubsection{Variation of Output Force}

Figure 4-15 shows the output force at joint 4. Unlike the input force, the output force varies non-linearly with time, with a maximum value of 61 kpound_force and a minimum of 8 kpound_force.

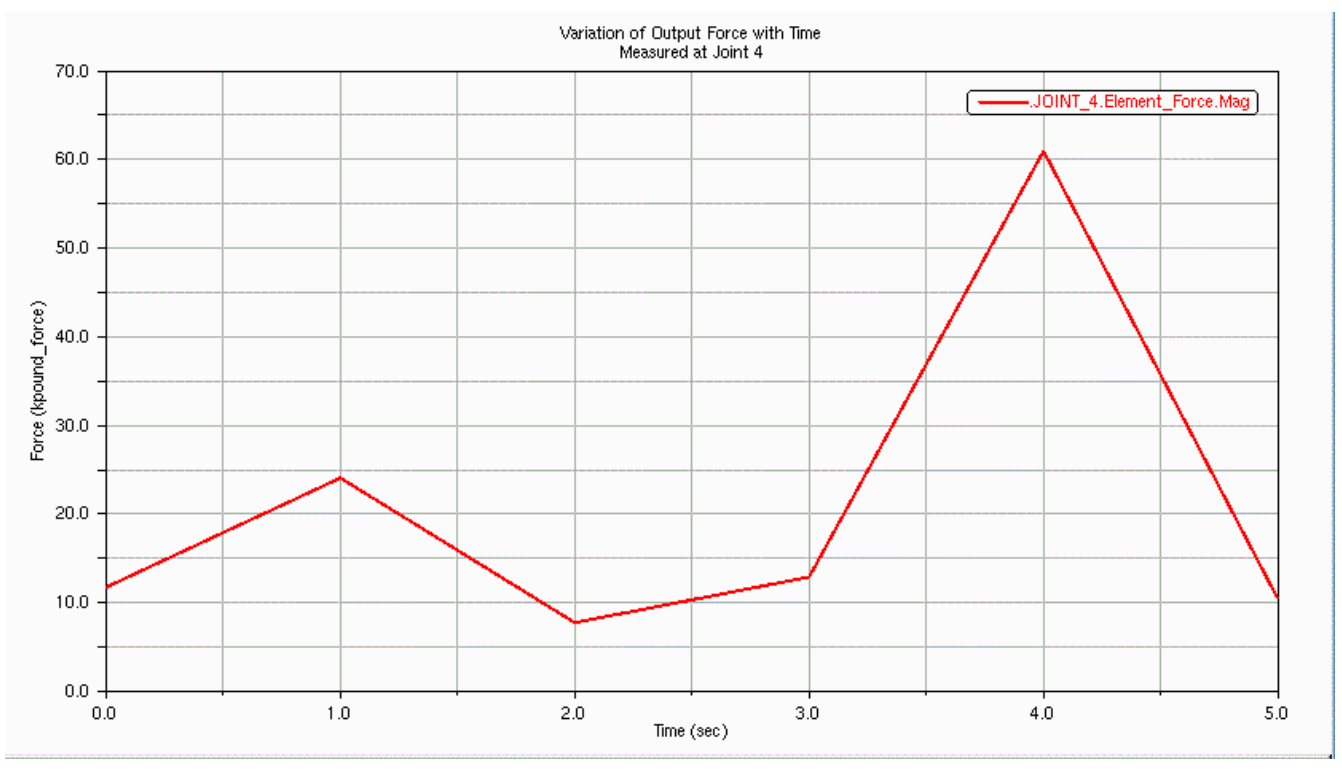

Figure 4-15: Variation of Output Force

\subsubsection{Variation of Coupler Curves}

The variation of the coupler curves, which show the path traced by the mechanism are shown in Figure 4-16

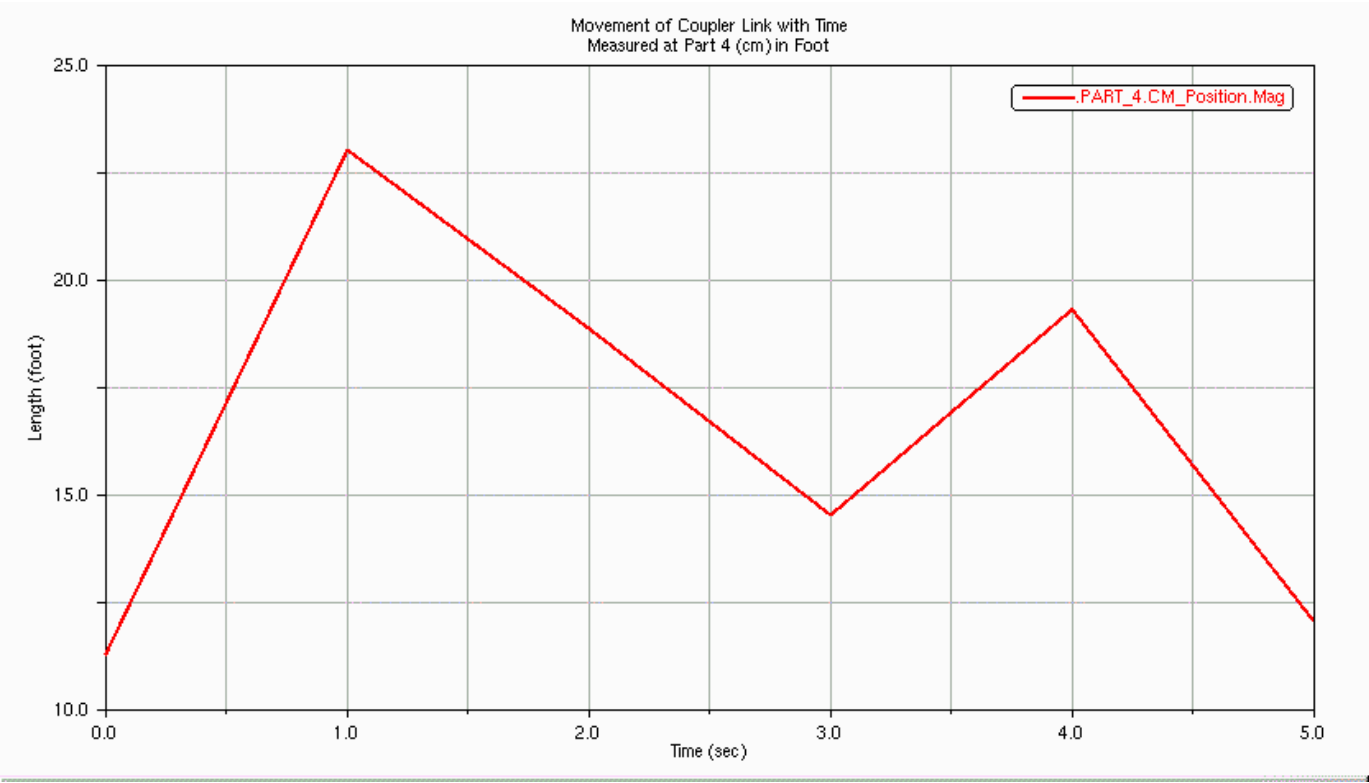

Figure 4-16: Distance moved by the coupler Link when the Mechanism moves. 


\subsubsection{Mechanical Advantage}

The mechanical advantage is calculated as $F_{\text {out }} / F_{\text {in }}$ where the maximum $F_{\text {out }}$ is 61

kpound_force and the minimum is 8 kpound_force. And the $F_{\text {in }}$ is calculated as $\mathrm{T} / \mathrm{r}$, where T is 100 kpound_force-foot and $\mathrm{r}$ is 11.12 foot Therefore the range of mechanical advantage obtained with this design is given in the table below:

Table 4: Table showing range of M.A. obtained for design 2

\begin{tabular}{|l|c|c|}
\hline $\begin{array}{c}\mathrm{F}_{\text {in }} \\
\text { (kpound_force) }\end{array}$ & $\begin{array}{c}\mathrm{F}_{\text {out }} \\
\text { (kpound_force) }\end{array}$ & Mech. Adv. (M.A) \\
\hline 9.0 & 61.0 (maximum) & 7.0 \\
\hline 9.0 & 8.0 & 0.92 \\
\hline
\end{tabular}

\subsection{Results for Design Number 3}

\subsubsection{Movement of Mechanism Through Four Accuracy Points}

The Figure 4-12 shows the movement of mechanism through four accuracy points designated by P1, P2, P3 and P4. The Guide valve is placed eight feet horizontally and one feet below the reference point as shown, the distances P2 - P1, P3 - P1 and P4 - P1 are indicated as delta2, delat3 and delat4 in the MATLAB ${ }^{\mathrm{TM}}$ shown in Appendix. As explained earlier that a pair of $m$ (ground pivots) and $k$ (moving pivots) values form a half of mechanism or dyad of a mechanism. So we need to have two sets of values to form a mechanism. 


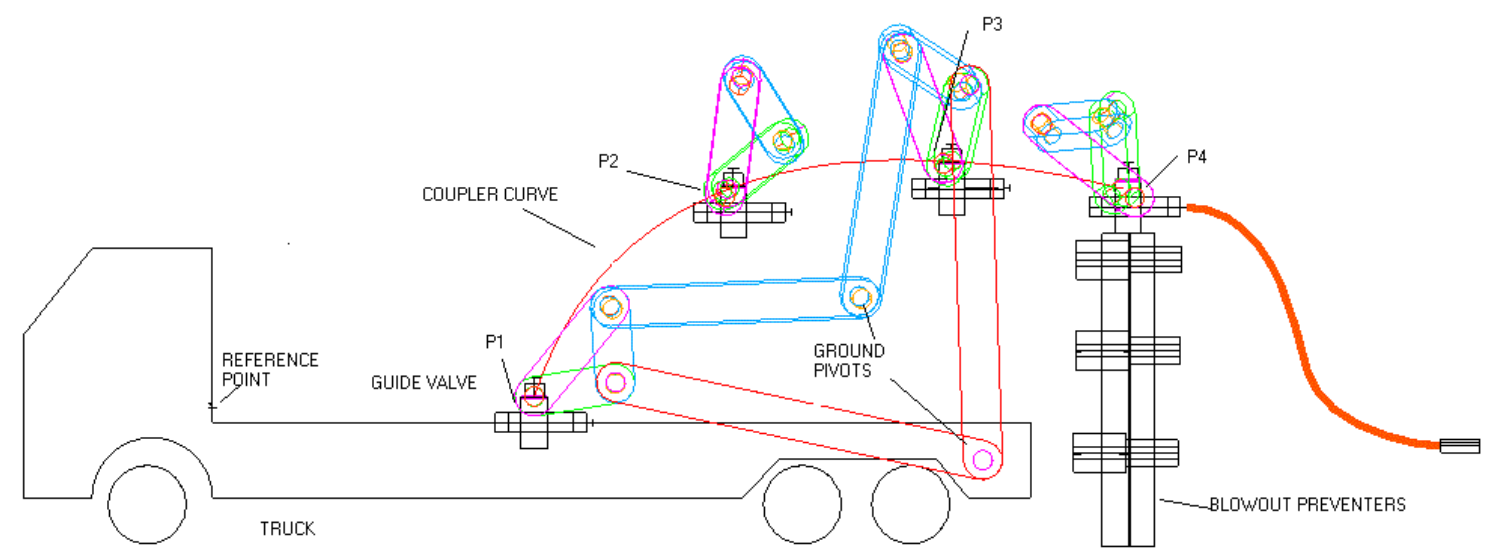

Figure 4-17: Movement of Mechanism Through Four Accuracy Points for Design Number 3

\subsubsection{Specifications}

For the second design, the mechanism obtained had the following specifications

$\mathrm{W}=11.3$ foot

$\mathrm{W}_{1}=14.4$ foot

Coupler length $=16$ foot.

Where $\mathrm{W}$ is the length of the output link, and $\mathrm{W}_{1}$ is the length of the input link. The configuration of this mechanism as obtained from ADAMS is given in Figure 4-18. 

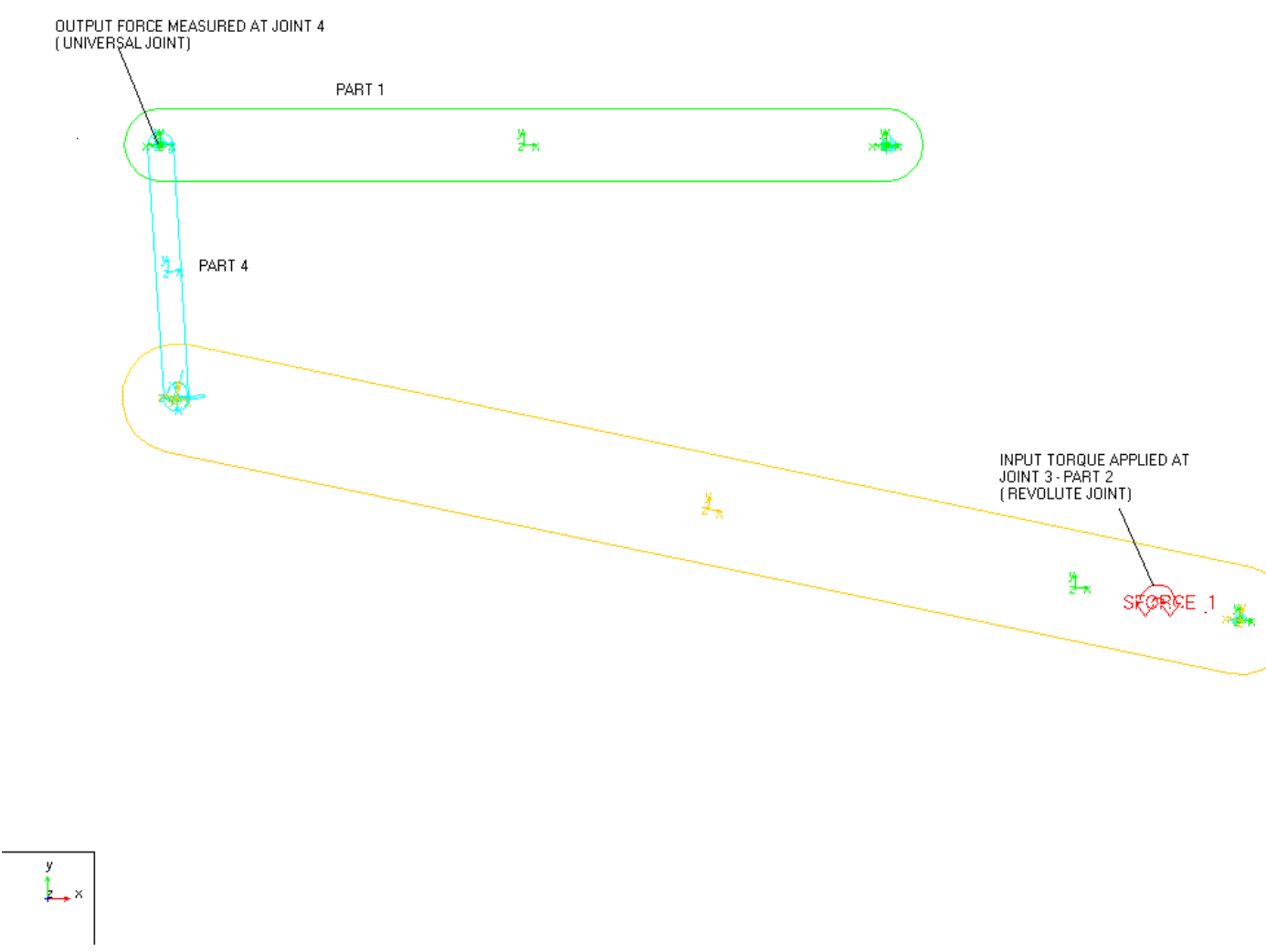

Figure 4-18: Configuration of Design Number 3

\subsubsection{Variation of Input Torque}

Figure 4-19 shows the variation of the input torque with time for the second design, whose specifications are given in Section. 4.5.2. It is clear from the figure that the input torque is constant over time and has the value of 100kpound_force-foot.

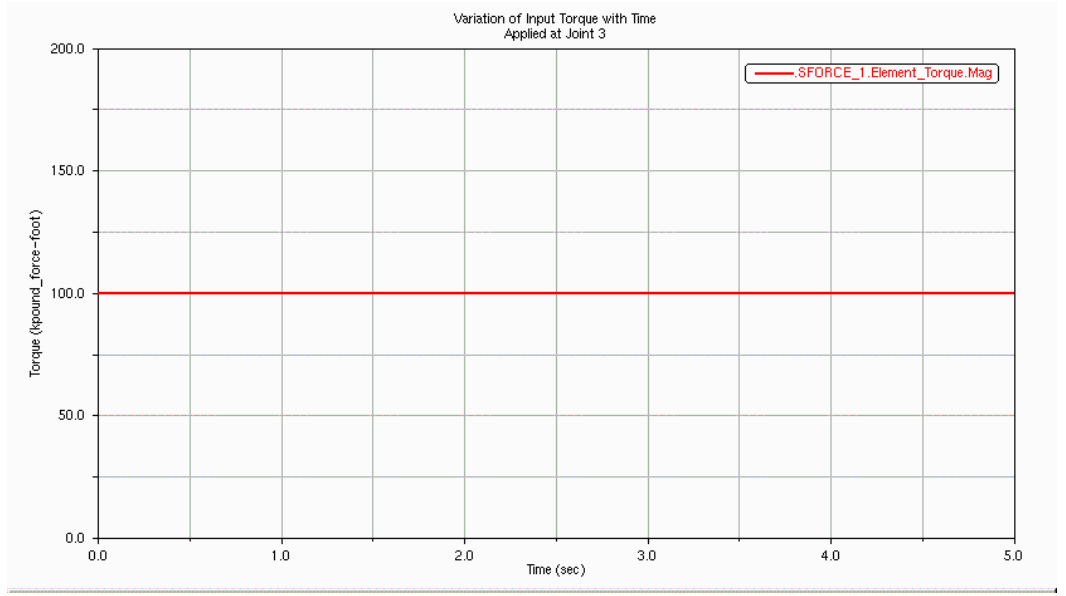

Figure 4-19: Variation of Input Torque 


\subsubsection{Variation of Output Force}

Figure 4-20 shows the output force at joint 4. Unlike the input force, the output force varies non-linearly with time, with a maximum value of 20 kpound_force and a minimum of 9 kpound_force.

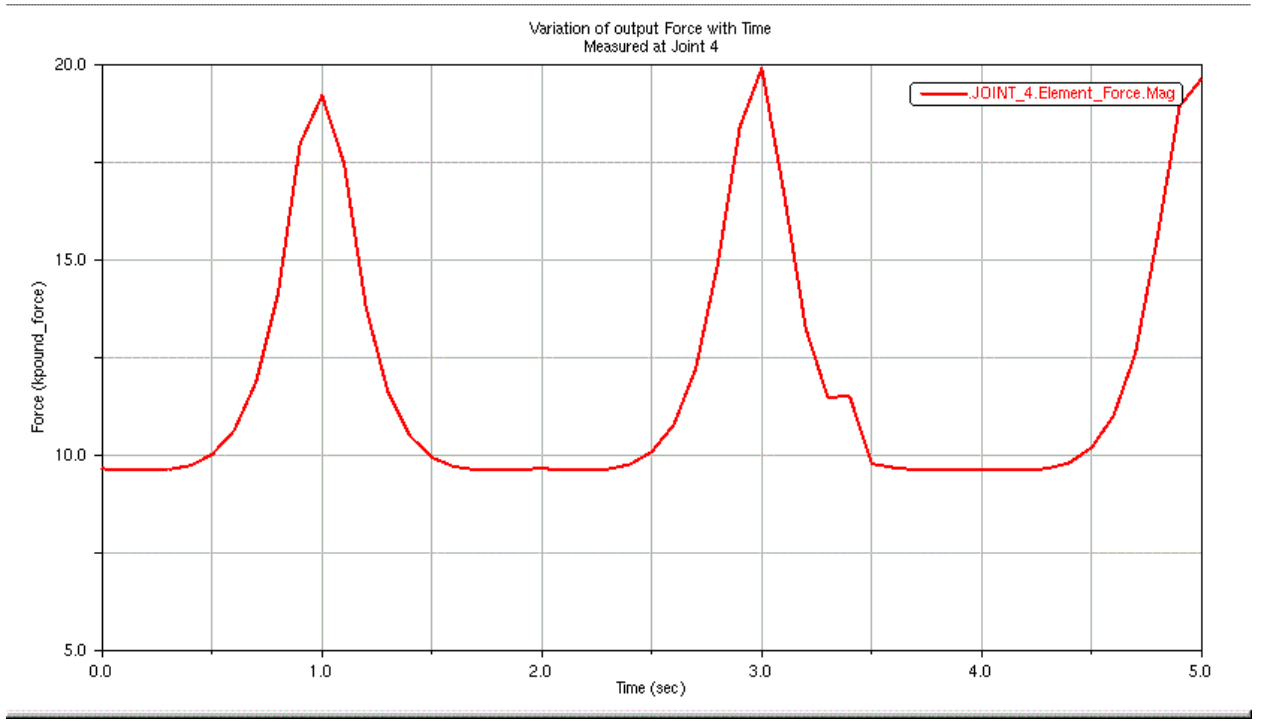

Figure 4-20: Variation of Output Force

\subsubsection{Variation of Coupler Curves}

The variation of the coupler curves, which show the path traced by the mechanism are shown in Figure4-21.

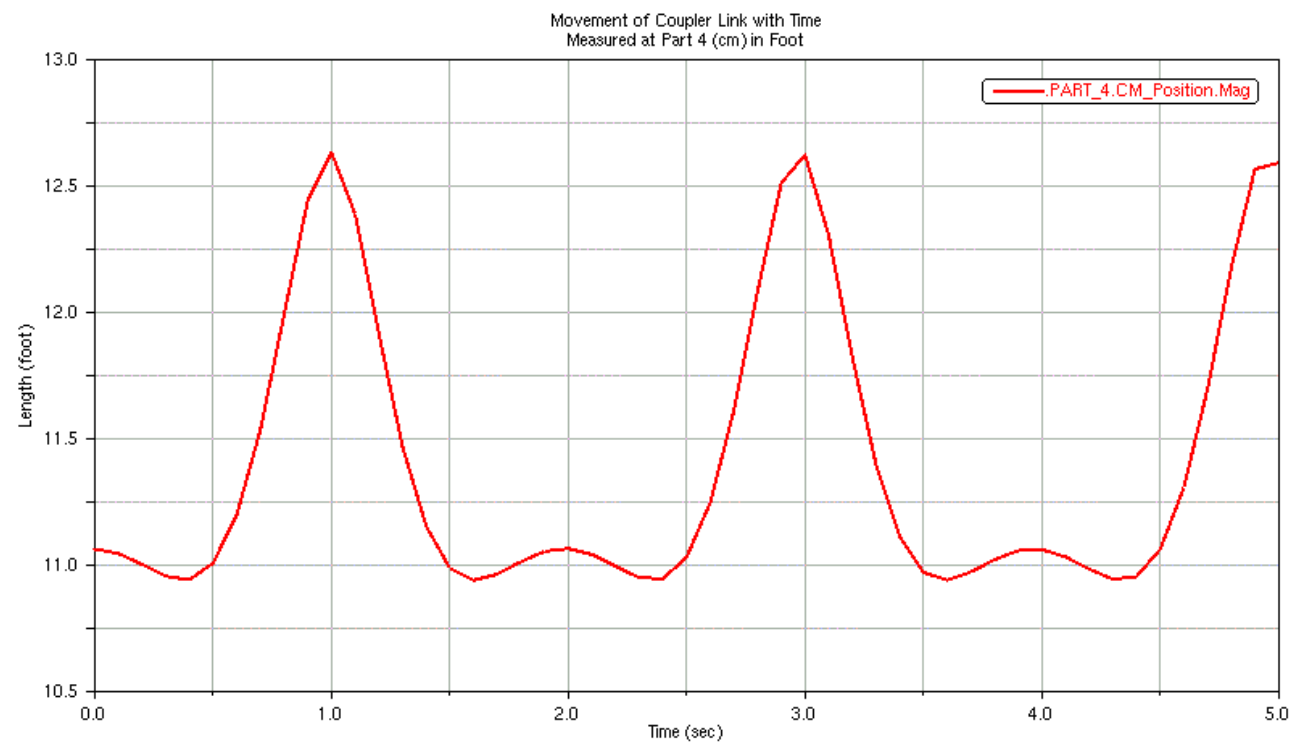

Figure4-21: Distance moved by the Coupler Link when the Mechanism moves. 


\subsubsection{Mechanical Advantage}

The mechanical advantage is calculated as $F_{\text {out }} / F_{\text {in }}$ where the maximum $F_{\text {out }}$ is 20

kpound_force and the minimum is 9 kpound_force. And the $F_{\text {in }}$ is calculated as $\mathrm{T} / \mathrm{r}$, where $\mathrm{T}$ is 100 kpound_force-foot and $\mathrm{r}$ is 14.4 foot Therefore the range of mechanical advantage obtained with this design is given in the table below:

Table 5: Table showing range of M.A. obtained for design 3

\begin{tabular}{|l|c|c|}
\hline $\begin{array}{c}\mathrm{F}_{\text {in }} \\
\text { (kpound_force) }\end{array}$ & $\begin{array}{c}\mathrm{F}_{\text {out }} \\
\text { (kpound_force) }\end{array}$ & Mech. Adv. (M.A) \\
\hline 6.9 & 20.0 (maximum) & 3.0 \\
\hline 6.9 & 9.0 & 1.3 \\
\hline
\end{tabular}




\section{Chapter 5. Conclusions}

A suitable four-bar mechanism for lifting the guide valve onto the truck bed was designed. It was found to have a good mechanical advantage when compared to similar four bar designs. Four-position synthesis and Burmester curves were utilized. The link lengths and angles required for the mechanical advantage ratio were obtained. Two design alternatives were investigated. From a consideration of the mechanical advantage alone, design number. 2 is better.

\subsection{Review and Contributions}

As outlined in the Introduction and Materials and Methods chapters, the goals of this thesis was to come up with suitable designs for lifting the guide valve onto the bed of a truck. This involved calculating the link lengths and angles necessary. Another important consideration was that the mechanical advantage was to be as great as possible.

Four position synthesis and Burmester curves were utilized to achieve this goal. The method was outlined in the Methods and Materials chapter. The general-purpose matrix and vector manipulation program, MATLAB was used in creating the Burmester curves for the simulation. These values were then input to the mechanical dynamics simulation software, ADAMS to get the link lengths. The mechanical advantage ratio was used to pick the best design.

The mechanical advantage ratio of the mechanisms was found to be in the range of $0.9-7.0$. Three different design alternatives were considered. The mechanical advantage of design 2 was 7.0, which was greater than that of design 1, which is 6.0. Therefore, design 2 is the better design from the mechanical viewpoint.

\subsection{Suggestions for Future Work}

The results from this study provide a method for designing a four-bar mechanism for a task encountered in the well service industry. Suggestions for future work include:

A study of other factors that may influence the design. For example, it will be worth while to consider the stresses in the links and evaluate them to check for failure due to yielding and fracture. 
An evaluation of the cost and economics of using this mechanism over current methods used in the oil service industry.

Presently the links are considered rigid in future, work can be done for the links to be hydraulic where in the links can be retractable by the fluid pressure and can perform the same way as a four-bar mechanism.

The links can be designed using gears, which are considered to be highly efficient.

\subsection{Selection of Mechanism}

The $k$ and $m$ values obtained from the Burmester curves are used in designing a mechanism as for different values of $k$ and $m$ we get different mechanisms there should be a method of selecting the mechanism. The method followed in selecting the values are:

The $m$ values, which are the ground pivots, are the points, which should lie on the truck bed so the values should be positive. Since the synthesis was done by taking the point on the truck bed. The values, which are eliminated, are shown in Appendix A.

When the mechanism is built in ADAMS and dynamically simulated it should pass the four positions which are considered for the synthesis, and should have better mechanical advantage.

When the mechanism is simulated in ADAMS if the output link is smaller than the input link then the forces required to start the mechanism are higher than the input forces and the mechanism fails at that point most of the mechanism fail in the beginning of the simulation itself.

\subsection{Effect of Ground Variation}

In the Figure 4-7 it is assumed that the guide valve is placed at eight feet horizontally and one feet below the reference origin which is my first accuracy position P1. If the guide valve is moved or placed different than the P1 shown. The mechanisms shown in Figure 4-8 and Figure 4-13 can still be used if the links (designated as Part1 Part2) are actuated hydraulically so the links can adjusted on the truck to match the variations of local ground conditions. 


\section{A.1 MATLAB ${ }^{\circledR}$ Program for Burmester Curves}

clear all;

clc;

Delta2 $=7.5+8 \mathrm{i}$

Delta3 $=16+9 \mathrm{i}$

Delta $4=22.5+8 \mathrm{i}$

Alpha $2=45 *$ pi $/ 180$;

Alpha3 $=60 *$ pi $/ 180$

Alpha4 $=90 * \mathrm{pi} / 180$

$\mathrm{R} 1=8-\mathrm{i}$;

fid = fopen('K1.txt','w');

for $\mathrm{n}=1: 61$

beta $2=(\mathrm{n}-1) * \mathrm{pi} / 30$;

D2 = det ([exp(i*Alpha3)-1 Delta3;exp(i*Alpha4)-1 Delta4]);

D3 = -det ([exp(i*Alpha2)-1 Delta2;exp(i*Alpha4)-1 Delta4]);

D4 = det ([exp(i*Alpha2)-1 Delta2;exp(i*Alpha3)-1 Delta3]);

D1 = -D2-D3-D4;

$\mathrm{D}=\mathrm{D} 1+\mathrm{D} 2 * \exp (\mathrm{i} *$ beta2 $)$;

$\mathrm{d} 4=\mathrm{abs}(\mathrm{D} 4)$;

$\mathrm{d} 3=\operatorname{abs}(\mathrm{D} 3)$;

$\mathrm{d}=\operatorname{abs}(\mathrm{D})$;

psi3 = angle(D3);

psi4 $=$ angle(D4);

psi $=$ angle $(\mathrm{D})$;

theta $3=\operatorname{acos}\left(\left(d 4^{\wedge} 2-d 3^{\wedge} 2-d^{\wedge} 2\right) /(2 * d 3 * d)\right)$

if $(\cos ($ theta 3$)==0)$ theta3 $=\mathrm{pi} / 2.0$;

elseif (theta3 $<0$ ) 


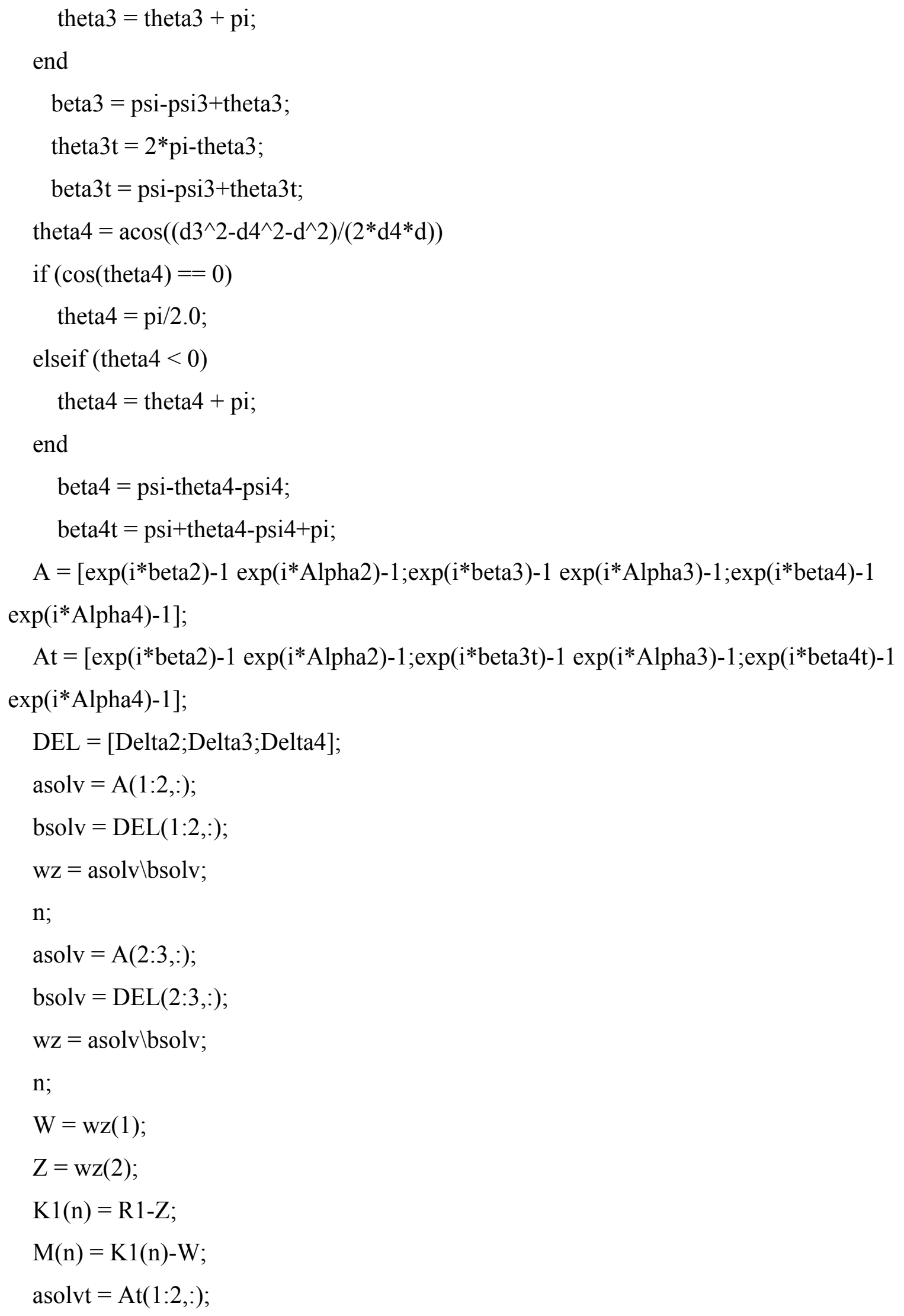




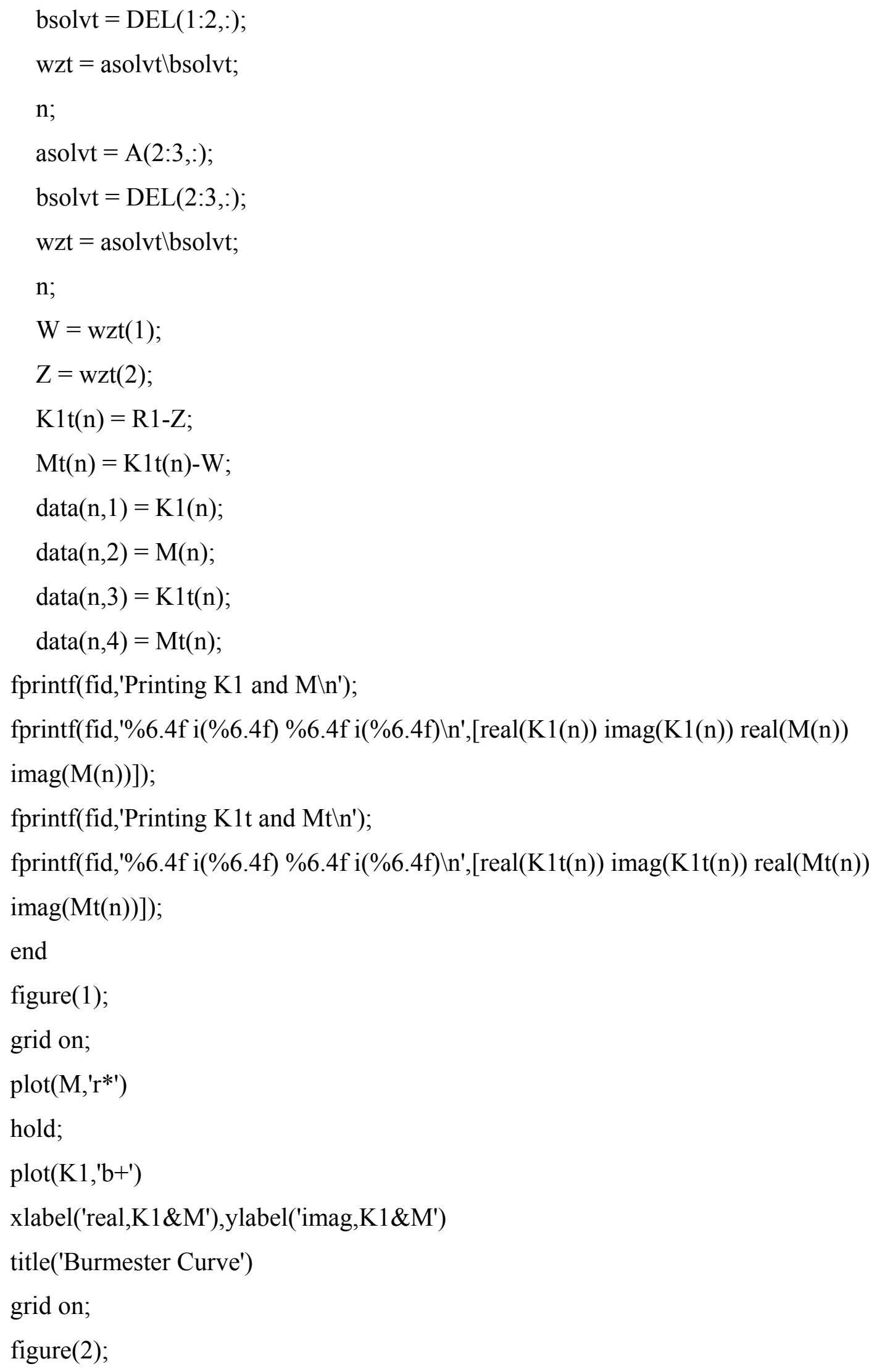


grid on;

$\operatorname{plot}\left(\mathrm{Mt}, \mathrm{r}^{* \prime}\right)$

hold;

$\operatorname{plot}(\mathrm{K} 1 \mathrm{t}, \mathrm{b}+\mathrm{\prime})$

xlabel('real,K1t\&Mt'),ylabel('imag,K1t\&Mt')

title('Burmester Curve')

grid on;

fclose(fid);

\section{A.2 MATLAB Plot for $\boldsymbol{k}$ and $\boldsymbol{m}$ curves}

The $m$ and $k$ curves for the angles $\alpha_{2}=\pi / 4, \alpha_{3}=\pi / 3$ and $\alpha_{4}=\pi / 2$ is shown in Figure. A.1.

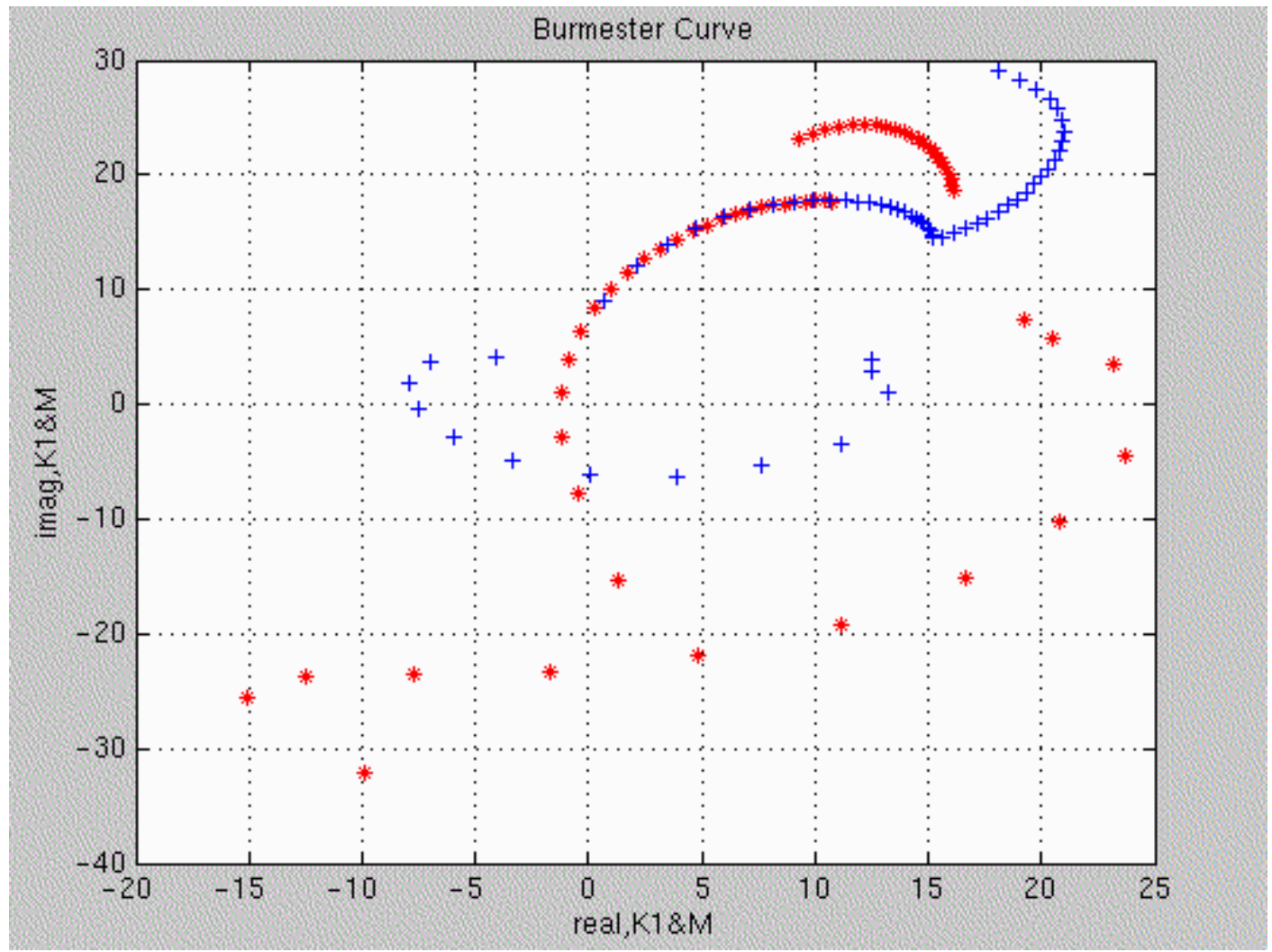

Figure A.1: $m$ and $k$ (Burmester) curve for $\alpha_{2}=\pi / 4, \alpha_{3}=\pi / 3$ and $\alpha_{4}=\pi / 2$

The $m$ and $k$ curves for the angles $\alpha_{2}=46^{*} \pi / 180, \alpha_{3}=\pi / 3$ and $\alpha_{4}=\pi / 2$ is shown in Figure A.2. 


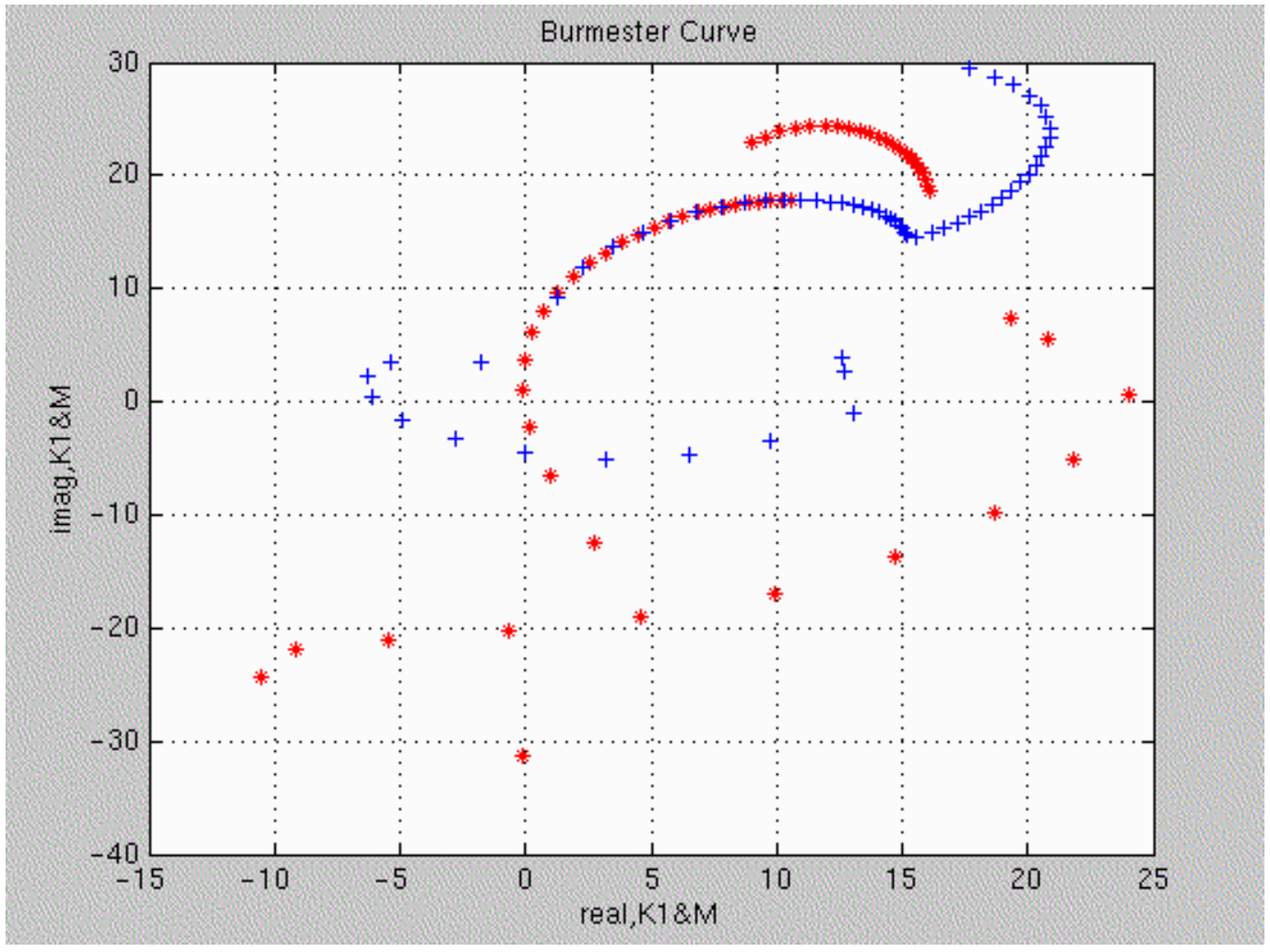

Figure A.2 The $m$ and $k$ curves for the angles $\alpha_{2}=46^{*} \pi / 180, \alpha_{3}=\pi / 3$ and $\alpha_{4}=\pi / 2$ is shown below. The $m$ and $k$ curves for the angles $\alpha_{2}=\pi / 3, \alpha_{3}=\pi / 6$ and $\alpha_{4}=\pi / 2$ is shown in Figure A.3.

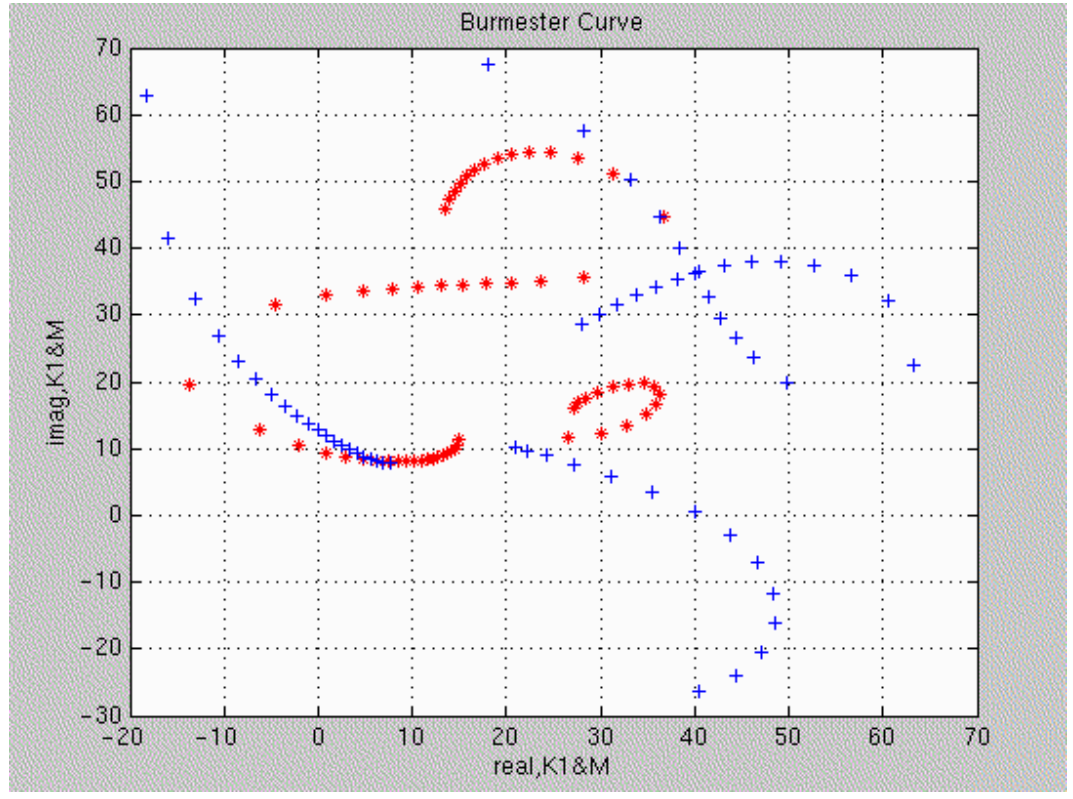

Figure A.3: The $m$ and $k$ curves for the angles $\alpha_{2}=\pi / 3, \alpha_{3}=\pi / 6$ and $\alpha_{4}=\pi / 2$ 


\section{A.3. Numerical values of $k$ and $m$ obtained using the MATLAB program}

The values used in plotting the figures A.1, A.2 and A.3 were obtained using the data presented in this section.

\section{A.3.1: Data listing for Figure A.1}

Printing K1 and M

$2.0931 \mathrm{i}(12.0533)-0.4778 \mathrm{i}(-7.7823)$

Printing $\mathrm{K} 1$ and $\mathrm{M}$

$3.4543 \mathrm{i}(14.0130)-1.1444 \mathrm{i}(-2.8167)$

Printing $\mathrm{K} 1$ and $\mathrm{M}$

$4.7745 \mathrm{i}(15.3620)-1.1975 \mathrm{i}(0.9594)$

Printing $\mathrm{K} 1$ and $\mathrm{M}$

$6.0141 \mathrm{i}(16.2961)-0.8897 \mathrm{i}(3.9646)$

Printing $\mathrm{K} 1$ and $\mathrm{M}$

$7.1532 \mathrm{i}(16.9324)-0.3679 \mathrm{i}(6.4051)$

Printing $\mathrm{K} 1$ and $\mathrm{M}$

$8.1859 \mathrm{i}(17.3498) 0.2766 \mathrm{i}(8.4097)$

Printing K1 and M

$9.1141 \mathrm{i}(17.6043) 0.9856 \mathrm{i}(10.0690)$

Printing K1 and M

$9.9440 \mathrm{i}(17.7364) 1.7222 \mathrm{i}(11.4503)$

Printing $\mathrm{K} 1$ and $\mathrm{M}$

$10.6835 \mathrm{i}(17.7756) 2.4630 \mathrm{i}(12.6051)$

Printing $\mathrm{K} 1$ and $\mathrm{M}$

$11.3409 \mathrm{i}(17.7437) 3.1934 \mathrm{i}(13.5735)$

Printing $\mathrm{K} 1$ and $\mathrm{M}$

$11.9244 \mathrm{i}(17.6569) 3.9044 \mathrm{i}(14.3869)$

Printing $\mathrm{K} 1$ and $\mathrm{M}$

$12.4412 \mathrm{i}(17.5272) 4.5911 \mathrm{i}(15.0705)$

Printing $\mathrm{K} 1$ and $\mathrm{M}$ 
$12.8982 \mathrm{i}(17.3638) 5.2507 \mathrm{i}(15.6441)$

Printing K1 and $\mathrm{M}$

$13.3012 \mathrm{i}(17.1734) 5.8821 \mathrm{i}(16.1238)$

Printing $\mathrm{K} 1$ and $\mathrm{M}$

13.6552 i(16.9613) $6.4851 \mathrm{i}(16.5226)$

Printing $\mathrm{K} 1$ and $\mathrm{M}$

13.9649 i(16.7313) 7.0602 i(16.8510)

Printing $\mathrm{K} 1$ and $\mathrm{M}$

$14.2340 \mathrm{i}(16.4865) 7.6083 \mathrm{i}(17.1176)$

Printing $\mathrm{K} 1$ and $\mathrm{M}$

14.4659 i(16.2293) 8.1304 i(17.3293)

Printing $\mathrm{K} 1$ and $\mathrm{M}$

14.6636 i(15.9613) 8.6278 i(17.4920)

Printing $\mathrm{K} 1$ and $\mathrm{M}$

14.8296 i(15.6840) 9.1017 i(17.6104)

Printing $\mathrm{K} 1$ and $\mathrm{M}$

14.9661 i(15.3985) 9.5534 i(17.6886)

Printing K1 and M

15.0753 i(15.1054) 9.9841 i(17.7298)

Printing $\mathrm{K} 1$ and $\mathrm{M}$

15.1589 i(14.8054) 10.3952 i(17.7366)

Printing $\mathrm{K} 1$ and $\mathrm{M}$

15.2186 i(14.4989) $10.7879 \mathrm{i}(17.7115)$

Printing $\mathrm{K} 1$ and $\mathrm{M}$

18.1482 i(28.9867) 9.2808 i(23.1419)

Printing $\mathrm{K} 1$ and $\mathrm{M}$

19.0666 i(28.3147) 9.8622 i(23.6508)

Printing $\mathrm{K} 1$ and $\mathrm{M}$

$19.7974 \mathrm{i}(27.5123) 10.4704 \mathrm{i}(24.0175)$

Printing $\mathrm{K} 1$ and $\mathrm{M}$

20.3387 i(26.6282) 11.0769 i(24.2494) 
Printing K1 and M

$20.7019 \mathrm{i}(25.7039) 11.6606 \mathrm{i}(24.3601)$

Printing $\mathrm{K} 1$ and $\mathrm{M}$

$20.9063 \mathrm{i}(24.7718) 12.2076 \mathrm{i}(24.3664)$

Printing $\mathrm{K} 1$ and $\mathrm{M}$

$20.9752 \mathrm{i}(23.8549) 12.7103 \mathrm{i}(24.2853)$

Printing $\mathrm{K} 1$ and $\mathrm{M}$

$20.9317 \mathrm{i}(22.9680) 13.1662 \mathrm{i}(24.1327)$

Printing $\mathrm{K} 1$ and $\mathrm{M}$

$20.7975 \mathrm{i}(22.1197) 13.5760 \mathrm{i}(23.9224)$

Printing K1 and M

$20.5913 \mathrm{i}(21.3140) 13.9425 \mathrm{i}(23.6655)$

Printing $\mathrm{K} 1$ and $\mathrm{M}$

$20.3286 \mathrm{i}(20.5518) 14.2696 \mathrm{i}(23.3710)$

Printing $\mathrm{K} 1$ and $\mathrm{M}$

$20.0217 \mathrm{i}(19.8322) 14.5615 \mathrm{i}(23.0458)$

Printing $\mathrm{K} 1$ and $\mathrm{M}$

$19.6801 \mathrm{i}(19.1529) 14.8222 \mathrm{i}(22.6948)$

Printing $\mathrm{K} 1$ and $\mathrm{M}$

$19.3106 \mathrm{i}(18.5113) 15.0554 \mathrm{i}(22.3215)$

Printing $\mathrm{K} 1$ and $\mathrm{M}$

$18.9181 \mathrm{i}(17.9046) 15.2641 \mathrm{i}(21.9278)$

Printing $\mathrm{K} 1$ and $\mathrm{M}$

$18.5053 \mathrm{i}(17.3303) 15.4508 \mathrm{i}(21.5148)$

Printing $\mathrm{K} 1$ and $\mathrm{M}$

$18.0736 \mathrm{i}(16.7858) 15.6169 \mathrm{i}(21.0823)$

Printing K1 and M

$17.6228 \mathrm{i}(16.2693) 15.7633 \mathrm{i}(20.6292)$

Printing $\mathrm{K} 1$ and $\mathrm{M}$

$17.1511 \mathrm{i}(15.7793) 15.8898 \mathrm{i}(20.1534)$

Printing $\mathrm{K} 1$ and $\mathrm{M}$ 
16.6556 i(15.3149) $15.9950 \mathrm{i}(19.6515)$

Printing $\mathrm{K} 1$ and $\mathrm{M}$

$16.1313 \mathrm{i}(14.8757) 16.0760 \mathrm{i}(19.1184)$

Printing $\mathrm{K} 1$ and $\mathrm{M}$

$15.5704 \mathrm{i}(14.4617) 16.1279 \mathrm{i}(18.5464)$

Printing $\mathrm{K} 1$ and $\mathrm{M}$

$12.5080 \mathrm{i}(3.9605) 19.2497 \mathrm{i}(7.3440)$

Printing K1 and $\mathrm{M}$

$12.5359 \mathrm{i}(2.8306) 20.4945 \mathrm{i}(5.7352)$

Printing $\mathrm{K} 1$ and $\mathrm{M}$

$13.2633 \mathrm{i}(1.0668) 23.1620 \mathrm{i}(3.5302)$

Printing $\mathrm{K} 1$ and $\mathrm{M}$

11.1109 i(-3.4693) $23.6883 \mathrm{i}(-4.4251)$

Printing $\mathrm{K} 1$ and $\mathrm{M}$

$7.6298 \mathrm{i}(-5.3874) 20.7995 \mathrm{i}(-10.1516)$

Printing $\mathrm{K} 1$ and $\mathrm{M}$

3.8845 i(-6.2601) 16.6035 i(-15.1375)

Printing $\mathrm{K} 1$ and $\mathrm{M}$

$0.0934 \mathrm{i}(-6.0686) 11.1660 \mathrm{i}(-19.1700)$

Printing $\mathrm{K} 1$ and $\mathrm{M}$

-3.3436 i(-4.8351) 4.8592 i(-21.9131)

Printing K1 and M

$-5.9960 \mathrm{i}(-2.7880)-1.6769 \mathrm{i}(-23.2696)$

Printing $\mathrm{K} 1$ and $\mathrm{M}$

$-7.5541 \mathrm{i}(-0.3549)-7.7020 \mathrm{i}(-23.5935)$

Printing $\mathrm{K} 1$ and $\mathrm{M}$

$-7.8929 \mathrm{i}(1.9521)-12.5100 \mathrm{i}(-23.7810)$

Printing $\mathrm{K} 1$ and $\mathrm{M}$

$-6.9548 \mathrm{i}(3.6417)-15.0753 \mathrm{i}(-25.4681)$

Printing $\mathrm{K} 1$ and $\mathrm{M}$

$-4.0382 \mathrm{i}(4.1088)-9.8868 \mathrm{i}(-32.1624)$ 
Printing $\mathrm{K} 1$ and $\mathrm{M}$

$0.7364 \mathrm{i}(9.0115) 1.3578 \mathrm{i}(-15.3349)$

Printing $\mathrm{K} 1$ and $\mathrm{M}$

$2.0931 \mathrm{i}(12.0533)-0.4778 \mathrm{i}(-7.7823)$

\section{A.3.2: Data listing for Figure A.2}

Printing $\mathrm{K} 1$ and $\mathrm{M}$

$2.3266 \mathrm{i}(11.8344) 0.9821 \mathrm{i}(-6.5778)$

Printing K1 and M

$3.4814 \mathrm{i}(13.7001) 0.1437 \mathrm{i}(-2.3372)$

Printing K1 and $\mathrm{M}$

$4.6464 \mathrm{i}(15.0490)-0.1331 \mathrm{i}(1.0227)$

Printing $\mathrm{K} 1$ and $\mathrm{M}$

$5.7762 \mathrm{i}(16.0268)-0.0508 \mathrm{i}(3.7821)$

Printing $\mathrm{K} 1$ and $\mathrm{M}$

$6.8432 \mathrm{i}(16.7256) 0.2650 \mathrm{i}(6.0828)$

Printing $\mathrm{K} 1$ and $\mathrm{M}$

$7.8334 \mathrm{i}(17.2110) 0.7305 \mathrm{i}(8.0161)$

Printing K1 and M

$8.7417 \mathrm{i}(17.5315) 1.2889 \mathrm{i}(9.6484)$

Printing $\mathrm{K} 1$ and $\mathrm{M}$

$9.5681 \mathrm{i}(17.7239) 1.9015 \mathrm{i}(11.0309)$

Printing $\mathrm{K} 1$ and $\mathrm{M}$

$10.3159 \mathrm{i}(17.8161) 2.5419 \mathrm{i}(12.2046)$

Printing K1 and M

$10.9896 \mathrm{i}(17.8293) 3.1919 \mathrm{i}(13.2024)$

Printing $\mathrm{K} 1$ and $\mathrm{M}$

$11.5946 \mathrm{i}(17.7802) 3.8397 \mathrm{i}(14.0511)$

Printing $\mathrm{K} 1$ and $\mathrm{M}$

$12.1363 \mathrm{i}(17.6811) 4.4772 \mathrm{i}(14.7724)$

Printing $\mathrm{K} 1$ and $\mathrm{M}$ 
12.6198 i(17.5420) 5.0993 i(15.3844)

Printing K1 and M

$13.0500 \mathrm{i}(17.3704) 5.7026 \mathrm{i}(15.9016)$

Printing $\mathrm{K} 1$ and $\mathrm{M}$

$13.4312 \mathrm{i}(17.1721) 6.2853 \mathrm{i}(16.3362)$

Printing $\mathrm{K} 1$ and $\mathrm{M}$

$13.7673 \mathrm{i}(16.9518) 6.8465 \mathrm{i}(16.6982)$

Printing $\mathrm{K} 1$ and $\mathrm{M}$

14.0618 i(16.7130) 7.3857 i(16.9959)

Printing $\mathrm{K} 1$ and $\mathrm{M}$

14.3179 i(16.4587) 7.9032 i(17.2363)

Printing $\mathrm{K} 1$ and $\mathrm{M}$

14.5384 i(16.1911) 8.3991 i(17.4252)

Printing K1 and $\mathrm{M}$

$14.7256 \mathrm{i}(15.9120) 8.8743 \mathrm{i}(17.5673)$

Printing $\mathrm{K} 1$ and $\mathrm{M}$

14.8819 i(15.6227) 9.3293 i(17.6668)

Printing $\mathrm{K} 1$ and $\mathrm{M}$

15.0093 i(15.3244) 9.7650 i(17.7270)

Printing $\mathrm{K} 1$ and $\mathrm{M}$

15.1096 i(15.0180) 10.1823 i(17.7509)

Printing $\mathrm{K} 1$ and $\mathrm{M}$

$15.1845 \mathrm{i}(14.7042) 10.5823 \mathrm{i}(17.7409)$

Printing K1 and M

17.6733 i(29.3975) 8.9996 i(22.8811)

Printing $\mathrm{K} 1$ and $\mathrm{M}$

18.6614 i(28.7599) $9.5570 \mathrm{i}(23.4428)$

Printing $\mathrm{K} 1$ and $\mathrm{M}$

$19.4627 \mathrm{i}(27.9728) 10.1542 \mathrm{i}(23.8603)$

Printing $\mathrm{K} 1$ and $\mathrm{M}$

$20.0707 \mathrm{i}(27.0877) 10.7607 \mathrm{i}(24.1383)$ 
Printing K1 and M

$20.4940 \mathrm{i}(26.1499) 11.3524 \mathrm{i}(24.2891)$

Printing K1 and M

$20.7506 \mathrm{i}(25.1955) 11.9131 \mathrm{i}(24.3291)$

Printing $\mathrm{K} 1$ and $\mathrm{M}$

$20.8636 \mathrm{i}(24.2506) 12.4333 \mathrm{i}(24.2754)$

Printing $\mathrm{K} 1$ and $\mathrm{M}$

$20.8568 \mathrm{i}(23.3327) 12.9087 \mathrm{i}(24.1447)$

Printing $\mathrm{K} 1$ and $\mathrm{M}$

$20.7527 \mathrm{i}(22.4522) 13.3391 \mathrm{i}(23.9514)$

Printing $\mathrm{K} 1$ and $\mathrm{M}$

$20.5707 \mathrm{i}(21.6143) 13.7264 \mathrm{i}(23.7074)$

Printing $\mathrm{K} 1$ and $\mathrm{M}$

$20.3274 \mathrm{i}(20.8207) 14.0741 \mathrm{i}(23.4225)$

Printing $\mathrm{K} 1$ and $\mathrm{M}$

$20.0358 \mathrm{i}(20.0709) 14.3859 \mathrm{i}(23.1040)$

Printing $\mathrm{K} 1$ and $\mathrm{M}$

$19.7059 \mathrm{i}(19.3630) 14.6659 \mathrm{i}(22.7574)$

Printing $\mathrm{K} 1$ and $\mathrm{M}$

$19.3453 \mathrm{i}(18.6943) 14.9174 \mathrm{i}(22.3863)$

Printing $\mathrm{K} 1$ and $\mathrm{M}$

$18.9589 \mathrm{i}(18.0623) 15.1436 \mathrm{i}(21.9931)$

Printing $\mathrm{K} 1$ and $\mathrm{M}$

$18.5500 \mathrm{i}(17.4640) 15.3468 \mathrm{i}(21.5789)$

Printing $\mathrm{K} 1$ and $\mathrm{M}$

$18.1198 \mathrm{i}(16.8970) 15.5285 \mathrm{i}(21.1435)$

Printing $\mathrm{K} 1$ and $\mathrm{M}$

17.6683 i(16.3592) 15.6893 i(20.6858)

Printing $\mathrm{K} 1$ and $\mathrm{M}$

$17.1937 \mathrm{i}(15.8490) 15.8292 \mathrm{i}(20.2036)$

Printing K1 and M 
16.6926 i(15.3653) 15.9464 i(19.6929)

Printing $\mathrm{K} 1$ and $\mathrm{M}$

16.1593 i(14.9073) $16.0380 \mathrm{i}(19.1481)$

Printing $\mathrm{K} 1$ and $\mathrm{M}$

$15.5846 \mathrm{i}(14.4745) 16.0982 \mathrm{i}(18.5594)$

Printing $\mathrm{K} 1$ and $\mathrm{M}$

$12.6066 \mathrm{i}(3.8546) 19.3667 \mathrm{i}(7.3257)$

Printing $\mathrm{K} 1$ and $\mathrm{M}$

$12.7153 \mathrm{i}(2.6012) 20.8052 \mathrm{i}(5.6050)$

Printing $\mathrm{K} 1$ and $\mathrm{M}$

$13.0586 \mathrm{i}(-1.0053) 24.0491 \mathrm{i}(0.7139)$

Printing $\mathrm{K} 1$ and $\mathrm{M}$

$9.7453 \mathrm{i}(-3.4458) 21.8096 \mathrm{i}(-5.1634)$

Printing $\mathrm{K} 1$ and $\mathrm{M}$

$6.4851 \mathrm{i}(-4.6548) 18.7318 \mathrm{i}(-9.8143)$

Printing $\mathrm{K} 1$ and $\mathrm{M}$

$3.1572 \mathrm{i}(-5.0019) 14.7171 \mathrm{i}(-13.7685)$

Printing $\mathrm{K} 1$ and $\mathrm{M}$

-0.0339 i(-4.5155) $9.9067 \mathrm{i}(-16.8859)$

Printing $\mathrm{K} 1$ and $\mathrm{M}$

-2.8040 i(-3.2877) 4.6254 i(-19.0339)

Printing $\mathrm{K} 1$ and $\mathrm{M}$

-4.8813 i(-1.5352) -0.6689 i(-20.2728)

Printing $\mathrm{K} 1$ and $\mathrm{M}$

$-6.0753 \mathrm{i}(0.4212)-5.4625 \mathrm{i}(-20.9656)$

Printing $\mathrm{K} 1$ and $\mathrm{M}$

$-6.2805 \mathrm{i}(2.2160)-9.1627 \mathrm{i}(-21.8690)$

Printing $\mathrm{K} 1$ and $\mathrm{M}$

-5.3417 i(3.4683) -10.5112 i(-24.4026)

Printing $\mathrm{K} 1$ and $\mathrm{M}$

$-1.7934 \mathrm{i}(3.4773)-0.1181 \mathrm{i}(-31.3117)$ 
Printing K1 and M

$1.2395 \mathrm{i}(9.1326) 2.7874 \mathrm{i}(-12.5555)$

Printing $\mathrm{K} 1$ and $\mathrm{M}$

$2.3266 \mathrm{i}(11.8344) 0.9821 \mathrm{i}(-6.5778)$

\section{A.3.3: Data listing for Figure A.3}

Prinqting $\mathrm{K} 1$ and $\mathrm{M}$

$-3.8050 \mathrm{i}(13.9016) 3584981190212205.0000 \mathrm{i}(3718525743977776.5000)$

Printing $\mathrm{K} 1$ and $\mathrm{M}$

$15.5365 \mathrm{i}(13.9925)-78.0788 \mathrm{i}(9.2749)$

Printing $\mathrm{K} 1$ and $\mathrm{M}$

$15.8431 \mathrm{i}(13.6516)-31.9701 \mathrm{i}(14.4609)$

Printing $\mathrm{K} 1$ and $\mathrm{M}$

$15.9795 \mathrm{i}(13.4354)-16.1587 \mathrm{i}(15.9796)$

Printing K1 and M

16.0438 i(13.2745) -8.0943 i(16.6475)

Printing $\mathrm{K} 1$ and $\mathrm{M}$

16.0703 i(13.1426) -3.1782 i(16.9952)

Printing $\mathrm{K} 1$ and $\mathrm{M}$

$16.0740 \mathrm{i}(13.0276) 0.1452 \mathrm{i}(17.1900)$

Printing $\mathrm{K} 1$ and $\mathrm{M}$

$16.0629 \mathrm{i}(12.9231) 2.5502 \mathrm{i}(17.3005)$

Printing $\mathrm{K} 1$ and $\mathrm{M}$

$16.0412 \mathrm{i}(12.8251) 4.3770 \mathrm{i}(17.3592)$

Printing $\mathrm{K} 1$ and $\mathrm{M}$

$16.0115 \mathrm{i}(12.7311) 5.8160 \mathrm{i}(17.3835)$

Printing $\mathrm{K} 1$ and $\mathrm{M}$

$15.9753 \mathrm{i}(12.6394) 6.9821 \mathrm{i}(17.3834)$

Printing K1 and M

$15.9338 \mathrm{i}(12.5487) 7.9490 \mathrm{i}(17.3649)$

Printing K1 and M 
15.8874 i(12.4580) 8.7658 i(17.3317)

Printing $\mathrm{K} 1$ and $\mathrm{M}$

15.8366 i(12.3665) 9.4668 i(17.2863)

Printing $\mathrm{K} 1$ and $\mathrm{M}$

$15.7817 \mathrm{i}(12.2736) 10.0765 \mathrm{i}(17.2302)$

Printing $\mathrm{K} 1$ and $\mathrm{M}$

$15.7226 \mathrm{i}(12.1785) 10.6128 \mathrm{i}(17.1644)$

Printing $\mathrm{K} 1$ and $\mathrm{M}$

15.6595 i(12.0807) 11.0894 i(17.0894)

Printing $\mathrm{K} 1$ and $\mathrm{M}$

$15.5922 \mathrm{i}(11.9796) 11.5166 \mathrm{i}(17.0054)$

Printing $\mathrm{K} 1$ and $\mathrm{M}$

$15.5207 \mathrm{i}(11.8748) 11.9026 \mathrm{i}(16.9125)$

Printing $\mathrm{K} 1$ and $\mathrm{M}$

15.4448 i(11.7657) 12.2537 i(16.8106)

Printing $\mathrm{K} 1$ and $\mathrm{M}$

15.3644 i(11.6516) 12.5751 i(16.6994)

Printing $\mathrm{K} 1$ and $\mathrm{M}$

15.2792 i(11.5323) 12.8709 i(16.5784)

Printing $\mathrm{K} 1$ and $\mathrm{M}$

19.0215 i(22.9573) 11.8002 i(22.9719)

Printing $\mathrm{K} 1$ and $\mathrm{M}$

$19.4416 \mathrm{i}(22.5220) 12.3277 \mathrm{i}(23.1760)$

Printing $\mathrm{K} 1$ and $\mathrm{M}$

$19.7758 \mathrm{i}(22.0531) 12.8416 \mathrm{i}(23.3101)$

Printing $\mathrm{K} 1$ and $\mathrm{M}$

$20.0236 \mathrm{i}(21.5631) 13.3320 \mathrm{i}(23.3784)$

Printing K1 and M

$20.1869 \mathrm{i}(21.0633) 13.7910 \mathrm{i}(23.3862)$

Printing $\mathrm{K} 1$ and $\mathrm{M}$

$20.2702 \mathrm{i}(20.5631) 14.2130 \mathrm{i}(23.3396)$ 
Printing K1 and M

$20.2795 \mathrm{i}(20.0701) 14.5945 \mathrm{i}(23.2450)$

Printing K1 and M

$20.2220 \mathrm{i}(19.5898) 14.9340 \mathrm{i}(23.1088)$

Printing K1 and M

$20.1054 \mathrm{i}(19.1260) 15.2316 \mathrm{i}(22.9367)$

Printing $\mathrm{K} 1$ and $\mathrm{M}$

$19.9374 \mathrm{i}(18.6807) 15.4888 \mathrm{i}(22.7339)$

Printing $\mathrm{K} 1$ and $\mathrm{M}$

$19.7257 \mathrm{i}(18.2551) 15.7081 \mathrm{i}(22.5050)$

Printing $\mathrm{K} 1$ and $\mathrm{M}$

$19.4772 \mathrm{i}(17.8489) 15.8926 \mathrm{i}(22.2538)$

Printing $\mathrm{K} 1$ and $\mathrm{M}$

$19.1983 \mathrm{i}(17.4616) 16.0457 \mathrm{i}(21.9834)$

Printing K1 and M

$18.8944 \mathrm{i}(17.0922) 16.1710 \mathrm{i}(21.6962)$

Printing $\mathrm{K} 1$ and $\mathrm{M}$

$18.5703 \mathrm{i}(16.7394) 16.2719 \mathrm{i}(21.3944)$

Printing K1 and M

$18.2297 \mathrm{i}(16.4020) 16.3515 \mathrm{i}(21.0791)$

Printing $\mathrm{K} 1$ and $\mathrm{M}$

$17.8756 \mathrm{i}(16.0790) 16.4128 \mathrm{i}(20.7516)$

Printing K1 and M

$17.5102 \mathrm{i}(15.7693) 16.4579 \mathrm{i}(20.4123)$

Printing $\mathrm{K} 1$ and $\mathrm{M}$

$17.1347 \mathrm{i}(15.4724) 16.4889 \mathrm{i}(20.0614)$

Printing $\mathrm{K} 1$ and $\mathrm{M}$

$16.7500 \mathrm{i}(15.1876) 16.5070 \mathrm{i}(19.6987)$

Printing $\mathrm{K} 1$ and $\mathrm{M}$

$16.3558 \mathrm{i}(14.9151) 16.5128 \mathrm{i}(19.3239)$

Printing K1 and M 
$15.9517 \mathrm{i}(14.6549) 16.5067 \mathrm{i}(18.9359)$

Printing $\mathrm{K} 1$ and $\mathrm{M}$

$15.5364 \mathrm{i}(14.4080) 16.4879 \mathrm{i}(18.5336)$

Printing $\mathrm{K} 1$ and $\mathrm{M}$

$15.1080 \mathrm{i}(14.1755) 16.4551 \mathrm{i}(18.1155)$

Printing $\mathrm{K} 1$ and $\mathrm{M}$

$14.6644 \mathrm{i}(13.9596) 16.4061 \mathrm{i}(17.6799)$

Printing K1 and M

$14.2025 \mathrm{i}(13.7634) 16.3375 \mathrm{i}(17.2246)$

Printing $\mathrm{K} 1$ and $\mathrm{M}$

$13.7193 \mathrm{i}(13.5910) 16.2443 \mathrm{i}(16.7476)$

Printing $\mathrm{K} 1$ and $\mathrm{M}$

$10.8962 \mathrm{i}(2.4844) 20.4960 \mathrm{i}(2.8407)$

Printing $\mathrm{K} 1$ and $\mathrm{M}$

$10.8352 \mathrm{i}(1.5989) 21.5999 \mathrm{i}(1.0928)$

Printing $\mathrm{K} 1$ and $\mathrm{M}$

$10.8816 \mathrm{i}(0.6054) 23.0905 \mathrm{i}(-0.9750)$

Printing $\mathrm{K} 1$ and $\mathrm{M}$

$11.1070 \mathrm{i}(-0.5009) 25.1778 \mathrm{i}(-3.4325)$

Printing $\mathrm{K} 1$ and $\mathrm{M}$

11.6343 i(-1.6982) 28.2246 i(-6.3324)

Printing $\mathrm{K} 1$ and $\mathrm{M}$

12.6743 i(-2.8833) 32.8775 i(-9.6153)

Printing $\mathrm{K} 1$ and $\mathrm{M}$

$14.5666 \mathrm{i}(-3.7090) 40.2862 \mathrm{i}(-12.7669)$

Printing $\mathrm{K} 1$ and $\mathrm{M}$

$17.6757 \mathrm{i}(-3.1033) 52.1650 \mathrm{i}(-13.6103)$

Printing $\mathrm{K} 1$ and $\mathrm{M}$

$21.1192 \mathrm{i}(2.0272) 67.9161 \mathrm{i}(-4.2454)$

Printing $\mathrm{K} 1$ and $\mathrm{M}$

$25.2929 \mathrm{i}(15.3985) 92.5236 \mathrm{i}(36.9711)$ 
Printing $\mathrm{K} 1$ and $\mathrm{M}$

$17.2590 \mathrm{i}(22.1706) 105.4722 \mathrm{i}(77.7441)$

Printing $\mathrm{K} 1$ and $\mathrm{M}$

$3.1313 \mathrm{i}(17.2654) 2839917488443629.0000 \mathrm{i}(1708229750225005.2500)$ 


\section{References}

Beggs,J S., Mechanism, New York, McGraw Hill Book Company, 1955

Bickford, J J., Mechanisms for Intermittent Motions, New York, Industrial Press, 1972

Burmester, "Burmester Theory for Four Precision Positions: An Extended Discourse with

Application to the Dimensional Synthesis of Arbitrary Planar Linkages."Ph D diss.,

University of Minnesota, (1984).

Erdman, A.G., and Sandor, G.N. (1984) Advanced Mechanism Design, Third Edition,

Prentice-Hall.

Erdman, A.G., and Sandor, G.N. (1984) Mechanism Design, Third Edition, Prentice-Hall.

Fang, E. W. (1994) Simultaneous Type and Dimensional Synthesis of Mechanisms by

Genetic Algorithms, Mechanism Synthesis and Analysis, ASME, 70, 35-41.

Fang, W.E., and Freudenstein, F (1990) The Stratified Representation of Mechanisms,

Journal of Mechanical Design, 112, 514-519.

Freudenstein, F (1954) An Analytical Approach to the Design of Four-Link Mechanisms, Transactions of the ASME, April, 483-492.

Gupta, K.C. (1979) Synthesis of Position, Path and Function Generating 4-Bar Mechanisms with Completely Rotatable Driving Links, Mechanism and Machine Theory, 15,93-101.

Hall, A S., Kinematics and Linkage Design. West Lafayette, Indiana; Balt Publishers, 1961

Hartenberg, R.S. and Denavit (1964) Kinematic Synthesis of Linkages, Mcgraw-Hill Book Company.

Lei, S., and Tsai, Y (1994) A method for type synthesis of mechanisms using phase diagrams,

Lyman, D.D.(1978) A Practical Approach to Designing Four-Bar Linkages for Guiding Rigid Bodies, Earthmoving Industry Conference, Central Illinois Section, Peoria, IL.

Mechanism Synthesis and Analysis, ASME,70, 43-49.

Molian, S (1997) Mechanism Design-The Practical Kinematics and Dynamics of Machinery, Pergamon Press.

Mukherjee, A., Awtar, S. and Gupta, V. (1997) Synthesis of Four-bar Mechanisms using Pattern Matching Approach and GA search, Indian Institute of Technology, Kanpur, India. 
Murphy, M.D., and Midha, A (1994) Type synthesis of Compliant mechanisms employing a simplified approach to segment type, Mechanism Synthesis and Analysis, 70,51-60.

Olson, D G, A G Erdman, and D.R.Riley, "A systematic Procedure for Type Synthesis of Mechanisms With Literature Review,"Mechanism and Machine Theory, Vol. 20 (1985), No.4

Paul, B (1975) Analytical Dynamics of Mechanisms-A Computer Oriented Overview, Mechanism and Machine Theory, 10, 481-507.

Pratap, R (1999) Getting Started with MATLAB 5-A quick introduction for Scientists and Engineers, Oxford University Press.

Rauschert, K.A. (1985) Mechanical Linkages, SAE Paper 850807.

Reuleaux, F Kinematics of Machinery, Macmillan, London, 1876; republished by Dover, New York, 1963.

Shigley, J.E., and Uicker, J.J. (1995), Theory of Machines and Mechanisms, McGraw-Hill. Struble, K.R., Gustafson, J.E. and Erdman, A.G. (1977) Case Study: Synthesis of a Four Bar Linkage to Pick and Place Filters Using the LINCAGES Computer Package. Proceedings:

The $5^{\text {th }}$ Applied Mechanisms Conference, Oklahoma City.

Waldron, K.J., and Kinzel, G.L. (1999) Kinematics, Dynamics and Design of machinery, John Wiley and Sons.

Wampler, C.W (1993) Type Synthesis of Mechanisms for Variable Valve Automation, SAE Paper 930818.

Yang, T., and Yao, F (1994) Topological Characteristics and Automatic Generation of Structural Synthesis of Planar Mechanisms based on the ordered single-openedchains,Mechanism Synthesis and Analysis, 70, 67-74. 